Portland State University

PDXScholar

Fall 12-2-2015

\title{
The Biology of Eastern Kingbirds at Malheur National Wildlife Refuge: Survival, Reproduction, and Testosterone Secretion
}

Lucas J. Redmond

Portland State University

Follow this and additional works at: https://pdxscholar.library.pdx.edu/open_access_etds

Part of the Population Biology Commons, and the Poultry or Avian Science Commons Let us know how access to this document benefits you.

\section{Recommended Citation}

Redmond, Lucas J., "The Biology of Eastern Kingbirds at Malheur National Wildlife Refuge: Survival, Reproduction, and Testosterone Secretion" (2015). Dissertations and Theses. Paper 2622.

https://doi.org/10.15760/etd.2618

This Dissertation is brought to you for free and open access. It has been accepted for inclusion in Dissertations and Theses by an authorized administrator of PDXScholar. Please contact us if we can make this document more accessible: pdxscholar@pdx.edu. 
The Biology of Eastern Kingbirds at Malheur National Wildlife Refuge: Survival, Reproduction, and Testosterone Secretion

by

Lucas J. Redmond

A dissertation submitted in partial fulfillment of the requirements for the degree of

Doctor of Philosophy

in

Biology

Dissertation Committee:

Michael T. Murphy, Chair

Kathleen M. O'Reilly

Jason E. Podrabsky

Catherine de Rivera

Randy Zelick

Portland State University

2015 
(C) 2015 Lucas J. Redmond 


\begin{abstract}
This dissertation presents the results of a study that I undertook to better understand the breeding biology of Eastern Kingbirds (hereafter, kingbirds) at Malheur National Wildlife Refuge in southeastern Oregon from 2003 to 2009. Kingbirds are longdistance migratory songbirds that breed across much of North America. This species is socially monogamous but, via frequent extra-pair copulations, is genetically polygamous. Kingbirds exhibit relatively high breeding site fidelity, often returning to the same tree to nest in subsequent years. Both members of a pair provide parental care, but there are often specific duties performed by both male and female kingbirds. For example, males typically perform much of the vigilant nest defense that this species is well known for and contribute, to an extent, to the feeding of nestlings. Females, on the other hand, are entirely responsible for incubating and brooding.
\end{abstract}

Beginning in 2002, most adults within the population of kingbirds at Malheur had been banded with a unique combination of three colored plastic leg bands and an aluminum USFWS band. Also, as many nests were located in each year as possible, and any young that survived to fledging age were banded with a unique combination of leg bands. Considerable effort was then spent each year to locate as many banded individuals as possible, which allowed me to document adult and juvenile survival. Annual survival rates of adult male and female kingbirds in the population at Malheur did not differ and were relatively high at approximately 0.65. Juvenile survival rate was approximately 0.29 , indicating that slightly less than one-third of nestlings survive the interval between fledging and their first potential breeding season. Resighting probability 
was high for both sexes, although higher for adult males (0.94) than for adult female (0.84). The latter finding is consistent with the higher site fidelity of males than of females. Resighting probabilities for juveniles were much lower at 0.68 and 0.40 for males and females, respectively. Again, this was expected because natal site fidelity is typically much lower than breeding site fidelity. Compared to most other reports, resighting probability and return rates of juvenile kingbirds was high, presumably because the riparian habitats where kingbirds breed at Malheur function as an ecological island surrounded by, for kingbirds, unsuitable high desert habitat. Thus, unless they disperse very long distances, the only option for juvenile kingbirds is to begin nesting on the refuge.

The collection of blood samples from birds has become an increasingly common practice in ornithology. The data that can be gained from these samples allow a number of interesting questions to be asked such as understanding the genetic mating system of a species, patterns of hormone secretion, and discerning migratory pathways via stable isotope analysis. The volume of blood collected is usually small and was assumed to cause no long-term negative effects on sampled individuals. However, few studies have rigorously examined the effect of blood sampling on survival. I used a multistate markrecapture analysis to assess the effect blood sampling on annual survival of kingbirds by combining the annual survival data described above with whether or not individuals were subjected to blood sample collection. The results of this analysis indicated that blood sampling had no effect on annual survival rates of kingbirds. Whether or not this is the case for other species remains to be seen. However, my results support the assumption 
that when done correctly, blood sampling has little to no long-term negative effects on birds.

Comparative analyses of many bird species show that testosterone secretion exhibits fairly predictable patterns among breeding birds of different mating systems. Monogamous species reach a peak during mate attraction and the period of female fertility which is then followed by a sharp decline when young are in the nest. By contrast, males of polygynous species tend to maintain higher levels of testosterone throughout the breeding season to, presumably, maximize opportunities for acquiring additional mates. Kingbirds are socially monogamous but cryptically polygamous. However, because of high rates of extra-pair paternity, variation in reproductive success among males is much higher than what is expected for a monogamous species, and, instead, is similar to what has been reported for polygynous species. Therefore from 2005 to 2009 I measured testosterone concentrations from the blood samples collected from male kingbirds to determine the breeding season profile of testosterone secretion in kingbirds and to understand the factors that influence testosterone variation among individuals. Contrary to expected for a monogamous species, the testosterone profile of kingbirds did not exhibit the brief peak in testosterone followed by a precipitous decline. Testosterone peaked early in the season, but declined very slowly as the nest cycle progressed. I attributed this gradual decline in testosterone to the cryptically polygynous nature of the kingbird extra-pair mating system. I also found substantial variation in testosterone concentration among male kingbirds and was able to identify several factors contributing to this variation. As expected, testosterone declined as the breeding season 
progressed (independent of stage in nest cycle) and nest density increased, while increases in testosterone were correlated with the number of fertile females within the population. This suggests that male kingbirds were capable of modulating testosterone concentrations to both cope with an increase in conspecific density, but also to ready themselves for times when extra-pair copulations were more likely. 
To Jen and our two children, Maggie and Harry.

Without your encouragement this would never have been possible.

Begin the begin. 


\section{ACKNOWLEDGEMENTS}

First and foremost, I would like to extend my most sincere gratitude to my graduate adviser, Michael T. Murphy. In the spring of 2002 we had a phone call that would forever change my life, resulting in acceptance as a graduate student at Portland State University. He took a chance on me, and I would like to think that it paid off for all involved. I would also like to thank the rest of my dissertation committee for their guidance and input on the research for my dissertation.

This dissertation is the culmination of eight years of field work (2002-2009) at Malheur National Wildlife Refuge, a portion of which time was used to complete a Master's degree. Thanks are in order for many people. First, I would like to thank the personnel of Malheur for giving me, and all the other kingbird researchers, the access we needed to conduct our field work at Malheur. Special thanks to Rick Roy, now Field Manager at the Burns District Office of the Bureau of Land Management, who as Refuge Manager of Malheur greatly eased the red tape involved with research on a national wildlife refuge. Cal and Alice Elshoff were not only gracious hosts for many years, but were also delightful to get to know. It would be hard to choose two other people as devoted to conservation as Cal and Alice. A number of other graduate students were involved with kingbird research during my time at Malheur and the team effort that we showed significantly increased the strength of all of our research. Amy Dolan (20022004) was instrumental early on in getting the larger project off the ground, and the ease I had in taking lead in field work in 2005 is in no small part due to her hard work. Karen 
Sexton (2002-2004) and her project on dawnsong in kingbirds showed us all that getting up at 2:00 AM could lead to good things. Unfortunately for her, but fortunately for anyone else working with her, Karen was a mosquito magnet. Sorry, Karen, but when I was out with you, I didn't need to use much bug spray, thank you. Nathan Cooper (20062008) came in at a time when the methods we used to capture kingbirds, males especially, were undergoing a great deal of change. This lead to such an increase in capture efficiency that in 2008, Nate and I caught more kingbirds in one year than anyone else had or has since. Thanks Nate. Chris Chutter (2009-2010) began his field work during my last year at Malheur. Chris' prior experience with mist netting meant that he was well prepared to step in and start catching kingbirds with ease and I enjoyed working with him. Throughout these years, undergraduate students from Portland State volunteered their time to come to Malheur to help. A heartfelt thank you to Matt Paroulek, Bruce Miller, John Deshler, Sarah Cancellieri, and Sarah Moncrief. Finally, through an NSF grant, we were able to pay several students from the University of Portland as field assistatnts. Thanks go to Devon Johnstone, Margie Paris, and Corey Kaleshnik.

Gary Pace and Ernie Szuch at the University of Michigan-Flint had instrumental roles in putting my life on the path of graduate school. Both were two of the most important teachers I have ever had. Without their help, I would not have even thought of being here. Dr. Pace (out of the utmost respect, that is how you will always be) taught me to always look at nature with an open eye and be interested in even the most miniscule of organisms. He also taught me the joys of photography and racquetball. 
Ernie Szuch helped instill an early interest in birds that has carried through to this day and taught me to always think critically. Dr. Pace and Ernie, I can't thank you enough.

Finally, I would like to thank those of my family who have either encouraged me to achieve whatever I want in life or given their support in this endeavor. To my parents, I give my gratitude to your continued encouragement in my choice of careers. Mom and Dale, without your assistance, this would never have been possible. In 2008, my life changed, for the better, when my first child was born. Since then, my wife and I have increased our family by one member. To all three of you, Jen, Maggie, and Harry, I hope I have, and continue to do so, done right by your accounts. Jen, thank you for helping me strive to be a better person on all accounts. Maggie, your sense of wonder of the world never ceases to amaze me and I would teach you everything I know and more. Harry, your sense of imagination and intelligence is nothing short of amazing, I wouldn't be surprised if you are given an Academy Award one day. To the three of you, whenever everything seemed like an insurmountable task, all I needed was to think about who and what I was doing this for and you gave me the strength to carry on. Thank you. 


\section{TABLE OF CONTENTS}

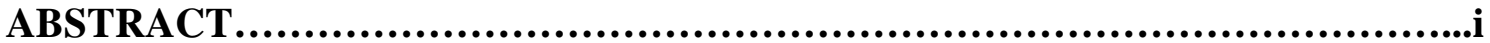

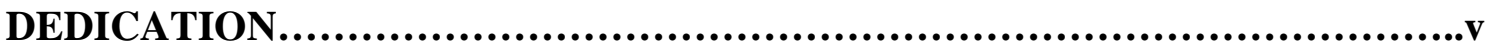

ACKNOWLEDGEMENTS..........................................................vi

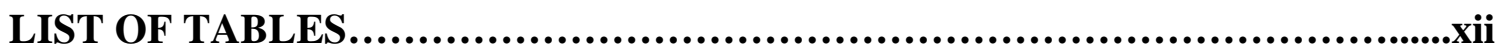

LIST OF FIGURES..............................................................iii

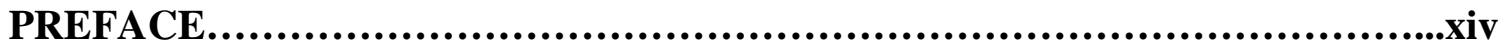

CHAPTER 1: Introduction............................................................

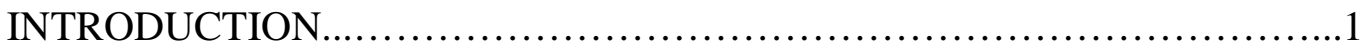

EASTERN KINGBIRDS AT MALHEUR NATIONAL WILDLIFE REFUGE..8 ANNUAL SURVIVAL RATES OF KINGBIRDS.............................10

TESTOSTERONE SECRETION IN MALE KINGBIRDS.......................12

CHAPTER 2: Using Complementary Approaches to Estimate Survival of Juvenile and Adult Eastern Kingbirds.......................................................13

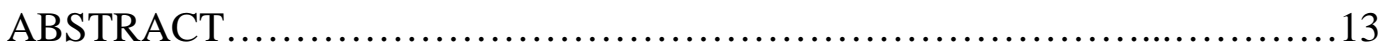

INTRODUCTION.......................................................

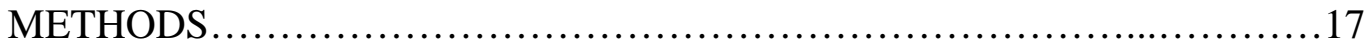

Study site and field methods.........................................17

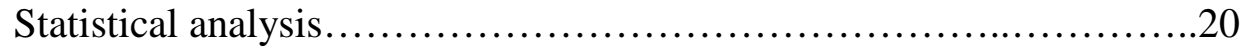

Demographic balancing............................................23

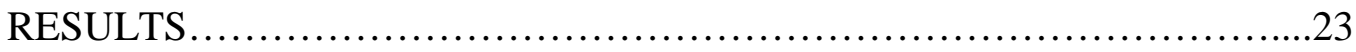

Demographic balancing............................................26 


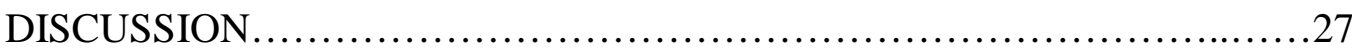

MARK, enumeration, and demographic balancing...................28

Conclusions.....................................................30

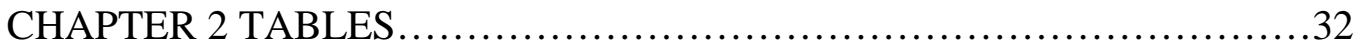

CHAPTER 2 FIGURES................................................. 35

CHAPTER 3: Multistate Mark-Recapture Analysis Reveals No Effect of Blood Sampling on Survival and Recapture of Eastern Kingbirds (Tyrannus tyrannus)..38

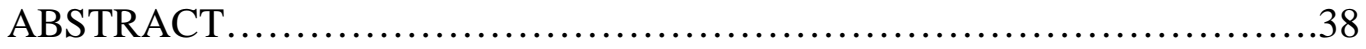

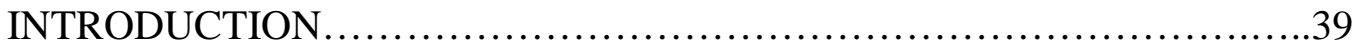

METHODS........................................................... 42

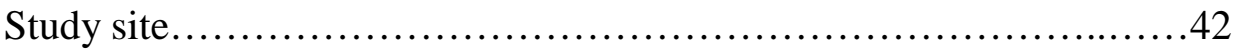

Data preparation............................................43

Model-selection procedure......................................44

Model structure and hypotheses...................................45

RESULTS..........................................................47

Transition probability ........................................48

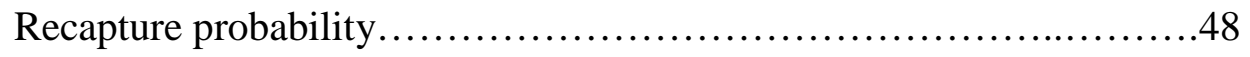

Survival probability...........................................49

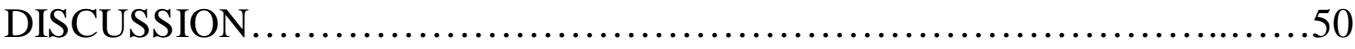

CHAPTER 3 TABLES...............................................56

CHAPTER 4: Testosterone secretion in a socially monogamous but sexually promiscuous migratory passerine..................................................62

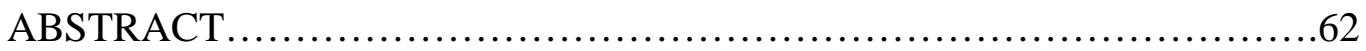




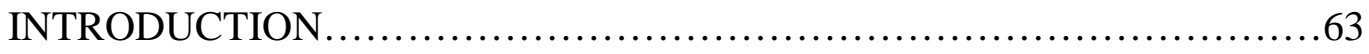

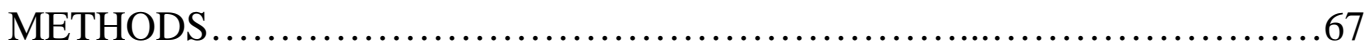

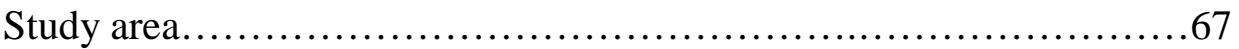

Capture and blood sampling.........................................68

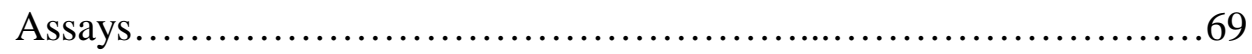

Statistical analyses.................................................. 70

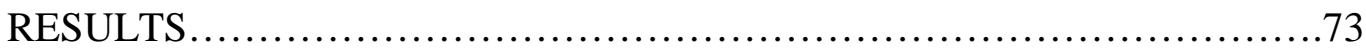

Testosterone concentration in kingbirds...............................73

Testosterone profile of kingbirds....................................74

Variation in T: temporal influences and social environment..............75

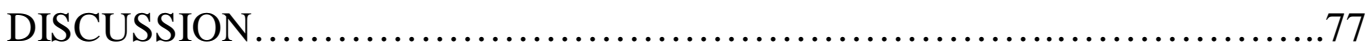

Testosterone profile of Eastern Kingbirds..............................78

Social aspects of testosterone variation.............................. 80

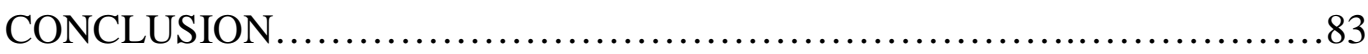

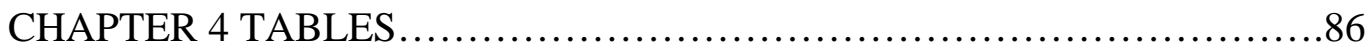

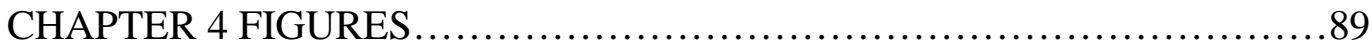

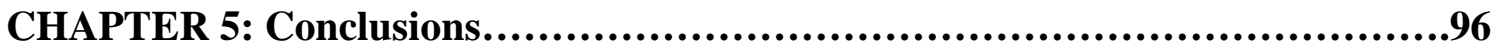

KINGBIRD DEMOGRAPHY AND FACTORS INFLUENCING SURVIVAL.97

TESTOSTERONE IN EASTERN KINGBIRDS.............................101

CLOSING REMARKS................................................ 102

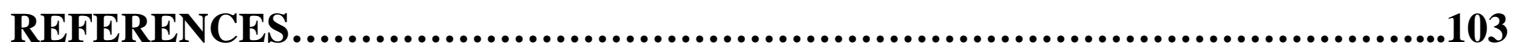

APPENDIX: Chapters 2, 3 and 4 Copyright Information.........................127 


\section{LIST OF TABLES}

\section{CHAPTER 2 TABLES}

Table 2.1: Results of model selection......................................32

Table 2.2: Model averaged estimates of survival and resighting probability......34

\section{CHAPTER 3 TABLES}

Table 3.1: Model notation and description..............................56

Table 3.2: Results of model selection....................................58

Table 3.3: Model-averaged parameter estimates of transition, resighting, and survival probabilities................................................61

\section{CHAPTER 4 TABLES}

Table 4.1: Results of model selection....................................86

Table 4.2: Model averaged parameter estimates for factors associated with testosterone variation...............................................87

Table 4.3: Testosterone variation across the nest cycle in kingbirds.............88 


\section{LIST OF FIGURES}

\section{CHAPTER 2 FIGURES}

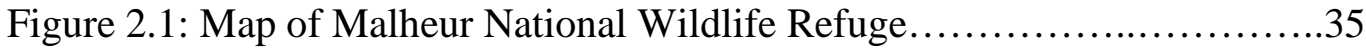

Figure 2.2: Annual Variation in Survival of Eastern Kingbirds at Malheur

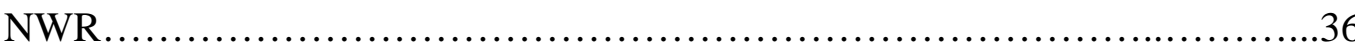

Figure 2.3: Annual Variation in Population Size of Eastern Kingbirds at Malheur

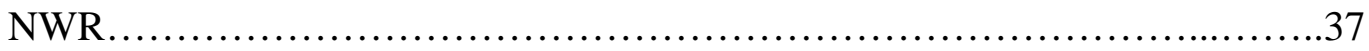

\section{CHAPTER 4 FIGURES}

Figure 4.1: Correlations between testosterone and (a) date, and (b) time of day of capture........................................................91

Figure 4.2: Relationship between time to capture and testosterone.............92

Figure 4.3: Variation in testosterone across stages of the nest cycle.............93

Figure 4.4: Changes in testosterone between successive captures..............94

Figure 4.5: Correlations between testosterone and (a) nest density, and (b) fertile females in the population............................................95 


\section{PREFACE}

CHAPTER 2 has already been published in The Journal of Field Ornithology:

Redmond L. J. and M. T. Murphy. 2012. Using complementary approaches to estimate survival of juvenile and adult Eastern Kingbirds. Journal of Field Ornithology 83: 247-259.

This publication was awarded the Best Student Paper in The Journal of Field Ornithology for 2012.

CHAPTER 3 has already been published in The Auk:

Redmond L. J. and M. T. Murphy. 2011. Multistate mark-recapture analysis reveals no effect of blood sampling on survival and recapture of Eastern Kingbirds (Tyrannus tyrannus). Auk 128: 514-521.

CHAPTER 4 is in review in General and Comparative Endocrinology:

Redmond L. J., M. T. Murphy, N. W. Cooper, and K. M. O’Reilly. In review. Testosterone secretion in socially monogamous but cryptically polygamous migratory passerine. General and Comparative Endocrinology.

Please see the APPENDIX for copyright information regarding these publication. 


\section{CHAPTER 1}

\section{Introduction}

From its beginnings as a science in the $20^{\text {th }}$ century, ornithology has made massive contributions to our understanding of the natural world. Joseph Grinnell's seminal paper The Niche Relationships of the California Thrasher (1917) introduced the important concept of the ecological niche, while Robert MacArthur's (1958) studies of niche partitioning in parulid warblers set the stage for the development of the role of competition in structuring ecological communities. The importance of territoriality in the lives of birds was established by Margaret Morse Nice (1941) and Jerram Brown (1964), while studies of cooperative breeding by Jerram Brown (1970), Glenn Wooldfenden (and later John Fitzpatrick; Woolfenden and Fitzpatrick 1984), and Walt Koenig and colleagues (Koenig and Mumme 1981) helped establish the fundamental role of kinship as the underlying principle driving cooperative breeding and apparent altruism in vertebrates. Work by Gordon Orians (1969), and Stephen Emlen and Lewis Oring (1977) helped elucidate the basis for variation in mating systems of vertebrates, while important contributions to the study of physiological ecology, and in particular, field endocrinology were being made through research by Donald Farner, Richard Mewaldt and colleagues (see below). But nothing had more impact than the debates between David Lack and Alexander F. Skutch over the ultimate basis for variation in clutch size in birds (Lack 1947, 1948; Skutch 1949) because these served as the foundation for the development of modern life history theory (Stearns 1976, 1992; see review by Ricklefs 2000). 
David Lack is arguably the most important contributor to ornithology of the $20^{\text {th }}$ century for not only did his work help crystallize thoughts on life history evolution, but his 1954 The Natural Regulation of Animal Numbers and 1968 Ecological Adaptations for Breeding in Birds solidified the role of density-dependence in the regulation of animal numbers, and served as the principle source of information on the breeding biology of birds, respectively. But Lack was not infallible, and two of the many important contributions that he made have come under intense scrutiny in recent years. First, Lack (1968) concluded that $~ 90 \%$ of bird species were monogamous, and secondly, that the general inverse relationship seen between reproductive rate (i.e., clutch size) and annual survival rates of birds was a trade-off driven by differences in the ability of parents to provision young; birds with high reproductive rates inevitably experienced higher mortality rates. The discovery of the widespread occurrence of extra-pair paternity (see below) has weakened, to a degree, the former conclusion, while much research on a host of taxa has led most to conclude that it is more likely that differences in mortality rates are the ultimate source of variation in reproductive rates (see Stearns 1976, 1992, Ricklefs 2000, Martin 2004).

Lack's conclusion that most bird species are monogamous was based on social relationships between individuals, and as monogamy is defined (long-term one-on-one reproductive relationship between two individuals), Lack was correct given the information available at the time in stating that most birds are socially monogamous. Unlike the pattern observed in mammals, compared to monogamy, polygyny (one male acquiring several mates) is less common in birds, and polyandry (one female: multiple 
males) is very rare. However, with the introduction of molecular methods to the study of parentage our world view has changed. We now understand that most socially monogamous species, especially passerines, are not genetically monogamous as evidenced by the finding that young are frequently sired by males outside of the pairbond (reviewed by Griffith et al. 2002). Although rates of extra-pair fertilizations are low in some species, the number of young fathered by extra-pair males has been shown to be equal to or even higher than the number of young sired by within-pair males (Dixon et al. 1994, Double and Cockburn 2000). Because it is such a widespread phenomenon, several hypotheses have been proposed to explain the adaptive significance of extra-pair fertilizations.

Extra-pair fertilizations are an additional source of reproductive success for males of monogamous species and may increase variation in reproductive success among males leading to opportunities for sexual selection (Webster et al. 1995; Dolan et al. 2007). On the other hand, extra-pair gains and losses could balance out leading to no net increase in reproductive success (Freeman-Gallant et al. 2005). From a female perspective, extrapair fertilizations may be a means of insuring against infertility of the social mate (Wetton and Parkin 1991, Sheldon 1994) or they may provide some type of indirect genetic benefit (reviewed by Akçay and Roughgarden 2007). One way in which females may benefit is by seeking extra-pair males that possess desirable traits that would then be inherited by young thus increasing their fitness (the "good genes hypothesis"; Jennions and Petrie 2000). An alternative, the "compatible genes hypothesis" predicts that females 
would chose extra-pair mates whose genetics best compliment their own (Zeh and Zeh 1997).

Despite the exact mechanism involved, an important component of mate choice is how females evaluate male quality. Males advertise their quality to potential mates a number of ways ranging from behavioral signals to morphological signals to territory quality. Regardless of the type, these signals are only useful to females if they honestly convey the quality of a male. To convey the most information to perspective females, these signals should be associated with both a benefit and a cost. Variation in circulating levels of the steroid hormone testosterone among males, for example, has been identified as an honest signal of male quality. Testosterone stimulates behaviors that lead to increased mating opportunities for males (see below), thus increasing reproductive success. Testosterone secretion, however, comes at a cost. Testosterone stimulates mating behaviors while inhibiting parental care (Van Roo 2004), potentially decreasing reproductive success if modulation of circulating testosterone does not occur. The behaviors that are elicited by testosterone would increase energy expenditure (increases in territory size; Chandler et al. 1994) and could expose males to a higher risk of predation (increases in song output; Hunt et al. 1995). High levels of testosterone can also have an immunosupporesive effect on individuals (Dufty et al. 2000, Peters 2000). Given the potential costs, it would be expected that only high quality individuals can maintain high levels of testosterone for prolonged periods of time.

Regardless of whether Lack's view of life history evolution was correct (i.e., reproductive rates drive mortality rates), the field of life history theory hinges critically 
on having accurate estimates of survival, especially of differences between age classes (Stearns 1992). But therein lies the problem because documenting survival is one of the most vexing problems in ecology. Some taxa, such as mammals, can be difficult to detect due to their often secretive nature and because they are mostly nocturnal. In this case, extensive efforts in the field are required to ensure that as many individuals that are alive are encountered as possible. Although they are mostly diurnal and are much more easily observed than most mammals, birds present an especially difficult challenge because they can readily disperse large distances between resighting periods. Juvenile dispersal distance can be especially high (Greenwood and Harvey 1982), often resulting in the movement of juveniles out of their natal population. Movement of individuals among populations results in the fact that populations of many bird species are open as opposed to closed. Estimating survival in open populations is made all the more difficult because of uncertainty of the fate of individuals that are not encountered. Unless they are recovered in some way, it is impossible to distinguish between dead and dispersed individuals. Although theoretically possible, it is logistically unfeasible to survey all potential areas that individuals can disperse into (e.g. Spendelow et al. 1995).

Cormack (1964), Jolly (1965), and Seber (1965) helped to overcome this difficulty by developing a model that estimates both apparent survival and resighting probabilities over multiple sessions. This method allows for a more robust understanding of the demography of a population of animals. Although, the Cormack-Jolly-Seber (CJS) model is a powerful tool for ecologists, it can be difficult to understand (because of underlying assumptions and design criteria that are required for accurate estimation of 
data) and implement (because of the mathematics involved). Lebreton et al. (1992) helped to lay the groundwork for a unified approach to utilizing CJS models that was comparable among studies and this framework is still referred to more than 20 years later. Of perhaps greater importance is the development of computer software that lessens the tedium of the math behind the CJS model. The most widely utilized software is Program MARK (White and Burnham 1999). This program is well-liked not only because it is relatively easy to use compared to similar software, but also because of its ability to conduct some of the more specialized extensions of the CJS model. MARK thus allows for fairly simple and straightforward estimates of survival (e.g. Yackel Adams et al. 2006), but it can also be used to conduct hypothesis driven analyses of the effects of a number of individual characteristics on survival. For example, Lescroel et al. (2009) used MARK to test whether there was a difference in survival rates between successful and unsuccessful Adelie Penguins (Pygoscelis adeliae).

A field not touched by Lack or others until the beginning of the latter half of the $20^{\text {th }}$ century is that between ecology and endocrinology. Although widely appreciated from the study of laboratory animals, the relationship between hormones and reproductive behavior of birds remained largely unexplored until the pioneering efforts of Donald Farner, Ralph Mewaldt, and James R. King. Their physiological approach to the study of the timing of reproduction, molt and migration of White-crowned Sparrow (Zonotrichia leucophrys; e.g., Farner and Mewaldt 1953, Farner et al. 1954, King 1961) set the stage for later work by many, but perhaps most importantly, John Wingfield and 
his studies on the patterns of secretion and the role that testosterone plays in the reproductive biology of birds.

Testosterone, and other androgens, affects important behavioral and physiological characteristics associated with reproduction in male vertebrates. From a behavioral perspective, testosterone has a positive effect on mating behaviors such as mate attraction (Van Duyse et al. 2000, Foerster et al. 2002) and territoriality (Chandler et al. 1994, Silverin et al. 2004), while at the same time inhibiting parental behaviors such as care of offspring (Van Roo et al. 2003). One of the early goals of Wingfield and other researchers was to document patterns of testosterone secretion in a number of species (e.g. Wingfield 1984). Comparing results among these studies, it soon became apparent that interspecific differences in testosterone secretion were related to mating systems (reviewed by Hirschenhauser et al. 2003). Monogamous species exhibit a peak in testosterone early in the breeding season while males compete with other males for territories and access to mates, followed by a sharp decline as incubation begins (Wingfield et al. 1990). In polygynous species, testosterone is high early in the breeding season, but declines relatively slowly as the breeding season progresses (Beletsky et al. 1989).

The reason for this difference is the role that males play in parenting between monogamous and polygynous species. In monogamous species, males typically are in some part responsible for caring for young. The behaviors that testosterone would illicit are in direct competition with parental behaviors and studies since have shown that high testosterone inhibits parental care (Ketterson et al. 1992). Males of monogamous species 
are thus faced with a trade-off and appear to have been selected for lower levels of testosterone as the nest cycle progresses to increase reproductive success. Males of polygynous species, on the other hand, are not faced with this trade-off because of their limited role in raising offspring. Instead, selection appears to have favored relatively high levels of testosterone throughout the nest cycle, allowing polygynous males to continuously attract additional females throughout the breeding season.

\section{EASTERN KINGBIRDS AT MALHEUR NATIONAL WILDLIFE REFUGE}

Eastern Kingbirds are members of the family Tyrannidae. Also known as tyrantflycatchers, tyrannids are confined to the Nearctic and Neotropical biogeographic zones. Tyrannidae is the most speciose family of birds, and, not surprisingly, is very diverse in terms of their biology and natural history (Fitzpatrick 1980, 1981, 1985). Eastern Kinbgirds (hereafter, kingbirds) are long-distance migrants that breed across much of North America and overwinter largely in Amazonia. The preferred breeding season habitat is relatively open spaces, such as grasslands, meadows, and marshes that have some larger woody plants in which they construct their nests. Diet during the breeding season consists mostly of insects and other small animals and is supplemented, at times, with fruit. Kingbirds are socially monogamous, and males and females often form pair bonds over multiple years. The latter is a consequence, in all probability, of high site fidelity and relatively high annual survival (Murphy 1996 and see below) of the two sexes. Both sexes contribute to parental care, but there are some sex-specific duties. For example, females are entirely responsible for constructing nests, incubating eggs, and 
brooding nestlings. Both sexes feed nestlings, and in at least some populations, females tend to feed young to a greater extent (Woodard and Murphy 1999). On the other hand, males are more responsible for nest vigilance and defense against potential predators (Redmond et al. 2009). Incubation takes, on average, 15 days and nestlings remain in the nest for 16 to 17 additional days. This is followed by an extended period of post-fledging parental care which can last from 3 to 5 weeks (Morehouse and Brewer 1968). Although single-brooded, kingbirds will attempt replacement nests after nest failure if enough time remains in the breeding season. Breeding site fidelity is quite high in this species, especially for individuals that successfully raised young in the previous year (Murphy 1996).

I conducted this research in southeastern Oregon at Malheur National Wildlife Refuge. At approximately $750 \mathrm{~km}^{2}$, Malheur is one of the largest wetland complexes in North America. The Donner und Blitzen River which flows the entire length of the refuge in a south to north direction supplies most of the water to the refuge. Water levels are heavily manipulated by refuge personnel which creates large areas of seasonally flooded grassland, marshes, and bodies of water that are lined by dense willow thickets. These mesic habitats are preferred by kingbirds that breed on the refuge, and are surrounded by much drier habitat types that are characteristic of Oregon's vast High Desert. Plants found in these habitats include sagebrush (Artemisia spp.) rabbitbrush (Chrysothamnus spp.), greasewood (Sarcobatus vermicularis), and western juniper (Juniperus occidentalis). Unless found extremely close to some body of water, these habitats are not utilized by kingbirds breeding on the refuge. 


\section{ANNUAL SURVIVAL RATES OF KINGBIRDS}

Estimates of annual survival for populations breeding in eastern North America have already been produced (Murphy 1996). However, because of the open populations typical in the eastern portion of this species’ range, individuals disperse readily between populations. Because dispersal out of a population is indistinguishable from death, unless that individual moves back into the population that is being monitored, these types of movements result in less accurate estimates of annual survival rates. From a breeding habitat perspective, Malheur presents an ideal setting to study kingbird population dynamics. Because preferred and non-preferred habitats are easily distinguished from one another it was relatively easy to define distinct boundaries to the population of kingbirds at Malheur. The island-like nature of the refuge and the surrounding high desert habitat also results in a relatively closed population. Because the refuge is so isolated from other areas of appropriate kingbird habitat, dispersal into/out of the Malheur population is very limited. Studies conducted in such a sharply defined population with relatively little to no immigration or emigration can result in very accurate estimates of annual survival. In chapter 2, I present the results of a several year study whose goal was to estimate adult and juvenile survival rates of kingbirds breeding at Malheur.

From a biological perspective, knowing annual survivorship (or its inverse, annual mortality) is an important step in understanding the life history of a species. From a conservation perspective, estimating survival rates for different groups within a 
population (e.g., adult and juvenile survival) can be used to help guide management decisions for threatened or endangered populations. And from the standpoint of basic biological research, it is essential to know whether the handling and experimental procedures employed compromise a study subject's probability of survival.

My dissertation is part of a larger collaborative effort to understand the genetic mating system of kingbirds. This involved the collection of blood samples from individual kingbirds for genetic analysis and hormone assays. Prior to 2009 the tacit assumption among ornithologists was that the collection of blood samples from birds, when done properly, resulted in few, if any, negative consequences for the individuals sampled. This assumption was based on relatively few studies that attempted to assess the effects of blood sampling on birds (reviewed by Sheldon et al. 2008). Although these studies found very little, if any, short-term effects of blood sampling on survival, it can be argued that they were not appropriately designed to address the possible long-term impacts (e.g. annual survival rates) that blood sampling could have on free-living animals. Indeed, Brown and Brown (2009) in a study that was designed to follow individuals across multiple years found that blood sampling caused a significant decrease in survival rates in Cliff Swallows (Petrochelidon pyrrhonota). This finding raised concern that blood sampling, an increasingly frequent practice in ornithological studies, did, indeed, have long-term consequences for birds. Chapter 3 addresses the effect of blood sampling on annual survival in kingbirds. 


\section{TESTOSTERONE SECRETION IN MALE KINGBIRDS}

Not all monogamous species exhibit the expected breeding season testosterone profile expected for their mating system, and, instead, their profiles are more similar to polygynous species (e.g., Peters et al. 2001, Jawor et al. 2006, Eikenaar et al. 2011). A possible explanation for these exceptions would be that males continue to secrete elevated levels of testosterone longer than expected so that they can increase reproductive success via extra-pair fertilizations. Given the role that testosterone plays in mating behaviors, it would be expected for there to be a link between testosterone and extra-pair fertilizations. However, this prediction has received little attention at present (but see Raouf et al. 1997, Garamszegi et al. 2005, Eikenaar et al. 2011) and more data are needed for monogamous species that exhibit high levels extra-pair fertilizations to strengthen generalizations about patterns of testosterone secretion in these species.

Kingbirds are socially monogamous, but extra-pair fertilizations occur frequently and can represent up to half of all the young produced in a given year (Rowe et al. 2001). Extra-pair fertilizations also increase variation in reproductive success among males to a degree in which kingbirds are more like a polygynous species (Dolan et al. 2007). Thus, kingbirds are an ideal species in which to evaluate the importance of social and genetic mating systems in explaining patterns of testosterone secretion. Chapter 4 documents the breeding season testosterone profile in kingbirds. I also evaluated the relative importance of several temporal and social variables in relation to variation in testosterone secretion among males. 


\title{
CHAPTER 2
}

\section{Using Complementary Approaches to Estimate Survival of Juvenile and Adult Eastern Kingbirds}

\begin{abstract}
Survival rates of young birds during the period between nest departure and their first breeding season is an important but difficult statistic to measure because of low natal site fidelity, especially for long-distance migrants. From 2002 to 2008, we conducted a capture-mark-re-sight study of Eastern Kingbirds (Tyrannus tyrannus), a NearcticNeotropical migrant, at Malheur National Wildlife Refuge, Oregon, to estimate juvenile $\left(\mathrm{S}_{\mathrm{J}}\right)$ and adult $\left(\mathrm{S}_{\mathrm{A}}\right)$ survival. The return rate of juvenile kingbirds was high $(0.224)$ and not significantly different from program MARK's estimate of $S_{J}(0.291)$. On average, and for both sexes, program MARK's estimate of $S_{A}$ for birds banded as nestlings (0.64) was similar to that for birds first banded as adults (0.65). Enumeration methods and MARK yielded similar estimates of $\mathrm{S}_{\mathrm{A}}$, especially for males banded as adults. We attribute the similarity of re-sighting rate of birds banded as nestlings to $S_{J}$, and the similarity of $\mathrm{S}_{\mathrm{A}}$ estimated using program MARK and by enumeration methods to the high site fidelity of most juvenile and adult kingbirds at our ecologically isolated study site. An independent estimate of $S_{J}$ calculated using local estimates of population growth and average annual production of young year ${ }^{-1}$ suggested that true $\mathrm{S}_{\mathrm{J}}$ and $\mathrm{S}_{\mathrm{A}}$ were probably slightly higher than program MARK's estimates because of undocumented permanent emigration, especially of birds first banded as adults. Demographic balancing suggests
\end{abstract}


that true $\mathrm{S}_{\mathrm{A}}$ and $\mathrm{S}_{\mathrm{J}}$ were roughly 0.70 and 0.30 , respectively. In general, our multiple estimates of $S_{\mathrm{J}}$ were similar. However, MARK estimates of $\mathrm{S}_{\mathrm{J}}$ tended to be lower than those produced by demographic balancing. Because of the difficulty in separating between permanent emigration and mortality and the effect it has on empirical estimates of survival we urge researchers to utilize multiple methods of survival estimation, when possible, to validate the precision of their estimates.

\section{INTRODUCTION}

Knowledge of age-specific patterns of survival is important for understanding life history evolution (Stearns 1992), population dynamics (Lande 1988, Ryan et al.1993, Small et al. 2007, Buehler et al. 2008), and for managing exploited or threatened species (Braden et al. 1997, Woodworth 1999). Unfortunately, survival rates are difficult to measure. The validity of using local return/re-sighting rates (i.e., the proportion of a marked portion of a population to return or be re-sighted) to estimate survival depends on the degree of permanent and temporary emigration of individuals from study sites and, if individuals are present, their detection probability. Under ideal conditions (residency, limited dispersal, and high re-sighting probability), local return rate can yield accurate estimates of survival (e.g., Tarwater et al. 2011), but ideal conditions rarely exist. Methods have thus been developed to account for temporary emigration and less than perfect detection probabilities, but current methods still cannot separate mortality from permanent emigration (Anders and Marshall 2005, Cooper et al. 2008). 
Improvements in the statistical treatment of survival data have resulted in publication of a growing number of estimates of "apparent survival” (i.e., survival corrected for temporary emigration and detection probability) of adult birds (hereafter $\mathrm{S}_{\mathrm{A}}$; e.g. Cilimburg et al. 2002, Gardali et al. 2003, Dugger et al. 2010). However, our knowledge of survival rates of birds during the period from nest departure until first breeding remains poor. Studies of offspring survival in the weeks just after fledging (Naef-Daenzer et al. 2001, Cohen and Lindell 2004, Yackel Adams et al. 2006, Berkeley et al. 2007) generally show that survival rates during the first 1 to 2 weeks after fledging are low, but then stabilize and attain relatively high levels (e.g., Ausprey and Rodewald 2011). Some attempts have also been made to measure survival of migrants in their wintering areas (Sillett and Holmes 2002), and of independent young during the period between independence and recruitment (Tarwater et al. 2011, Tarof et al. 2011), but, in general, few studies of offspring survival have encompassed the entire period between nest departure and the first breeding season (but see Keyser et al. 2004, Stenzel et al. 2007, Tarof et al. 2011).

Available estimates of local juvenile survival (hereafter $\mathrm{S}_{\mathrm{J}}$ ) are usually below the values needed to maintain observed population sizes (Arcese 1989, Wheelwright and Mauck 1998, DiQuinzio et al. 2001). Presumably, this is because of the low probability that marked juveniles will be re-sighted (Weatherhead and Forbes 1994), which can probably be attributed to the greater dispersal distances of juveniles compared to adults (Greenwood and Harvey 1982). Intensive, multi-year re-sighting efforts may increase encounters with long-distance dispersers and improve estimates of $\mathrm{S}_{\boldsymbol{J}}$ (e.g., Baker et al. 
1995, Lebreton et al. 2003, Winkler et al. 2005), but limited time and resources usually present insurmountable obstacles (but see Stenzel et al. 2007). This is a particular problem for long-distance migrants where natal philopatry is generally very low (Weatherhead and Forbes 1994). For instance, Shutler et al. (2006) detected $<5 \%$ of banded nestling Tree Swallows (Tachycineta bicolor) as adults despite intensive study of well-established colonies.

Researchers thus often estimate $S_{J}$ indirectly. Ricklefs (1973) reasonably argued that recruitment should equal and just balance adult mortality in populations that are stable and, for species where the age at first reproduction is one year, $\mathrm{S}_{\mathrm{J}}$ would thus be equivalent to recruitment. However, this approach requires accurate estimates of adult mortality and per capita annual offspring production. A second, more common indirect approach for estimating $\mathrm{S}_{\mathrm{J}}$ is to assume that $\mathrm{S}_{\mathrm{J}}$ is some proportion of $\mathrm{S}_{\mathrm{A}}$, typically half (Temple and Cary (1988, Donovan et al. 1995, McCoy et al. 1999). The latter approach suffers from two deficiencies. First, a reliable estimate of $\mathrm{S}_{\mathrm{A}}$ itself may not be available and, second, it is unclear that a general " $50 \%$ rule" is widely applicable because few studies have good quantitative estimates of both $\mathrm{S}_{\mathrm{A}}$ and $\mathrm{S}_{\mathrm{J}}$.

We used seven years of mark/re-sight data to estimate annual $\mathrm{S}_{\mathrm{A}}$ and $\mathrm{S}_{\mathrm{J}}$ for a color-banded population of Eastern Kingbirds (Tyrannus tyrannus), a long-distance, Nearctic-Neotropical migrant. The relative isolation of our study site in eastern Oregon allowed high re-sighting rates of previously banded adults and young. High re-sighting rates, combined with our application of Cormack-Jolly-Seber (CJS) methods, allowed us to (1) rigorously measure $S_{J}$ and $S_{A}$ for individuals in the same population, and (2) 
compare survival rates of adults obtained using CJS and enumeration methods. In addition, (3) we used estimates of population size over the study period to determine population growth rate, which we then combined with direct estimates of annual offspring production per pair to provide an independent estimate of $\mathrm{S}_{\mathrm{J}}$ by demographic balancing to compare to that obtained using the CJS model. Finally, (4) because estimates of kingbird $\mathrm{S}_{\mathrm{A}}$ based on CJS methods are available for a population in New York in eastern North America (Murphy 1996), we were able to compare $\mathrm{S}_{\mathrm{A}}$ for core (New York) and peripheral (Oregon) populations breeding under different conditions.

\section{METHODS}

Study site and field methods. We studied Eastern Kingbirds (hereafter kingbirds) at Malheur National Wildlife Refuge (MNWR; 42 49’ N, $118^{\circ} 54^{\prime}$ W) from 2002 through 2008. MNWR is located in southeastern Oregon at the northern end of the Great Basin Desert. MNWR is surrounded by high desert, and the kingbird population is restricted to the riparian zone of the Donner und Blitzen River (and tributaries) that runs through the center of the refuge because kingbirds built their open-cup nests almost exclusively in willow (Salix spp.) trees on the banks of the river. Rarely, kingbirds nested in the big sagebrush (Artemisia tridentata) or rabbitbrush (Chrysothamnus spp.) of the high desert, and only if shrubs were within 150 to $200 \mathrm{~m}$ of the river (LJR and MTM, unpubl. data).

Our main study area was along a 20-km section of the river located at the south end of MNWR beginning near Paige Springs campground and ending just north of the 
bridge to Krumbo Reservoir (Fig. 1). We also included suitable habitat found along a major tributary (East Canal; EC) of the Donner und Blitzen River that runs along the eastern boundary of the refuge. The Center Patrol Road (CPR) paralleled the main channel of the river at a distance of generally $\leq 5 \mathrm{~m}$ for most of the river's length. Likewise, a gravel road closely paralleled EC. We thus had immediate access to nesting habitat by both driving the roads and canoeing the length of the main river. Additional areas away from the river with trees were also surveyed on foot. A second site, Buena Vista (BV), which began with a new section of the CPR, was located $6 \mathrm{~km}$ north of the northern boundary of the main study site (Fig. 1). The CPR also paralleled the river's course at BV to again provide direct access to nesting habitat. Restrictions prevented us from surveying the area between our two study sites and the $\sim 20 \mathrm{~km}$ of riparian habitat north of the BV study site (Fig. 1). Other nesting habitat that we did not survey was available beginning $11 \mathrm{~km}$ to the east of BV on private lands near Diamond (Fig. 1). All unsurveyed sections supported fewer trees and appeared to be lower quality habitat for kingbirds, but incidental observations confirmed that kingbirds nonetheless nested in those areas.

Adult kingbirds arrive at MNWR beginning in mid-May and we were confident we detected nearly every pair present each year on our study site because of the conspicuousness of kingbirds, the openness of the habitat, and our daily surveys of the study areas by both vehicle (see below) and canoe. Accurate counts of pairs were also facilitated by the fact that $\geq 75 \%$ of pairs had at least one member banded in every year except the first ( $65 \%$ by the end of that year), and observations showed that pairs rarely if 
ever relocated after a within-season nest failure. To detect returning birds, we conducted daily searches of most of the study area (usually $>2$ observers per day) from mid-May to mid-June by slowly driving the roads that paralleled the river and its tributaries. Detections of late-arriving kingbirds (that usually did not breed) were made during daily nest checks that continued until early August of each year. We observed banded birds with 10 x 42 binoculars and 20-60X spotting scopes. First-year kingbirds (i.e., $<12$ months old and in their first potential breeding season) often return later than older birds (Cooper et al. 2009a), and Cooper et al. (2009b) showed that first-year birds of both sexes were less likely to hold a territory and breed when population size was high. Nonetheless, regular censuses of the entire study area throughout the breeding season allowed us to detect many non-territorial first-year birds (Cooper et al. 2009b).

Adult kingbirds were captured with mist nets. Males were captured using either song playback during dawn song periods (Sexton et al. 2007), or at the nest using taxidermic mounts of potential nest predators or when feeding nestlings. Females were only captured when feeding nestlings to minimize the possibility of nest abandonment. All adults were given a unique combination of three colored, plastic leg bands and one aluminum USGS band, and identified as female if they had a brood patch or male if they had a cloacal protuberance. We banded and bled nestlings when 12 to 13 days old to avoid premature fledging (normally between 15 to 17 days of age). Most nests were not checked after day 13 and we assumed, unless a later nest check showed otherwise, that all banded young fledged. Violation of the latter assumption would lead to an underestimate of first year survival. DNA was extracted from blood, and the sex of all young was 
determined through amplification of the CHD1W and CHD1Z introns using the 2550F/2718R primers (Fridolfsson and Ellegren 1999; see Dolan et al. 2007 for a complete description of laboratory methods).

Kingbirds raise only one brood per year, but generally renest after failed first attempts, and nearly all replacement nests are $\leq 100 \mathrm{~m}$ from first nests. We found $\geq 80 \%$ of nests before the start of egg-laying in every year, and checked them every 2 to 3 days to establish breeding dates (first egg of the clutch), clutch sizes, and number of young fledged.

Statistical analysis. We used program MARK version 4.3 (White and Burnham 1999) and basic enumeration procedures (Krebs 1999) to estimate juvenile and adult survival. We included censuses conducted through the 2008 breeding season so that detections of birds first banded in 2007 were possible. Model notation in MARK followed the suggestions of Lebreton et al. (1992), and we examined only those candidate models predicted by a priori knowledge of the system. No known methods exist to age adult kingbirds, and thus the sample of unbanded adults that we captured included birds in their first potential breeding season and a mixture of older birds of different ages. Banded nestlings that returned were, on the other hand, of known age. Included with the capture history of each individual were a set of dummy variables that placed each bird into one of four groups based on their age and sex when banded (adult male, nestling male, adult female, and nestling female). Throughout the model selection procedure, we assumed that apparent survival and re-sighting probability of juveniles differed from that of adults (e.g., a two age class model, expressed in model notation as: “a2”). We began 
with a global model that was parameterized such that survival differed both with sex and age at time of banding (i.e., nestling or adult) and was time dependent. The parameterization of re-sighting probability was similar, except it lacked time dependence because re-sighting effort did not vary among years. We then included several simplified models by removing either one or a combination of the following: (1) age at banding (nestling or adult; models with ' $\mathrm{g}$ ' in their notation) for $\mathrm{S}_{\mathrm{A}}$ (or resighting probability), (2) sex dependence (models with 's' in their notation), and (3) time dependence (models with ' $\mathrm{t}$ ' in their notation).

We used the bootstrap GOF test within MARK to test goodness of fit for the global model. Results of this test indicated that our global model did not fit the data well (deviance $=188.44$, rank 980 of 1000 simulations) and that the data were slightly overdispersed $(\hat{\mathrm{c}}=1.233$; calculated as [global model $\hat{\mathrm{c}} / \mathrm{mean} \hat{\mathrm{c}}$ from bootstrap simulations]). We corrected for this by adjusting $\hat{c}$ within MARK (Adjustments: c-hat) and used quasi-AIC (QAIC) instead of AIC. The ratio of sample size $(N=562)$ to number of parameters in the global model $(K=40)$ was less than 40 , and therefore QAIC corrected for small sample size (QAIC ${ }_{c}$ ) was used during model selection (Burnham and Anderson 2002). We used $\Delta$ QAICc $<2$ as a cutoff for models that were well supported by the data, and QAICc weights, evidence ratios (weight of model a/weight of model b), and model likelihoods as measures of support when making comparisons between two models. To account for model selection uncertainty (i.e., when multiple models were supported by the data), we used parameter estimates from all models with $\Delta$ QAICc $<7$ 
and their respective QAICc weights to calculate model averaged estimates of apparent survival and re-sighting probability (Burnham and Anderson 2002).

We used basic enumeration procedures (Krebs 1999) to further explore patterns of temporary emigration and annual transition probabilities (i.e., detected or not and, if the latter, reappearance in a later year) for birds $\geq 1$ year of age. We distinguished between individuals banded as adults and birds banded as nestlings that survived to their first potential breeding season. To calculate return rates between consecutive age classes, we acknowledged that a bird was alive during years when it was not observed, but later reappeared. For example, using 0 and 1 to represent a bird that was undetected and detected, respectively, a bird banded as a nestling in 2002 and that was first seen in 2004, not seen in 2005, seen in 2006, but never seen again, would be coded as 010100 (2003 [first potential breeding season] through 2008 [end of study], respectively). However, for calculating survival, we coded it as 111100 . By this notation, this individual had four opportunities to return as an adult and was thus counted as four "bird-years." Birds banded as nestlings in 2007 were not included in this analysis because their first potential breeding season as an adult was 2008 and thus we had no opportunity to determine if they survived to age 2. Individual histories of all birds were organized by "age” (not year) and sex so survival could be calculated between successive age classes as the quotient obtained by dividing the number of birds returning by the total number of bird-years within each age. Year of banding was considered age 1, which was the true age of only birds banded as nestlings. 
Demographic balancing. We used total annual counts of pairs (N) between 2002 and 2008 to calculate the finite rate of increase ( $\lambda$; i.e., population growth rate) by regressing $\ln (\mathrm{N})$ against year; $\lambda$ is equal to e raised to the power of the slope of $\ln (\mathrm{N})$ versus year (Akçakaya et al. 1997). We then used our estimates of $S_{A}$ and annual production of young per pair to generate an independent estimate of $S_{J}$ to compare to the estimates obtained from MARK. Annual production per pair was calculated for each year separately. We assumed an equal sex ratio (Dolan et al. 2009) so that annual female offspring production was half of the average annual production per pair, which we then averaged across years to obtain a grand mean female offspring per pair per year $(\mathrm{F})$ over the study period. $\lambda, \mathrm{S}_{\mathrm{A}}$, and $\mathrm{F}$ were then substituted into the equation describing population growth

$$
\lambda=\mathrm{S}_{\mathrm{A}}+\left(\mathrm{S}_{\mathrm{J}} \mathrm{x}\right)
$$

Equation 1

which we rearranged to compute the $\mathrm{S}_{\mathrm{J}}$ necessary to balance the equation. We also used equation 1 to evaluate whether estimates of $\mathrm{S}_{\mathrm{A}}$ and $\mathrm{S}_{\mathrm{J}}$ from MARK and the enumeration approach produced estimates compatible with observed $\mathrm{F}$ and $\lambda$. With the exception of MARK, all statistical analyses were performed using STATISTIX (2008).

\section{RESULTS}

The percentage of banded kingbird nestlings re-sighted did not differ among years (range $=17-28 \% ; \chi^{2}{ }_{5}=3.9, P=0.57$ ), and we re-sighted $22.4 \%$ (82 of 366) of nestlings banded from 2002 through 2007 in a subsequent year. Male nestlings (50 of 195, or 
$25.6 \%$ ) tended to return at a higher rate than female nestlings (32 of 171 , or $18.7 \%$ ), but the difference was not significant $\left(X^{2}=2.5, P=0.11\right)$. Over the same period, we banded 112 adult male and 84 adult female kingbirds, and re-sighted 73 and 55, respectively, in the year after they were banded. Local survival (i.e., re-sighting rate) of adults of both sexes from the year of banding to the next was thus $65 \%$.

Five of the candidate models from MARK received at least some support $(\triangle \mathrm{QAICc}<2)$, and the global model $\left(\Phi\left[\mathrm{g}, \mathrm{a} 2 \_\mathrm{s} * \mathrm{t} / \mathrm{s} * \mathrm{t}\right] p\left[\mathrm{~g}, \mathrm{a} 2 \_\mathrm{s} / \mathrm{s}\right]\right)$ performed relatively poorly compared to more simplified models (Table 1). The model with the strongest support was based on two age classes (juvenile and adult) and was group, sex, and timeindependent for apparent survival and group and sex dependent for re-sighting probabilities (Table 1). Parameterization of apparent survival in the four remaining models that were well supported was, overall, similar to that of the top model with two exceptions. First, two models were structured to include differences in apparent $\mathrm{S}_{\mathrm{A}}$ between birds banded as nestlings and birds banded as adults. Apparent $\mathrm{S}_{\mathrm{A}}$ of individuals banded as nestlings $\left(0.675,95 \% \mathrm{CI}=0.573\right.$ to 0.763 ; calculated from model $\left(\Phi\left[\mathrm{g}, \mathrm{a} 2 \_. / .\right]\right.$ $\left.p\left[\mathrm{~g}, \mathrm{a} 2 \_\mathrm{s} / \mathrm{s}\right]\right)$ was slightly higher than that for individuals banded as adults $(0.628,95 \%$ CI $=0.573$ to 0.680 ). However, confidence intervals for both estimates overlapped. There was also some suggestion that apparent $\mathrm{S}_{\mathrm{J}}$ differed between the sexes (model $\Phi\left[\mathrm{a} 2 \_\mathrm{s} /.\right]$ $\left.p\left[\mathrm{a} 2 \_\mathrm{s} / \mathrm{s}\right]\right)$ with juvenile males $(0.301,95 \% \mathrm{CI}=0.224-0.392)$ surviving at slightly higher rates than juvenile females $(0.271,95 \% \mathrm{CI}=0.182$ - 0.383). Again, there was considerable overlap in the confidence intervals of the two estimates. 
Because of the likelihood of model selection uncertainty (5 models with $\triangle$ QAICc $<2$ and 17 models with $2<\Delta$ QAICc $<7$ ), we used model averaging to produce estimates of apparent survival and re-sighting probabilities (Table 2). Re-sighting probability for first-year males was $71 \%$ higher than for first-year females (Table 2), but apparent $S_{J}$ was essentially identical ( 0.29). The pattern was similar for adults. Re-sighting probability was slightly higher for males than females, but apparent $S_{A}$ did not differ between the sexes $($ range $=0.637-0.653$; Table 2 ).

Estimates of survival using enumeration methods were largely consistent with the results of the MARK analyses. Estimated $\mathrm{S}_{\mathrm{A}}$ for males from MARK (Table 2) and by enumeration for birds banded as adults (0.636) and nestlings (0.653) were similar. $\mathrm{S}_{\mathrm{A}}$ of females banded as adults using enumeration (0.595) was below the MARK estimate, but still within the MARK estimate's 95\% confidence interval (Table 2). On the other hand, $\mathrm{S}_{\mathrm{A}}$ obtained using enumeration (0.753) was significantly above (based on $95 \% \mathrm{CI}$ ) the MARK estimate for females banded as nestlings (Table 2).

Examination of $\mathrm{S}_{\mathrm{A}}$ derived by enumeration between successive years suggested that $\mathrm{S}_{\mathrm{A}}$ of both sexes of birds banded as adults declined from the first to the second and third annual transitions (i.e., year 1 to 2 and year 2 to 3), but then rebounded to levels at (females) or above (males) $\mathrm{S}_{\mathrm{A}}$ from the first transition (year 0 to 1; Fig. 2). Because of smaller sample sizes, males and females banded as nestlings were combined to conduct a similar analysis. $\mathrm{S}_{\mathrm{A}}$ of adults banded as nestlings did not show the decline in the years following their entry into the banded adult population that was recorded for birds first banded as adults (Fig. 2). To the contrary, $\mathrm{S}_{\mathrm{A}}$ was relatively constant across age classes, 
and the $\mathrm{S}_{\mathrm{A}}$ of birds banded as nestlings averaged 0.702 (i.e., survival was the outcome in 107 of 152 possible bird-years), which was only 4\% higher and not significantly different from the $\mathrm{S}_{\mathrm{A}}$ of birds banded as nestlings that was estimated by the MARK model that incorporated group membership (0.675).

Demographic balancing. The kingbird population at MNWR declined between 2002 and 2008 and the finite rate of increase was $\lambda=0.888$ (Fig. 3). Average annual production of young per pair per year was $1.24(\mathrm{SE}=0.15, N=6$ years; range $=0.86$ 1.86). Using an $S_{A}$ of 0.65 (Table 2), $\lambda$ of 0.888 , and assuming an equal sex ratio such that annual female offspring production $(F)$ was half of the total $(1.24 / 2=0.62)$, the $S_{J}$ required to balance equation $1\left(\mathrm{~S}_{\mathrm{J}}=0.384\right)$ was $32.3 \%$ higher than that predicted by MARK (0.290). If we instead used the estimate of $S_{A}$ and $S_{J}$ from MARK, and observed $\mathrm{F}$, the resulting $\lambda(0.830)$ was only $6.6 \%$ below that observed. Because relatively high uncertainty also existed over $\mathrm{S}_{\mathrm{A}}$ (Table 2), a third scenario that we explored was to use

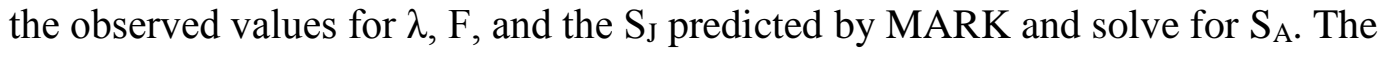
resulting $S_{A}(0.708)$ was nearly identical to the $S_{A}$ estimated by enumeration for adults first banded as nestlings (0.702; Fig. 2), and was not significantly different from the $\mathrm{S}_{\mathrm{A}}$ predicted by MARK for birds banded as nestlings when group membership was included in the model (0.675). 


\section{DISCUSSION}

Studies of Eastern Kingbirds conducted in the core of their geographic range in eastern North America (Oneonta, New York; Murphy 1996, 2000) provide a contrast to our Oregon study. A lower proportion of banded nestlings $(0.033, N=667)$ were resighted as adults at Oneonta $\left(X^{2}=95.3, P<0.001\right)$, and the difference between the Oneonta and MNWR populations likely reflects the difference in the distribution of available habitat and behavior of first-year kingbirds at the two sites. The Oneonta population was embedded in a much larger population distributed continuously in all directions for hundreds of kilometers, and into which surviving young probably dispersed widely. By contrast, usable habitat is limited at MNWR, and we have never found kingbirds nesting more than 200 m away from aquatic habitats. Because of the surrounding high desert habitat, MNWR is in many ways an ecological island for kingbirds. Similarly, Johnson and Geupel (1996) suggested that high juvenile return rates for Swainson's Thrushes (Catharus ustulatus) at Palomarin Field Station in California were due to dependence on limited riparian habitat in an area dominated by coastal scrub.

By contrast, survival rates of adult kingbirds at Oneonta and MNWR were similar. Some kingbirds in Oneonta were experimentally forced to raise enlarged broods and this reduced female survival (Murphy 2000). After removing these birds from consideration, survival rates based on enumeration for females (Oneonta: 0.597, $N=181$; MNWR: 0.644, $N=250$ ) and males (Oneonta: 0.662, $N=192 ;$ MNWR: 0.638, $N=301$ ) at the two sites were similar, as were estimates of $\mathrm{S}_{\mathrm{A}}$ based on CJS methods (Murphy 1996) (females: 0.600 [Oneonta] and 0.645 [MNWR]; males: 0.675 [Oneonta] and 0.644 
[MNWR]). Similarity in estimates of adult survival rates, despite the greater dispersal opportunities at Oneonta, suggest that adult dispersal tendencies probably do not differ among populations and that unbiased comparisons of $\mathrm{S}_{\mathrm{A}}$ are possible.

MARK, enumeration, and demographic balancing. $\mathrm{S}_{\mathrm{A}}$ estimated by MARK for adults of both sexes banded as adults and of adult males banded as nestlings (Table 2) were statistically indistinguishable from survival estimates obtained by enumeration (Tables 3). We attribute this to the high site fidelity of breeding adults (especially males; Murphy 1996), and the high re-sighting probability of adults of both sexes and of firstyear males (Table 2). By contrast, re-sighting probability of first-year females was lower than that of first-year males, and this greater uncertainty probably explains why the enumeration-based estimate of survival exceeded the MARK estimate (Tables 2 and 3).

However, $\mathrm{S}_{\mathrm{A}}$ from MARK was also almost certainly an underestimate of true survival because, despite high breeding site fidelity, (1) adults of both sexes sometimes disperse long distances in consecutive years (i.e., $>20 \mathrm{~km}$ between locations at our two MNWR study sites; LJR and MTM, unpubl. data), and (2) we could not survey all available habitat between and adjacent to our two study sites. The conclusion that true $\mathrm{S}_{\mathrm{A}}$ was underestimated is supported by comparisons of annual probability of survival for birds banded as adults to those banded as nestlings. The former group showed a sharp decline in probability of survival in their middle years whereas birds first banded as nestlings exhibited a constant probability of survival throughout their life (Fig. 2). One possible explanation for this difference is that most birds first banded as nestlings were not handled as adults. Except for the later years of our study (2006-2008), we avoided 
capturing previously banded birds and any captures of banded nestlings that returned was only incidental to the capture of unbanded mates. By contrast, every bird captured first as an adult, by definition, had to be captured and subjected to morphological measurements and blood draws (Redmond and Murphy 2011). We suggest that the difference in the probability of survival over the life of these two groups of birds (Fig. 2) is more apparent than real, and that birds captured and handled as adults may have been more likely to permanently emigrate than were birds not handled as adults. If so, then the survival rates of birds banded as nestlings probably better reflects true $\mathrm{S}_{\mathrm{A}}$. Enumeration methods are subject to negative bias (i.e., underestimation of survival; Krebs 1999) and thus there is no reason to suspect that the latter group yielded inflated survival estimates. Moreover, for adults banded as nestlings, the estimated survival rate obtained by enumeration (0.70) and by MARK when group was included as a parameter in the model (0.675) did not differ statistically.

That $\mathrm{S}_{\mathrm{A}}$ and $\mathrm{S}_{\mathrm{J}}$ were underestimated is also suggested by demographic balancing. We believe that $\mathrm{F}$ and $\lambda$ were measured accurately because we knew with certainty the number of young produced by virtually every pair in all years, and the conspicuousness of kingbirds makes their presence easy to document. Consequently, initial failure to balance equation 1 was likely because of inaccurate estimates of $S_{A}$ or $S_{J}$ or both. Rearranging and solving equation 1 with observed values of $\lambda, S_{A}$, and $F$ to predict $S_{J}$ produced a value (0.384) that seemed unlikely because it greatly exceeded the MARK estimate of $\mathrm{S}_{\mathrm{J}}$. Substitution of the MARK estimated $\mathrm{S}_{\mathrm{A}}$ and $\mathrm{S}_{\mathrm{J}}$ into equation 1 resulted in an $\sim 7 \%$ underestimate of $\lambda$. If we assume that survival of birds banded as nestlings 
provided the best estimate of $S_{A}(\sim 0.70$; Fig. 1$)$, and use an $S_{J}$ equal to male $S_{J}(0.30)$, the observed and calculated $\lambda$ are similar ( 0.888 vs. 0.886 ). Based on these calculations, we suggest that true $\mathrm{S}_{\mathrm{A}}$ and $\mathrm{S}_{\mathrm{J}}$ were 0.70 and 0.30 , respectively.

Conclusions Both the importance and difficulty of measuring $\mathrm{S}_{\mathrm{J}}$ cannot be overstated, especially for species where annual production and survival of young contribute substantially to population dynamics (Johnson and Geupel 1996, Rodenhouse et al. 1997, Murphy 2001, Arlt et al. 2008). For most species, accurate estimates of annual productivity can be obtained with adequate effort on the part of researchers, but regardless of effort, empirical measurement of $S_{J}$ is difficult if a species exhibits extremely low natal site fidelity (e.g., Shutler et al. 2006, Brown and Roth 2009). The geographic and ecological setting of our research site, and the behavioral characteristics of our study species, allowed us to document age-specific survivorship that we were then able to refine with supporting demographic analyses. Use of complementary approaches to estimate $S_{\mathrm{J}}$ that provide internal checks, validation, and refinement can hopefully be replicated for other species in similar situations. Given the similarity of $\mathrm{S}_{\mathrm{A}}$ in Oneonta and MNWR, despite the ecological differences between sites, we believe that the $\mathrm{S}_{\mathrm{J}}$ estimated for MNWR would apply equally well in Oneonta and other sites across the breeding range of Eastern Kingbirds, and would be preferable to application of the untested assumption that $S_{J}$ is half of $S_{A}$.

Our study adds to a growing body of rigorously collected and analyzed data sets that will eventually allow comparative analyses of avian life histories based on well documented estimates of age-specific survival. Furthermore, as reliable estimates of $S_{J}$ 
accumulate, we will eventually be able to test the validity of the oft repeated assumption that $\mathrm{S}_{\mathrm{J}}$ is a fixed proportion of $\mathrm{S}_{\mathrm{A}}$, or is otherwise a predictable property of a species.

\section{ACKNOWLEDGEMENTS}

We thank N. W. Cooper, A. C. Dolan, C. M. Chutter, and K. Sexton for assistance in the field. This work would not have been possible without the consent of the staff of Malheur National Wildlife Refuge, especially R. Roy. This project was supported, in part, by funds from the National Science Foundation (IOB-0539370) to M. T. Murphy, Portland State University, the American Museum of Natural History’s Frank M. Chapman Fund, and the American Ornithologists’ Union Research Awards program. 


\section{CHAPTER 2 TABLES}

Table 2.1. Results of model selection (ranked in order of strongest to least support) for estimates of apparent survival $(\Phi)$ and re-sighting probability $(p)$ of banded Eastern Kingbirds at Malheur National Wildlife Refuge, Oregon. Models whose QAICc weight (QAICc w) which summed to 0.95 are given [with the exception of the global model: $\left.\Phi\left(\mathrm{g}, \mathrm{a} 2 \_\mathrm{s} * \mathrm{t} / \mathrm{s} * \mathrm{t}\right) p\left(\mathrm{~g}, \mathrm{a} 2 \_\mathrm{s} / \mathrm{s}\right)\right]$. We compared models that were (notation includes a2) and were not (notation without a2) structured to include two age classes (juvenile and adult). Variation in model structure, as indicated by the following notation, also included sex dependence (s), time dependence (t), and group dependence (g; groups based on the age when individuals were banded and entered our dataset, nestling or adult) in parameter estimates. For example, the model [ $\left.\Phi\left(\mathrm{a} 2 \_. / \mathrm{t}\right) p\left(\mathrm{a} 2 \_\mathrm{s} / \mathrm{s}\right)\right]$ is sex and time independent for apparent juvenile survival and time dependent for adult survival, and sex dependent for juvenile and adult re-sighting probability. Also given are changes in QAICc score from the top model ( $\triangle$ QAICc), model likelihood (ML), number of parameters (K), and deviance (DEV) for each model.

\begin{tabular}{|c|c|c|c|c|c|c|}
\hline Model & QAICc & 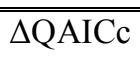 & QAICc $w$ & ML & $\overline{\mathrm{K}}$ & $\overline{\mathrm{DEV}}$ \\
\hline$\Phi\left(\mathrm{a} 2 \_. / .\right) p\left(\mathrm{~g}, \mathrm{a} 2 \_\mathrm{s} / \mathrm{s}\right)$ & 1061.8594 & 0.000 & 0.1597 & 1.0000 & 8 & 177.3187 \\
\hline$\Phi\left(\mathrm{a} 2 \_. / .\right) p\left(\mathrm{a} 2 \_\mathrm{s} / \mathrm{s}\right)$ & 1061.9420 & 0.0826 & 0.1532 & 0.9596 & 6 & 181.4708 \\
\hline$\Phi\left(\mathrm{g}, \mathrm{a} 2 \_. / .\right) p\left(\mathrm{~g}, \mathrm{a} 2 \_\mathrm{s} / \mathrm{s}\right)$ & 1063.2166 & 1.3572 & 0.0810 & 0.5073 & 9 & 176.6340 \\
\hline$\Phi\left(\mathrm{g}, \mathrm{a} 2 \_. / .\right) p\left(\mathrm{a} 2 \_\mathrm{s} / \mathrm{s}\right)$ & 1063.5769 & 1.7175 & 0.0676 & 0.4237 & 7 & 181.0734 \\
\hline$\Phi\left(\mathrm{a} 2 \_\mathrm{s} /.\right) p\left(\mathrm{a} 2 \_\mathrm{s} / \mathrm{s}\right)$ & 1063.7755 & 1.9161 & 0.0613 & 0.3837 & 7 & 181.2720 \\
\hline$\Phi\left(\mathrm{a} 2 \_. / \mathrm{s}\right) p\left(\mathrm{a} 2 \_\mathrm{s} / \mathrm{s}\right)$ & 1063.9632 & 2.1038 & 0.0558 & 0.3493 & 7 & 181.4597 \\
\hline$\Phi\left(\mathrm{a} 2 \_. / \mathrm{t}\right) p\left(\mathrm{a} 2 \_\mathrm{s} / \mathrm{s}\right)$ & 1064.0894 & 2.2300 & 0.0524 & 0.3279 & 11 & 173.4089 \\
\hline
\end{tabular}




\begin{tabular}{|c|c|c|c|c|c|c|}
\hline$\Phi\left(\mathrm{a} 2 \_. / \mathrm{t}\right) p\left(\mathrm{~g}, \mathrm{a} 2 \_\mathrm{s} / \mathrm{s}\right)$ & 1064.3552 & 2.4958 & 0.0458 & 0.2871 & 13 & 169.5578 \\
\hline$\Phi\left(\mathrm{a} 2 \_. / .\right) p\left(\mathrm{a} 2 \_\mathrm{s} /.\right)$ & 1064.4527 & 2.5933 & 0.0437 & 0.2734 & 5 & 186.0093 \\
\hline$\Phi\left(\mathrm{g}, \mathrm{a} 2 \_. / \mathrm{s}\right) p\left(\mathrm{~g}, \mathrm{a} 2 \_\mathrm{s} / \mathrm{s}\right)$ & 1065.0901 & 3.2307 & 0.0317 & 0.1988 & 10 & 176.4609 \\
\hline$\Phi\left(\mathrm{g}, \mathrm{a} 2 \_. / \mathrm{s}\right)$ p(a2_s/s) & 1065.3137 & 3.4543 & 0.0284 & 0.1778 & 8 & 180.7730 \\
\hline$\Phi\left(\mathrm{g}, \mathrm{a} 2 \_\mathrm{s} /.\right) p\left(\mathrm{a} 2 \_\mathrm{s} / \mathrm{s}\right)$ & 1065.6272 & 3.7678 & 0.0243 & 0.1520 & 9 & 179.0447 \\
\hline$\Phi\left(\mathrm{a} 2 \_\mathrm{s} / \mathrm{s}\right) p\left(\mathrm{a} 2 \_\mathrm{s} / \mathrm{s}\right)$ & 1065.7819 & 3.9225 & 0.0225 & 0.1407 & 8 & 181.2411 \\
\hline$\Phi\left(\mathrm{g}, \mathrm{a} 2 \_. / .\right) p\left(\mathrm{a} 2 \_\mathrm{s} /.\right)$ & 1066.1076 & 4.2482 & 0.0191 & 0.1195 & 6 & 185.6366 \\
\hline$\Phi\left(\mathrm{a} 2 \_\mathrm{s} /.\right) p\left(\mathrm{a} 2 \_\mathrm{s} /.\right)$ & 1066.1588 & 4.2994 & 0.0187 & 0.1165 & 6 & 185.6877 \\
\hline$\Phi\left(\mathrm{a} 2 \_. / .\right) p\left(\mathrm{a} 2 \_. / \mathrm{s}\right)$ & 1066.3541 & 4.4947 & 0.0169 & 0.1057 & 5 & 187.9108 \\
\hline$\Phi\left(\mathrm{a} 2 \_. / \mathrm{s}\right) p\left(\mathrm{a} 2 \_\mathrm{s} /.\right)$ & 1066.3905 & 4.5311 & 0.0166 & 0.1038 & 6 & 185.9193 \\
\hline$\Phi\left(\mathrm{a} 2 \_. / \mathrm{t}\right) p\left(\mathrm{a} 2 \_\mathrm{s} /.\right)$ & 1066.4773 & 4.6179 & 0.0159 & 0.0993 & 10 & 177.8480 \\
\hline$\Phi\left(\mathrm{a} 2 \_\mathrm{s} /.\right) p\left(\mathrm{a} 2 \_. / \mathrm{s}\right)$ & 1066.6372 & 4.7778 & 0.0146 & 0.0917 & 6 & 186.1661 \\
\hline$\Phi\left(\mathrm{g}, \mathrm{a} 2 \_\mathrm{s} / \mathrm{s}\right) p\left(\mathrm{a} 2 \_\mathrm{s} / \mathrm{s}\right)$ & 1067.3918 & 5.5324 & 0.0100 & 0.0629 & 10 & 178.7627 \\
\hline$\Phi\left(\mathrm{g}, \mathrm{a} 2 \_. / .\right) p\left(\mathrm{a} 2 \_. / \mathrm{s}\right)$ & 1067.9114 & 6.0520 & 0.0077 & 0.0485 & 6 & 187.4403 \\
\hline$\Phi\left(\mathrm{a} 2 \_\mathrm{s} / \mathrm{s}\right) p\left(\mathrm{a} 2 \_\mathrm{s} /.\right)$ & 1068.1465 & 6.2871 & 0.0069 & 0.0432 & 7 & 185.6430 \\
\hline \multicolumn{7}{|l|}{$\Phi\left(\mathrm{g}, \mathrm{a} 2 \_\mathrm{s} * \mathrm{t} / \mathrm{s} * \mathrm{t}\right) p(\mathrm{~g}$} \\
\hline a2_s/s) & 1105.1796 & 43.3202 & 0 & 0 & 40 & 152.8678 \\
\hline
\end{tabular}


Table 2.2. Model averaged estimates of apparent survival ( $\Phi)$ and re-sighting probabilities $(p)$ of juvenile and adult Eastern Kingbirds at Malheur National Wildlife Refuge, Oregon, from 2002 through 2008.

Separate estimates of adult survival are given for birds first banded as adults and birds banded as nestlings that survived to enter the breeding population. Data given are the weighted averages (unconditional SE, 95\% CI) of parameter estimates from the a priori groups of candidate models (Table 1).

\begin{tabular}{|c|c|c|c|c|}
\hline & & \multicolumn{3}{|c|}{ Age class } \\
\hline Parameter & Sex & Juvenile & $\begin{array}{c}\text { Adults banded as } \\
\text { adults }\end{array}$ & $\begin{array}{c}\text { Adults banded as } \\
\text { nestlings }\end{array}$ \\
\hline$\Phi$ & Male & $\begin{array}{l}0.292(0.0372 \\
0.225-0.370)\end{array}$ & $\begin{array}{l}0.649(0.0433 \\
0.560-0.728)\end{array}$ & $\begin{array}{l}0.638(0.0361, \\
0.565-0.706)\end{array}$ \\
\hline & Female & $\begin{array}{l}0.284(0.0394 \\
0.213-0.367)\end{array}$ & $\begin{array}{l}0.653(0.0457 \\
0.559-0.737)\end{array}$ & $\begin{array}{l}0.637(0.0375 \\
0.560-0.707)\end{array}$ \\
\hline$p$ & Male & $\begin{array}{l}0.676(0.0901, \\
0.482-0.823)\end{array}$ & $\begin{array}{l}0.901(0.0660 \\
0.681-0.975)\end{array}$ & $\begin{array}{l}0.944(0.0353 \\
0.820-0.984)\end{array}$ \\
\hline & Female & $\begin{array}{l}0.396(0.1009 \\
0.223-0.600)\end{array}$ & $\begin{array}{l}0.847(0.0530 \\
0.714-0.926)\end{array}$ & $\begin{array}{l}0.843(0.0493 \\
0.721-0.918)\end{array}$ \\
\hline
\end{tabular}




\section{CHAPTER 2 FIGURES}

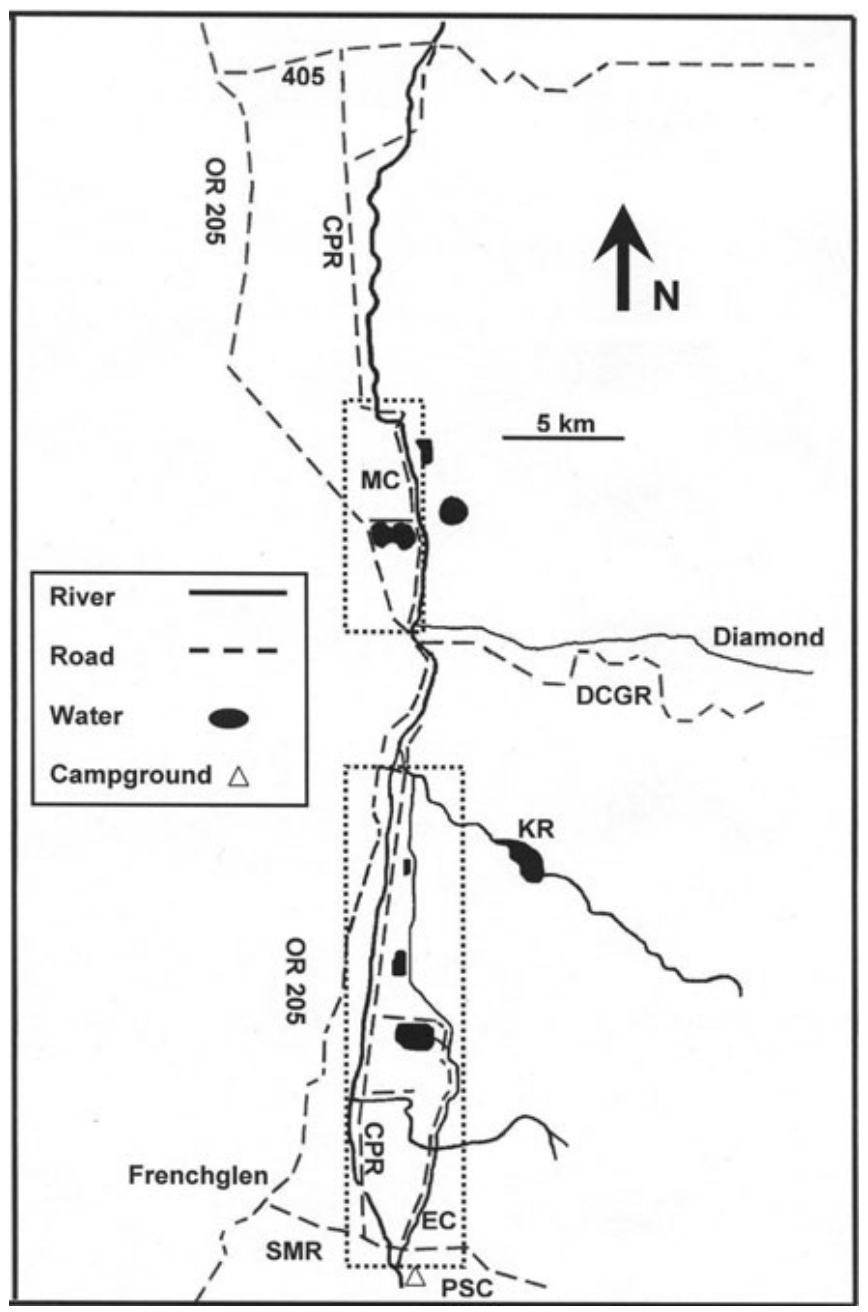

Figure 2.1. Map of Malheur National Wildlife Refuge in Harney County, Oregon, south of country highway 405. The areas enclosed by the dotted lines demarcate the main study area near Frenchglen, Oregon, and the secondary study area located near Buena Vista (BV). The Donner und Blitzen River supplies water to the refuge. State highway OR 205 formed the western boundary of the refuge. The Center Patrol Road (CPR) was the primary travel route on the refuge. Additional gravel roads used for travel included East Canal (EC) and Steen's Mountain Road (SMR). The latter provided access to Page Springs campground (PSC). Diamond Camp Grain Road (DCGR) was a paved road that bisected the refuge. $\mathrm{KR}=$ Krumbo Reservoir. 


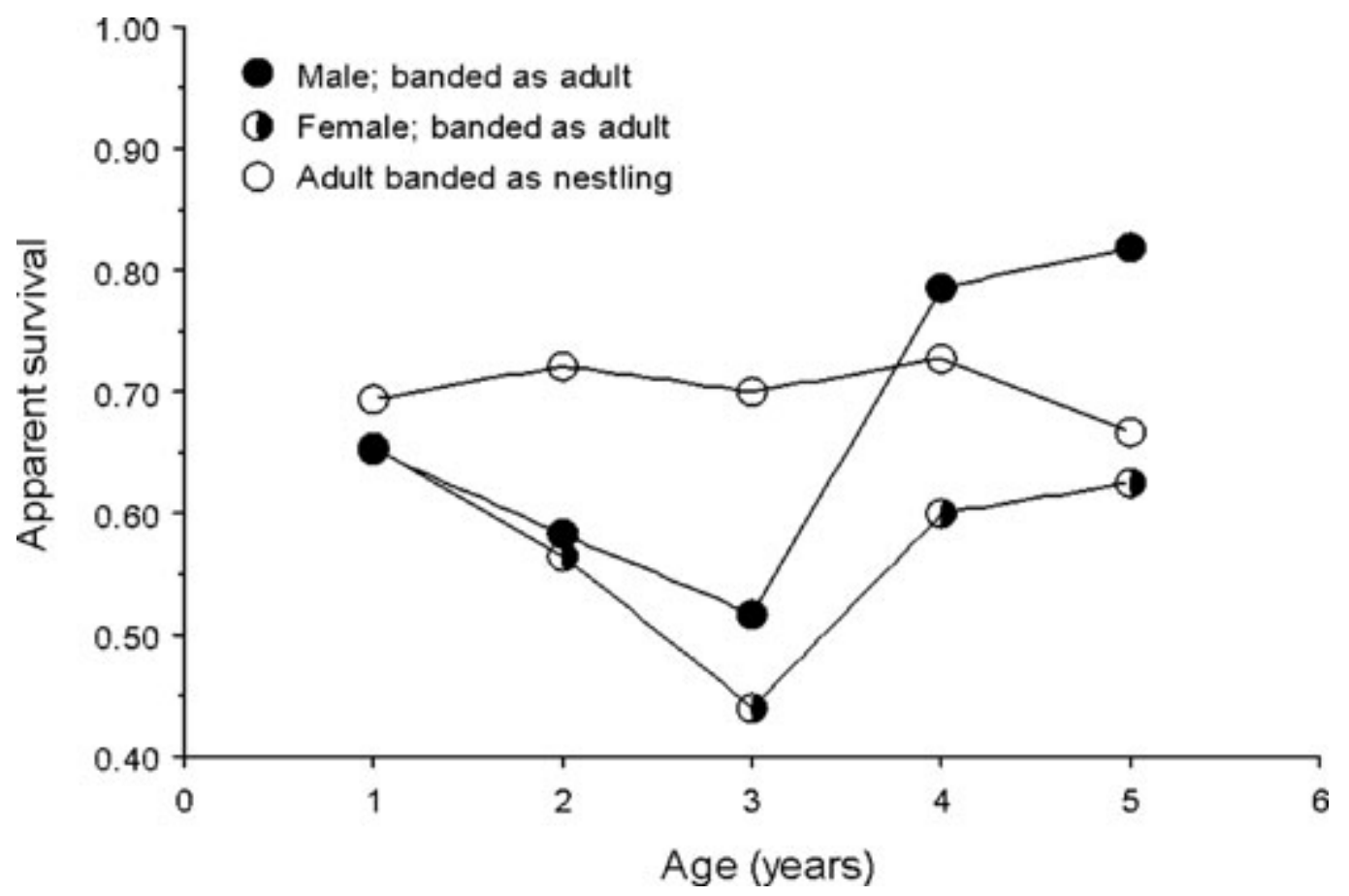

Figure 2.2. Comparison of the probability of annual survival (i.e., return) for Eastern Kingbirds at Malheur National Wildlife Refuge, Oregon, from 2002 to 2008, across the first seven years of life obtained by enumeration methods. Year 0 is the year of banding for birds banded as adults, whereas, for birds banded as nestlings, year 0 is the first possible year that a bird could have bred (i.e., the year that followed its hatching year). For birds banded as adults, the last two categories (4 to 5 and 5 to 6 ) were combined because of small sample size in the last year transition. Similarly, the sexes were combined because of small sample sizes for birds banded as nestlings. 


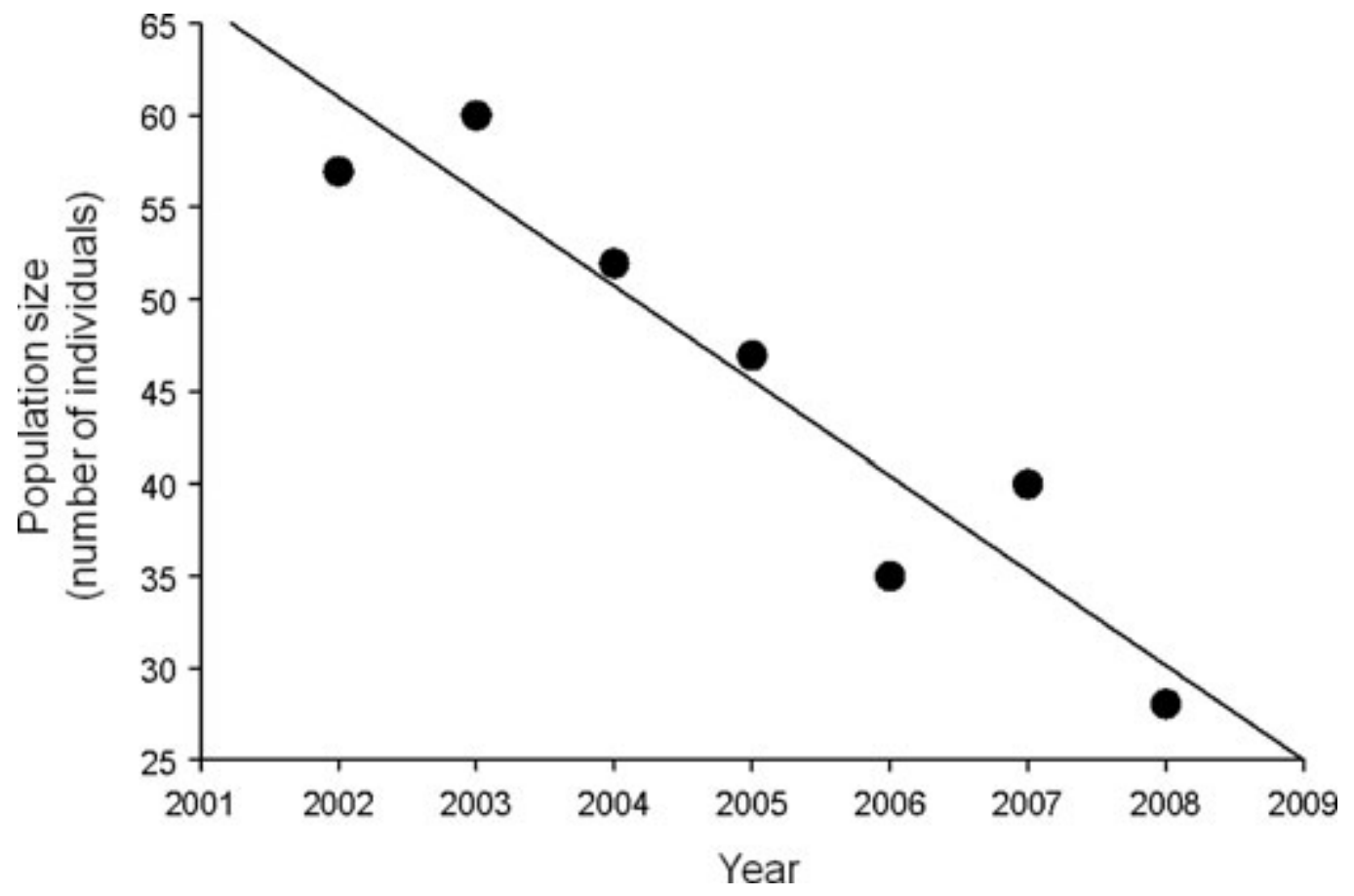

Figure 2.3. Population sizes of Eastern Kingbirds at Malheur National Wildlife Refuge between 2002 and 2008. The significant negative slope $(b)$ is reflective of the significant negative finite rate of increase $(\lambda)$ and the decline in population over the study period. 


\section{CHAPTER 3}

\section{Multistate Mark-Recapture Analysis Reveals No Effect of Blood Sampling on Survival and Recapture of Eastern Kingbirds (Tyrannus tyrannus)}

\section{ABSTRACT}

The experimentally supported and prevailing opinion is that blood sampling has few to no long-term effects on survival of birds when conducted properly, and blood sampling has become a vital addition to the toolbox of many ornithologists. However, many of the studies that concluded that blood sampling had negligible effects on birds used approaches that did not account for temporary emigration and probability of capture. To date, the only study to have done so found that blood sampling had a strong negative effect on survival. We conducted a mark-recapture analysis of 8 years of banding and bleeding data on Eastern Kingbirds (Tyrannus tyrannus) to determine whether survival was negatively influenced by blood sampling. Our analyses adjusted for temporary emigration and probability of recapture and accounted for (1) transitions between the bled and the nonbled state and (2) a change in protocol roughly midway through the study that resulted in a change from single to often multiple (and larger) draws of blood per year from single individuals. We found that survival rates of nonbled (0.61) and bled (0.67) males were statistically indistinguishable and that bled females had a higher probability of survival than nonbled females ( 0.68 and 0.58 , respectively). The change to larger and more frequent blood samples was also not associated with a change in survival. Our data show that when accepted protocols were followed, blood sampling had no detectable 
influence on the survival of adult Eastern Kingbirds. Whether this applies generally awaits analyses using similarly rigorous methods on other species.

\section{INTRODUCTION}

With the relative ease and affordability of modern laboratory techniques, increasing numbers of field biologists regularly collect blood samples from their study organisms to extract DNA for behavioral studies (Dolan et al. 2007, Balenger et al. 2009), to measure metabolites (Lyons et al. 2008, Lobato et al. 2010), hormones (Spinney et al. 2006, Van Hout et al. 2010), or stable isotopes (Studds and Marra 2005, Beaulieu et al. 2010), or to conduct immunological research (Hatch et al. 2010, Knowles et al. 2010). Although the widespread use of these techniques has opened many new and exciting lines of inquiry, with the increased regularity that blood is collected comes an increased need for researchers to ensure that they safely handle birds and minimize threats to survival. Loss of blood resulting from collection of a blood sample can cause an immediate decline in blood volume, which, in turn, can lead to a drop in blood pressure and cardiac output, which results in increased heart rate. Blood volume has the potential to be restored relatively quickly by absorption of extracellular fluids, but hemodilution will occur because lost red blood cells require at least 30 days to be replaced (Rodnan et al. 1957). This may lead to short-term anemia (Ploucha et al. 1981, Fair et al. 2007), which may have longer-term effects on survival because of decreases in hematocrit, hemoglobin, or plasma proteins.

To ameliorate any long-term effects that the loss of blood may have on survival, 
researchers are advised to collect a sample smaller than some previously determined maximum volume. For example, the Ornithological Council's Guidelines to the Use of Wild Birds in Research (Fair et al. 2010) recommends that $\leq 2 \%$ of the total body mass of an animal be collected as blood over the span of 2 weeks and that $\leq 1 \%$ be collected at any one time. The evidence to date (summarized by Sheldon et al. 2008) largely suggests that when these guidelines are followed, the collection of blood has no long-term effect on individual survival.

However, the papers included in Sheldon et al.’s (2008) review are not without their shortcomings that, to some extent, weaken the conclusion that blood sampling has no effect on survival. First, in many of these studies, the intervals over which survival was monitored were relatively short, ranging from a few days to months (Franks 1967, Raveling 1970, Utter et al. 1971, Bigler et al. 1977, Frederick 1986, Stangel 1986, Ardern et al. 1994), which may not have been sufficient to detect a decrease in survivorship of bled individuals. Second, and perhaps more importantly, all the studies that were conducted on free-living individuals, regardless of the length of study, measured and reported recapture rates of bled versus nonbled individuals (previous references, Wingfield and Farner 1976, Colwell et al. 1988, Dufty 1988, Hoysak and Weatherhead 1991, Perkins et al. 2004). Even in a simple survival analysis, failure to take the probability of recapture and of temporary emigration from the study area into account can lead to inaccurate estimates of survival (Martin et al. 1995). A better approach is to utilize methods that account for recapture probabilities and temporary emigration, such as the Cormack-Jolly-Seber (CJS) model (Cormack 1964, Jolly 1965, Seber 1965), and 
generalizations of this model, such as multistate capture-recapture models (Arnason 1972, 1973; Schwarz et al. 1993). The latter would be the more appropriate choice for determining whether drawing blood increases the probability of death, because multistate models, unlike the traditional CJS model, allow for categorical variables that may change over an individual's life (e.g., a state variable such as whether or not a blood sample was drawn).

Recently, Brown and Brown (2009) used multistate mark-recapture models to show that, contrary to the conclusions drawn from previously published works, blood sampling had a dramatic negative effect on the survival of Cliff Swallows (Petrochelidon pyrrhonota). These results drew attention to the long-held assumption that blood sampling does not have long-term detrimental effects on survival. However, the peculiarities of each study species and research site deem it essential that more studies be conducted to determine the generality of Brown and Brown's (2009) results in the Cliff Swallow. Here, we use data from a population of color-banded Eastern Kingbirds (Tyrannus tyrannus; hereafter "kingbirds”) to address the potential effects of blood sampling on survival. We have individually banded and drawn blood from kingbirds over an 8-year period in association with demographic work and studies of extrapair paternity (Dolan et al. 2007, 2009; L. J. Redmond unpubl. data). All birds had a blood sample drawn at their initial encounter, which was followed by recaptures within the same and subsequent years, during which blood may or may not have been drawn. Moreover, for males, the volume of the blood sample and the frequency with which individuals were sampled were increased roughly midway through our study, in conjunction with other 
studies. We used these data within a multistate mark-recapture framework to determine whether blood sampling negatively affected survival of adult kingbirds.

\section{METHODS}

Study site. We conducted the study on a color-banded population of kingbirds at Malheur National Wildlife Refuge in southeastern Oregon $\left(42^{\circ} 49^{\prime} \mathrm{N}, 118^{\circ} 54^{\prime} \mathrm{W}\right)$ from 2002 to 2009. Kingbirds on the refuge breed primarily in the riparian areas created by the Donner und Blitzen River and its associated secondary watercourses. Beginning in midMay, we conducted daily surveys by vehicle of the riparian areas of the refuge along a 45-km stretch of the river beginning at Paige Springs Campground at the southern end of the refuge. The Center Patrol Road closely parallels (3-5 m distance) the river throughout most of the study site, and this provided direct access to foraging and nesting habitats. Any suitable areas away from the river but within our overall study area were also visited to maximize the probability that we encountered previously marked kingbirds. Kingbirds show very high site-fidelity (Murphy 1996b, Redmond et al. 2009). Given that, and our thorough coverage of the portion of the refuge that defined our study site, we are confident that we encountered most marked birds.

Adult males were captured throughout the breeding season using a recording of a kingbird dawn-song that was played back near a mist net during the predawn period, when the male we were trying to capture was singing. Females and, to a lesser extent, males were captured at the nest while feeding young. Once captured, a blood sample was 
taken using a sterile needle via brachial venipuncture, and we then measured body mass, wing chord, and tarsus, bill, and tail lengths. Individuals were also banded with one numbered federal band and a unique combination of three-colored plastic bands. Total handling time was 20 min for each bird. Blood samples were taken initially to provide DNA for studies of parentage, and, therefore, individuals were recaptured only if they were incidentally caught while we attempted to capture another individual, or if the bird had to be recaptured to replace a lost color band. This was the case for females throughout the study, but beginning in 2005 we also began to recapture males both within and between years to draw multiple blood samples to describe seasonal variation in testosterone and to examine the relationship between individual variation in testosterone and extrapair mating success. Therefore, the frequency of blood sampling increased in the latter half of our study (both within and among years for individuals), and the volume taken (for males) increased from $\sim 60 \mu \mathrm{L}$ to as much as $250 \mu \mathrm{L}$. Regardless of the volume taken, the mass of the volume of blood sample (0.06-0.25 g) was below the suggested $1 \%$ maximum of total body mass, given the average body mass of the kingbirds that we sampled (= $39 \mathrm{~g}$, and thus, $0.39 \mathrm{~g}$ ).

Data preparation. We constructed multistate capture histories for color-banded kingbirds in the population. Multistate models were originally designed to represent movement and survival among different populations (e.g., Hestbeck et al. 1991, Breininger et al. 2009) but can be adapted for use with other types of categorical variables that could change over time (e.g., reproductive status or effort; Lescroel et al. 2009, Schaub and von Hirschheydt 2009). The state values in our models indicated 
whether or not blood was collected from an individual in a year. We also included a group variable in the capture histories to describe an individual's sex. To be included in our data set, blood must have been collected from an individual at least once when it was an adult. Because blood was collected from all individuals that were initially captured as adults, by default they were all included in the data set and we used their entire capture history (modified to match state values) as it was known to us. We also included individuals that were banded as nestlings, but only if the individual was captured and also bled at least once as an adult. For this subset of individuals, we slightly modified the capture histories to eliminate variation in survival following initial capture between individuals banded as nestlings and adults (i.e., juvenile and adult survival). This was done by modifying capture histories such that individuals banded as nestlings were not considered "alive” (a value other than zero in the capture history) until they were captured and bled as adults.

Model-selection procedure. We used the "multi-strata recaptures only" option in Program MARK (White and Burnham 1999) and the program M-SURGE, version 1.8.5 (Choquet et al. 2004), to compare models. We performed a goodness-of-fit (GOF) test on a global model that was fully time-, state-, and group-dependent for all parameters using U-CARE, version 2.3.2 (Choquet et al. 2009). All GOF tests were nonsignificant, which indicated that the models that we tested fit the data adequately. Therefore, we used Akaike's information criterion adjusted for small sample size (AIC $\mathrm{C}_{\mathrm{c}}$ ) as the criterion for model selection and concluded that models were well supported by the data when $\Delta \mathrm{AIC}_{\mathrm{C}}$ $<7$. We used Akaike weights $\left(w_{i}\right)$ to derive weighted estimates of parameter values 
(Burnham and Anderson 2002), which are given as the estimate \pm SE and $95 \%$ confidence intervals (CI). We considered overlap in 95\% CIs of one parameter with the estimated mean of another parameter as evidence that the two did not differ.

In order to minimize the number of models in the candidate set and avoid model redundancy, model comparison occurred in stages (e.g., Franklin et al. 2004), in which variation of model structure for each parameter (survival, recapture, and transition probabilities) was confined to a single stage. The order in which the stages were conducted was based on both an increase in biological relevance of the parameters, given our data set, and the questions of most importance for our analyses. In our models, transition probability between states (whether or not blood was drawn) was dependent on our ability to capture an individual and had no real biological meaning. Thus, the bestfitting model for transition probability was carried over to the second stage. Recapture probability was dependent on our ability to resight individuals, and we considered the possibility that collecting blood from an individual had an effect on recapture in the following year. The best-fitting model for recapture probability was carried over to the third, and final, stage. The primary purpose of these analyses was to determine whether collecting blood from an individual had an effect on survival; thus, survival probability was the parameter of most interest.

Model structure and hypotheses. Transition between states for our models indicated whether or not blood was collected from an individual in a given year. Because this parameter has no real biological relevance, we were less interested in testing specific hypotheses than in finding a model whose structure best explained variation in the data 
and minimized the number of estimable parameters for transition probability. We considered a total of eight models for transition probability, the most general of which $\left(\Psi\left[\operatorname{sex}^{*}\right.\right.$ b_D $\left.]\right)$ was sex-dependent and structured to account for changes in our bloodsampling protocol. Blood samples were required for DNA analyses only between 2002 and 2004 (Dolan et al. 2007), but from 2005 through 2009 we collected multiple blood samples from males for hormone assays (L. J. Redmond unpubl. data). Thus, we considered a set of models whose structure reflected the difference in frequency with which males and females were sampled. Several simplified models of varying structure were also compared, the simplest being $\Psi($.$) , in which transition probability was constant$ between states and the sexes.

We compared six models for recapture probability (Table 1). To test for an effect of blood sampling on recapture probability in the following year, we used Jolly-Move models (JMV; Brownie et al. 1993). Because MARK does not include JMV models, we used M-SURGE to complete this step of the analyses. Unlike the conditional ArnasonSchwarz model (CAS; Arnason 1972, Schwarz et al. 1993) in which recapture probabilities are dependent only on the current state, JMV models also consider the previous state. Thus, a JMV model was the most appropriate type of multistate model to test the hypothesis that blood sampling affected recapture probability of kingbirds. The most general model that we considered was a sex-dependent JMV model ( $p[\operatorname{sex} * \mathrm{~b}]-$ JMV). We also considered a second JMV model that was sex-independent but also statedependent ( $p[\mathrm{~b}]-\mathrm{JMV})$. These two models tested the hypothesis that blood sampling had an effect on future recapture probability, which, if supported, would suggest that birds 
dispersed beyond the limits of our study site in the year after they were bled. We compared the JMV models with four others that did not account for variation in recapture probability due to the previous blood-sampling state. Two of these were the CAS versions of the JMV models ( $p[\mathrm{~s} * \mathrm{~b}]-\mathrm{CAS}, p[\mathrm{~b}]-\mathrm{CAS}$ ), and the other two were stateindependent but sex-dependent ( $p[\operatorname{sex}])$ and an intercept-only model ( $p[]$.$) .$

The most general model for survival probability (S[sex*b_D]) that we considered was sex- and state-dependent, the latter being structured to account for the change in blood-sampling protocol in the same way that we adjusted for transition probability. This structure was important because it accounted for the potential increase in the frequency of blood collection from an individual and the increase in the volume of the sample taken. Because the change in protocol was largely restricted to males, we included a male-only model, as for transition probability. We also included a subset of models that were statedependent but that did not account for changes in blood-sampling protocol. Finally, two models were constructed (one sex-dependent, the other not) that tested for an initial effect of blood sampling on survival, but assumed that subsequent sampling events had no effect. All these models assumed differences in survival between bled and nonbled states and could be compared with models that were state-independent. In the set of models that we tested, we included a sex-dependent model and a null model that was sex- and stateindependent. In all, 11 models of survival probability were fit to the data. Results are presented as means $\pm \mathrm{SE}$.

\section{RESULTS}


From 2002 to 2009, 247 adult kingbirds (152 males and 95 females) fit the criteria that we deemed necessary for inclusion in the analyses of the relationship between blood sampling and survival. Of these, 214 were initially captured and bled as adults, and the remaining 33 were banded as nestlings but later captured and bled as adults. Within years, the number of individuals captured and bled ranged from 21 to 62, with a maximum for individuals of 3 and 1 blood draws for males and females, respectively. Across all years, blood was collected from individual males (maximum $=8$ times, mean $=1.50 \pm 0.07$ ) more frequently than from females (maximum $=4$ times, mean $=1.30 \pm$ $0.06 ; t=2.23, \mathrm{df}=245, P=0.026)$.

Transition probability. Transition probabilities between blood-sampling states were best explained by a model that accounted for differences in sampling protocol for males only (Table 2). This model was retained for the following stage, in which recapture probabilities were modeled.

Recapture probability. The JMV models ( $p\left[\mathrm{sex}^{*} \mathrm{~b}\right]-\mathrm{JMV}, p[\mathrm{~b}]-\mathrm{JMV}$ ) that tested for an effect of blood sampling on recapture probability received very little support from the data $\left(\Delta \mathrm{AIC}_{\mathrm{c}} \geq 11.98 ;\right.$ Table 2$)$. The best-fitting models $\left(\Delta \mathrm{AIC}_{\mathrm{c}}<7\right)$, instead, were a model that was structured to account for differences between the sexes $\left(p[\operatorname{sex}] ; \Delta \mathrm{AIC}_{\mathrm{c}}=\right.$ $0.0)$ and a CAS-type model $\left(p[\operatorname{sex} * \mathrm{~b}]-\mathrm{CAS} ; \Delta \mathrm{AIC}_{\mathrm{c}}=0.55\right)$ that included a sex*state interaction. The former was retained for the stage in which survival probability was modeled. Model-averaged estimates of recapture probability also indicated that there was no statistical difference between recapture rates of bled and nonbled individuals of either sex (Table 3). 
Survival probability. According to the $\Delta \mathrm{AIC}_{\mathrm{c}}$ values, all models of survival probability were relatively well supported by the data, which indicates a substantial amount of model-selection uncertainty (Table 2). The best-fitting model (S[b] $p$ [sex] $\left.\Psi\left[\mathrm{b} \_\mathrm{D}-\mathrm{m}\right]\right)$ predicted a difference in survival probability between bled and nonbled states. The other competing model (S[sex*b_I] $\left.p[\operatorname{sex}] \Psi\left[\mathrm{b} \_D-m\right]\right)$ also predicted a difference between states, but only for the interval immediately following the individual's first blood sample, with estimates of survival during subsequent intervals being the same as for nonbled individuals. However, the state-specific estimates of survival probability for both of these models were not consistent with the hypothesis that blood sampling had a negative effect on survival. For model (S[b] $\left.p[\operatorname{sex}] \Psi\left[\mathrm{b} \_\mathrm{D}-\mathrm{m}\right]\right)$, annual survival probability of bled individuals was $0.689 \pm 0.029$ (95\% CI: $0.630-0.742)$, compared with $0.575 \pm 0.034$ (95\% CI: 0.506-0.641) for nonbled individuals. Single-model estimates from $\left(S[\right.$ sex*b_I $] p[\operatorname{sex}] \Psi\left(\left[\mathrm{b} \_\mathrm{D}-\mathrm{m}\right]\right)$ indicated no differences between bled $(0.646 \pm$ 0.040; 95\% CI: 0.564-0.720) and nonbled males (0.659 \pm 0.038; 95\% CI: 0.581-0.728). Female estimates from this model were different: bled females survived at higher rates (0.732 $\pm 0.057 ; 95 \%$ CI: $0.610-0.829)$ than nonbled individuals ( $0.546 \pm 0.047 ; 95 \%$ CI: $0.453-0.635)$.

The model that tested the hypothesis that changes in blood-sampling protocol (i.e., larger and more frequent draws of blood from males from 2005 onward) had negative consequences for survival (S[b_D] $\left.p[\operatorname{sex}] \Psi\left[\mathrm{b} \_\mathrm{D}-\mathrm{m}\right]\right)$ was also supported $\left(\Delta \mathrm{AIC}_{\mathrm{c}}=2.03\right)$. Parameter estimates from this model were again inconsistent with the hypothesis that drawing blood negatively influenced survival. Individuals from which a 
large sample (2005 and on) was collected had survival probabilities (0.694 \pm 0.038 ; 95\% CI: 0.616-0.763) virtually identical to those of individuals from which a small sample (2002-2004) was collected ( $0.681 \pm 0.043 ; 95 \%$ CI: 0.592-0.759). Although models that were variations of this hypothesis did not perform as well, their model-specific estimates all suggested the same general pattern: an increase in sampling frequency and in the volume of blood per sample had no effect on survival probability. Of the models that did not test for a difference between blood-sampling states, the model (S[.] $p[\operatorname{sex}] \Psi\left[\mathrm{b} \_\mathrm{D}-\right.$ $\mathrm{m}])$ received the most support $\left(\Delta \mathrm{AIC}_{\mathrm{c}}=2.04\right)$ and produced an estimate of survival probability of $0.639 \pm 0.210$ (95\% CI: 0.596-0.680). Given the likelihood of modelselection uncertainty, we used all the models in the data set to generate weighted estimates of survival probability (Table 3). Overall, model-averaged estimates exhibited a similar pattern as previously shown: state-specific survival estimates for males did not differ, and although survival estimates for bled females were higher, they were likely not different from those for nonbled females.

\section{DISCUSSION}

Every individual included in our study was bled when first captured. Therefore, the transition that we modeled, which was the basis for our comparisons of bled and nonbled birds, was a bird's treatment in subsequent captures. This design standardized individuals to the same initial state and helped control for unknown past histories for each individual. With this design, we found little to no evidence that blood sampling adversely affected kingbirds. 
Aside from direct effects on survival, some have proposed that blood sampling could potentially lead to an increase in dispersal behavior (Voss et al. 2010), which would manifest itself as a lower probability of recapture of sampled than of nonsampled individuals. Our study and that of Brown and Brown (2009) are the only ones that have calculated recapture probabilities of nonbled and bled birds, and neither study found a difference. Recapture-resighting probability of male kingbirds was uniformly high ( $p \geq$ 0.96) regardless of blood-sampling state, which is consistent with previous studies that have shown that male kingbirds are extremely site-faithful (Murphy 1996b, Redmond et al. 2009). Females disperse more than males (Murphy 1996b), which is the most likely explanation for why the overall recapture probability (independent of state) was lower in females. Although the 95\% CI of the recapture probability of bled females did not overlap the male estimates, the recapture probability of nonbled females did. Among females, the model-averaged estimate of recapture rate for bled and nonbled individuals fell within each other’s 95\% CI and, thus, they did not differ. Finally, the JMV models provided no support for the hypothesis that resighting probability differed between bled and nonbled birds.

Collecting blood also had no negative effect on the survival of kingbirds. The nearly identical survival rates (based on overlap of estimates and 95\% CIs) of bled (0.67) and nonbled males (0.61) generally place them toward the upper end of survival rates for Nearctic-Neotropical migrants (Brown and Brown 1996, Gardali et al. 2003), which is consistent with the conclusion that there is little reason to suspect that our handling of these birds negatively affected survival. We do not deny that blood sampling has an 
immediate effect on the physiology of the individual sampled (reviewed by Sheldon et al. 2008, Voss et al. 2010) and that, when sampling is done improperly, these effects may manifest themselves as long-term negative consequences for survival. However, when the recommended protocols are followed, as suggested by Fair et al. (2010), our results suggest any negative effects of blood sampling can be avoided.

Brown and Brown (2009) proposed several explanations for the negative effect of blood sampling on Cliff Swallows. First, hemodilution may induce a number of changes in physiology, which may ultimately affect an individual's capacity for work. This may be especially important for aerial foragers, such as Cliff Swallows, because of their very high daily energy expenditure (Bryant 1997). Second, the trauma associated with the act of collecting blood can cause hematomas in the wing (when blood is collected via brachial venipuncture) or, potentially, muscle strain that may physically limit flight ability. Again, this may be of special concern for aerially foraging species. Blood lost to the formation of hematomas also represents an additional, but unknown, volume that may add to the volume of blood lost to sample collection, which, in some instances, may push the total blood loss beyond acceptable limits. Similarly, simultaneous blood loss through sample collection and by some other route (e.g., ectoparasites) could have a synergistic effect and tip the scales, so to speak, so that an individual incurs a negative effect. Many of the Cliff Swallow colonies in the Browns' study were heavily parasitized. The Browns applied an insecticide to reduce the load of hematophagous ectoparasites, and nonfumigated colonies were often those in which the effect of blood sampling was largest. Moreover, Voss et al. (2010) proposed that limited water availability at the 
Browns' arid Nebraska study site may have exacerbated the effects of fluid loss associated with collection of blood samples.

Kingbirds and Cliff Swallows are both long-distance migrants that overwinter south of the equator, in South America (Brown and Brown 1995a, Murphy 1996a). Aerial foraging, albeit of different styles, also characterizes both species. Comparisons of the two might therefore help evaluate the merits of the hypotheses that have been offered as potential explanations for why blood sampling seemingly negatively affected Cliff Swallow survival. Kingbirds are aerial hawking specialists (Fitzpatrick 1980) that capture single prey by a direct flight that is initiated from a perch. Cliff Swallows are aerial "filterers" that capture numerous small prey during a protracted flight. Kingbirds almost certainly spend less time in flight than Cliff Swallows, but nearly all of a kingbird's diet is obtained on the wing as they capture prey in high-speed flights (Murphy 1987). Thus, if short-term effects of blood sampling as a result of hemodilution or a hindrance to flight performance due to the formation of hematomas or muscle strain caused the poor survival of bled Cliff Swallows, it seems that bled kingbirds should have experienced the same and exhibited lower survival. That we did not find this casts doubt on the possibility that aerial foragers are of special concern and, in general, does not support the idea that shortterm declines in physiological performance drove the survival difference between bled and nonbled Cliff Swallows. We also believe that we can eliminate Voss et al.'s (2010) proposal that the arid Nebraska study site may have contributed to the reduced survival of bled birds because our study site, located in the Great Basin Desert, is considerably drier than the Browns’ Nebraska site. 
Two very noteworthy differences between Cliff Swallows and kingbirds is body size and the level of ectoparasitism that they experience. Kingbirds are $\sim 75 \%$ heavier than Cliff Swallows. Conceivably, larger birds are better able to tolerate the loss of blood and stress of being handled. However, the absence of any body-size effect in data summarized by Sheldon et al. (2008) makes this seem unlikely. On the other hand, an influence of ectoparasites seems plausible. The heavy parasite loads that Cliff Swallows experience (Brown et al. 1995b) are a far cry from the low-level infestations of hematophagous ectoparasites that adult kingbirds occasionally exhibit. Broods of kingbird young have only rarely been lost to severe infestations of ectoparasites, and on the whole, ectoparasitism does not appear to be a severe or common problem for kingbirds (Murphy 1996a). The consequences of ectoparasitism for Cliff Swallow biology are very high, as evidenced by the Browns’ long-term studies of the species and its parasites (Brown et al. 1995, Brown and Brown 1996. Thus, we suggest this as the most likely explanation for the different responses of the two species to the drawing of blood. Regardless, the discrepancy in results and the importance of this issue further highlight the need for a more focused examination of the effect of blood sampling on survival across a broad range of species, and we encourage the use of multistate markrecapture analyses to address this important question.

\section{ACKNOWLEDGEMENTS}

We thank the Malheur National Wildlife Refuge staff, but especially Refuge Biologist R. Roy, for supporting our work at the refuge. C. and A. Elshoff provided living space, 
advice, and friendship during our time at Malheur. Financial support for the work was provided by Portland State University, the American Museum of Natural History’s Frank M. Chapman Fund, the American Ornithologists’ Union Research Awards program, and a National Science Foundation grant (IOB-0539370) to M.T.M. 


\section{CHAPTER 3 TABLES}

Table 3.1. Notation and description of models tested for recapture $(p)$, and survival probabilities $(S)$ of Eastern Kingbirds at Malheur National Wildlife Refuge, Oregon, 2002-2009.

\begin{tabular}{|c|c|c|}
\hline Parameter & Model & Description \\
\hline \multirow[t]{6}{*}{$P$} & sex*b-JMV & $\begin{array}{l}\text { Tests for differences in } p \text { between sexes and blood-sampling states } \\
\text { (b). Both previous and current states were considered. }\end{array}$ \\
\hline & sex*b-CAS & $\begin{array}{l}\text { Tests for differences in } p \text { between sexes and blood-sampling states. } \\
\text { Unlike in the previous model, only the current state was considered. }\end{array}$ \\
\hline & b-JMV & $\begin{array}{l}\text { Tests for differences in } p \text { between states. Both previous and current } \\
\text { states were considered. }\end{array}$ \\
\hline & b-CAS & $\begin{array}{l}\text { Tests for differences in } p \text { between states. Unlike in the previous } \\
\text { model, only the current state was considered. }\end{array}$ \\
\hline & sex & Tests for differences in $p$ between sexes. \\
\hline & . & Null model. No difference in $p$ between sexes or states. \\
\hline \multirow[t]{2}{*}{$S$} & sex*b_D & $\begin{array}{l}\text { Tests for difference in } S \text { between sexes and states. Further tests for a } \\
\text { difference in } S \text { between sampling protocols used. }\end{array}$ \\
\hline & sex*b_D-m & $\begin{array}{l}\text { As above, but difference in sampling protocol is only tested among } \\
\text { males, not females. }\end{array}$ \\
\hline
\end{tabular}



sex*b_I Tests for a difference between sexes and an initial decrease in survival in interval following sampling, but intervals thereafter are the same as for nonbled state.
sex*b Tests for differences in $S$ between sexes and states.
b_D Tests for difference between states and the sample protocol used.
b_D-m As above, but protocol difference for sampled males only.
b_I Tests for an initial decrease in survival in interval following sampling, but intervals thereafter are the same as for nonbled state.
b_m Tests for difference between states, but for males only.
b Tests for differences in $S$ between states.
sex Tests for differences in $S$ between sexes.

. $\quad$ Null model. No difference in $S$ between sex or state. 
TABLE 3.2. Results of model selection for transition $(\Psi)$, recapture ( $p$ ), and survival probabilities $(S)$ with respect to sex and blood-sampling state (b) for Eastern Kingbirds breeding at Malheur National Wildlife Refuge, Oregon, 2002-2009. For $p$, “CAS” in model notation indicates that this parameter was modeled using the conditional Arnason-Schwarz method and "JMV" denotes the Jolly-Move model. Bloodsampling state was structured further to account for differences in sampling protocol for both sexes (b_D) and for males only (b_D-m; see text for description) and to reflect a one-time effect of blood sampling on survival (b_I).

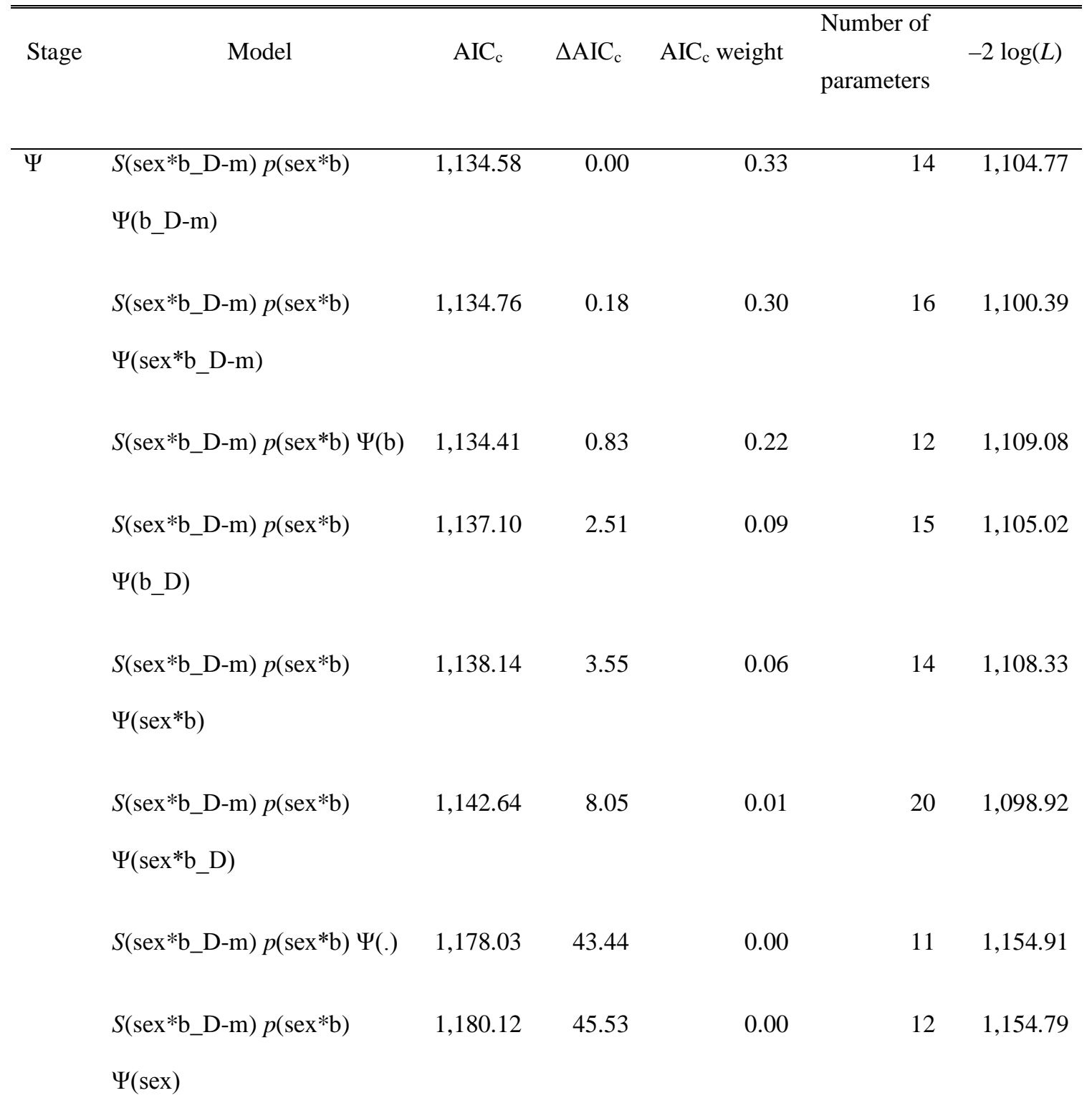




\begin{tabular}{|c|c|c|c|c|c|c|}
\hline$p$ & $S($ sex*b_D-m) $p($ sex $)$ & $1,134.03$ & 0.00 & 0.52 & 13 & $1,106.47$ \\
\hline & $\Psi($ b_D-m) & & & & & \\
\hline & $S\left(\operatorname{sex} * b \_D-m\right) p(\operatorname{sex} * b)-C A S$ & $1,134.58$ & 0.55 & 0.46 & 14 & $1,104.77$ \\
\hline & $\Psi($ b_D-m) & & & & & \\
\hline & $S($ sex*b_D-m) $p(\mathrm{~b})$-CAS & $1,141.65$ & 7.62 & 0.01 & 12 & $1,116.32$ \\
\hline & $\Psi($ b_D-m $)$ & & & & & \\
\hline & $S\left(\mathrm{sex} * \mathrm{~b} \_\mathrm{D}-\mathrm{m}\right) p(.) \Psi\left(\mathrm{b} \_\mathrm{D}-\right.$ & $1,142.23$ & 8.20 & 0.01 & 12 & $1,116.90$ \\
\hline & m) & & & & & \\
\hline & $S\left(\operatorname{sex} * \mathrm{~b} \_\mathrm{D}-\mathrm{m}\right) p(\mathrm{sex} * \mathrm{~b})-$ & $1,146.01$ & 11.98 & 0.00 & 20 & $1,102.29$ \\
\hline & JMV $\Psi\left(b \_D-m\right)$ & & & & & \\
\hline & $S($ sex*b_D-m) $p(\mathrm{~b})-\mathrm{JMV}$ & $1,146.82$ & 12.79 & 0.00 & 16 & $1,112.45$ \\
\hline & $\Psi($ b_D-m) & & & & & \\
\hline$S$ & $S(\mathrm{~b}) p(\mathrm{sex}) \Psi\left(\mathrm{b} \_\mathrm{D}-\mathrm{m}\right)$ & $1,128.03$ & 0.00 & 0.30 & 9 & $1,109.27$ \\
\hline & $S($ sex*b_I $) p(\operatorname{sex}) \Psi\left(\mathrm{b} \_\mathrm{D}-\mathrm{m}\right)$ & $1,129.62$ & 1.59 & 0.14 & 10 & $1,108.69$ \\
\hline & $S\left(\mathrm{~b} \_\mathrm{D}\right) p(\mathrm{sex}) \Psi\left(\mathrm{b} \_\mathrm{D}-\mathrm{m}\right)$ & $1,130.08$ & 2.03 & 0.11 & 10 & $1,109.15$ \\
\hline & $S() p.(\operatorname{sex}) \Psi($ b_D-m $)$ & $1,130.07$ & 2.04 & 0.11 & 7 & $1,115.60$ \\
\hline & $S($ b_I $) p($ sex $) \Psi($ b_D-m $)$ & $1,130.31$ & 2.28 & 0.10 & 8 & $1,113.70$ \\
\hline & $S\left(\mathrm{sex}^{*} \mathrm{~b}\right) p(\mathrm{sex}) \Psi\left(\mathrm{b} \_\mathrm{D}-\mathrm{m}\right)$ & $1,130.38$ & 2.35 & 0.09 & 11 & $1,107.26$ \\
\hline & $S(\operatorname{sex}) p(\operatorname{sex}) \Psi($ b_D-m $)$ & $1,131.56$ & 3.54 & 0.05 & 8 & $1,114.95$ \\
\hline & $S\left(\mathrm{~b} \_\mathrm{m}\right) p(\mathrm{sex}) \Psi(\mathrm{b}$ D-m $)$ & $1,132.32$ & 4.30 & 0.04 & 9 & $1,113.56$ \\
\hline
\end{tabular}


$S($ sex*b_D-m) p(sex)

$\Psi($ b_D-m)

$S\left(\operatorname{sex} * b \_\mathrm{D}\right) p(\operatorname{sex}) \Psi\left(\mathrm{b} \_\mathrm{D}-\right.$

$1,134.03$

6.00

0.02

m)

$S\left(\mathrm{~b} \_\mathrm{D}-\mathrm{m}\right) p(\mathrm{sex}) \Psi\left(\mathrm{b} \_\mathrm{D}-\mathrm{m}\right)$

$1,132.46$

4.44

0.03

12

$1,107.13$

$1,134.39$

6.37

0.01

$10 \quad 1,113.46$ 
Table 3.3. Model-averaged parameter estimates ( \pm SE) for recapture $(p)$ and survival $(S)$ probabilities of Eastern Kingbirds at Malheur National Wildlife Refuge, Oregon, 2002-2009. Parameter estimates were calculated using all models in the candidate set from their respective stages in the model-selection process. The volume of blood sample that was collected changed between 2004 and 2005, which is reflected under males (the amount collected for females was inconsistent, but mostly remained small).

\begin{tabular}{|c|c|c|c|c|}
\hline Parameter & Sex & State & Estimate & 95\% CI \\
\hline \multirow[t]{4}{*}{$P$} & Male & Bled & $0.981 \pm 0.009$ & $0.814-0.999$ \\
\hline & & Nonbled & $0.956 \pm 0.022$ & $0.843-0.989$ \\
\hline & Female & Bled & $0.743 \pm 0.061$ & $0.312-0.946$ \\
\hline & & Nonbled & $0.916 \pm 0.025$ & $0.598-0.988$ \\
\hline \multirow[t]{6}{*}{$S$} & Male & Bled - all & & \\
\hline & & individuals & $0.669 \pm 0.034$ & $0.584-0.744$ \\
\hline & & Small volume & $0.669 \pm 0.035$ & $0.584-0.744$ \\
\hline & & Large volume & $0.669 \pm 0.033$ & $0.584-0.746$ \\
\hline & & Nonbled & $0.608 \pm 0.034$ & $0.513-0.695$ \\
\hline & Female & Bled & $0.685 \pm 0.037$ & $0.571-0.781$ \\
\hline
\end{tabular}




\section{CHAPTER 4}

\section{Testosterone secretion in a socially monogamous but sexually promiscuous migratory passerine}

\section{ABSTRACT}

The steroid hormone testosterone (T) influences a multitude of traits critical to reproduction in vertebrates. In birds, high male T supports territory establishment and mate attraction, but is thought to interfere with parental care. Interspecific comparisons indicate that migratory species with short, synchronous breeding seasons have the highest peak $\mathrm{T}$, and that the seasonal profile of $\mathrm{T}$ exhibits a rapid decline with the onset of incubation by females. We describe the T profile of the migratory, socially monogamous, and biparental Eastern Kingbird (Tyrannus tyrannus) from the high desert of eastern Oregon, USA, where breeding occurs within a short 2-3 month period. Eastern Kingbirds are socially monogamous but exhibit high rates of extra-pair paternity as $\sim 60 \%$ of broods contain extra-pair young. We therefore evaluate whether Eastern Kingbirds exhibit the “typical” T profile expected for a synchronously breeding migratory species, or whether $\mathrm{T}$ is maintained at a more constant level as would be predicted for a species with opportunities for mating that extend over a majority of the breeding season. Our samples were divided into six periods of the reproductive cycle from territory establishment to the feeding of fledglings. T did not change across stages of the nest cycle. Instead, $\mathrm{T}$ declined with sampling date and nest density, and increased with the number of fertile females in the population. Male kingbirds advertise their presence through song for most 
of the breeding season, and we suggest that $\mathrm{T}$ is maintained throughout most of the breeding season because male fitness is equally dependent on within- and extra-pair reproductive success.

\section{INTRODUCTION}

The secretion of steroid hormones is an important proximate physiological mechanism governing the expression of many vertebrate reproductive characteristics (Adkins-Regan, 2007; Hau, 2007). In male birds, testosterone (T) is an especially important hormone because of its influence on male-male aggression and territoriality (Chandler et al., 1994; Canoine and Gwinner, 2002; Silverin et al., 2004), dominance status within groups (Peters et al., 2001), mate attraction displays such as song (Van Duyse et al., 2000; Foerster et al., 2002), mate guarding (Moore, 1984; Saino and Møller, 1995a), and possibly extra-pair mating behavior (Raouf et al., 1997; Garamszegi et al., 2005; Eikenaar et al. 2011a). T has also been shown to affect the development of sexual ornaments (Peters et al. 2006; Redpath et al., 2006; but see Owens and Short, 1995; Schlinger et al., 2008).

The stimulatory effect of $\mathrm{T}$ on mating behaviors can also result in the inhibition of parental behaviors (e.g., Raouf et al., 1997; Schoech et al., 1998; Peters et al., 2002) because high $\mathrm{T}$ males direct their activity to obtaining extra copulations, leaving less time for parental care (Oring et al., 1989; Cawthorn et al., 1998; De Ridder et al., 2000; Van Roo, 2004). Therefore, in species with male parental care, including most monogamous species, $\mathrm{T}$ is expected to decline rapidly prior to the commencement of paternal care 
(Hunt et al., 1995; Logan and Wingfield, 1995; Van Roo et al., 2003; Pinxten et al., 2007). Overall, a species’ mating system is an important predictor of its seasonal $\mathrm{T}$ profile (reviewed by Hirschenhauser et al., 2003). For example, in polygynous species, T secretion exhibits a much slower decline throughout the nest cycle because males participate little in parental care and, instead seek additional mating opportunities (Beletsky et al., 1989). The opportunity to obtain extra-pair copulations in monogamous species (Griffith et al., 2002) should also be considered as an important source of reproductive success and as a possible contributor to variation in testosterone among males. However, very little is known about how T secretion is modulated to balance extra-pair mating activity with parental behavior (but see Peters et al., 2001; Horton et al., 2010; Eikenaar et al., 2011b), and more attention needs to be given to monogamous species in which extra-pair fertilizations are important contributors to male reproductive success.

Peak $\mathrm{T}$ and $\mathrm{T}$ profiles (i.e., change with the reproductive cycle) also appear to vary with geographic distribution and migratory behavior. For instance, the breeding biology of many tropical birds is characterized by relatively long breeding seasons, yearround territoriality, and low breeding synchrony (Hau et al., 2008; Robinson et al., 2010; Stouffer et al., 2013). By contrast, temperate species are faced with relatively short breeding seasons, an intense period of territory establishment, and high breeding synchrony. These differences have been offered as an explanation for the generally lower peak T of tropical species compared to temperate species (Goymann et al., 2004). 
Similar reasoning presumably explains why migratory birds typically have higher peak $\mathrm{T}$ than resident species (Garamszegi et al., 2008).

A number of sources of intra-population variation in $\mathrm{T}$ secretion have been identified (reviewed by Kempenaers et al., 2008). Testosterone declines with time of day in many diurnal species (Bachman et al., 1987; Foerster et al., 2002; Hau et al., 2002) and with date in the breeding season, irrespective of day in the nest cycle (Hunt et al., 1995; Johnsen, 1998; Kempenaers et al., 2008). Male-male or male-female interactions can also influence the amount of $\mathrm{T}$ secreted by a male. As predicted by the 'challenge hypothesis’ (Wingfield et al., 1990), aggressive interactions between males should result in an increase in circulating T. This prediction has been confirmed in some species (Moore, 1984; Wingfield, 1984; Wikelski et al., 1999; McGlothlin et al., 2007), but not in others (Van Duyse et al., 2004; Landys et al., 2007; Landys et al., 2010). Aggressive male-male interactions are expected to increase as conspecific density increases, contributing to the positive association between $\mathrm{T}$ and conspecific density in some species (Wingfield and Hahn, 1994; Sasvári et al., 2009; Horton et al., 2010). Because of its role in mate attraction, $\mathrm{T}$ secretion also increases as a male's partner becomes fertile (Johnsen, 1998; Schwabl et al., 2005) and as the pool of fertile females within a population grows (Peters et al., 2001).

We studied individual and seasonal variation in T in Eastern Kingbirds (Tyrannus tyrannus) breeding in eastern Oregon, USA. Eastern Kingbirds (hereafter kingbirds) are territorial, Nearctic-Neotropical migratory passerines that breed over much of North 
America as socially monogamous pairs. Although biparental, females build nests and incubate eggs without male assistance. However, males do feed nestlings, though in at least some populations, females contribute more to nestling provisioning than males (Woodard and Murphy, 1999). While males do not feed the female during incubation, they take the lead in nest defense (Woodard and Murphy, 1999; Redmond et al., 2009a) and are therefore a critical component of nest success (e.g., Hayes and Robertson 1989).

Extra-pair copulations are common in kingbirds (Rowe et al., 2001) and withinand extra-pair mating success contribute equally to male reproductive success (Dolan et al., 2007). Variation in extra-pair mating success is sufficiently strong to create a significant opportunity for sexual selection (Dolan et al., 2007). Thus, this population of kingbirds provides an opportunity to examine variation in $\mathrm{T}$ in a migratory, socially monogamous species breeding in a highly seasonal environment where paternal care and extra-pair mating activity are likely to create conflicts between mating and paternal effort. Given the combination of migratory behavior, short breeding season, and the important role that males play in successfully raising offspring, we might predict a high peak $\mathrm{T}$ early in the season followed by rapid decline during incubation (Wingfield et al., 1990). However, because extra-pair fertilizations are an important component of male kingbird reproductive success (Dolan et al., 2007), we predicted that (1) T would not exhibit a sharp drop during incubation as seen in most monogamous species and would instead change little across stages of the nest cycle. Assuming males are sensitive to their individual social environments, we anticipated that (2) males would respond to their competitive environment and opportunities for additional fertilizations through extra-pair 
relations. Consequently, we predicted that (3) T would vary positively with nesting density and with the availability of fertile females at both local and population level scales.

\section{METHODS}

Study area. We conducted this study from 2005 to 2009 at Malheur National Wildlife Refuge (MNWR), located near Frenchglen, Harney County, Oregon $\left(42.817^{\circ} \mathrm{N}\right.$, $\left.118.900^{\circ} \mathrm{W}\right)$. The study site has been described in detail elsewhere (Redmond et al., 2009b; Redmond and Murphy, 2012). Briefly, the refuge consists of a large wetland complex surrounded by dry shrub-steppe habitat. Kingbirds nest almost exclusively in willows along the watercourses that run through the refuge (Redmond et al., 2009b). Between 35 and 50 pairs of kingbirds nested within the study site each year and birds of both sexes have been color-banded at Malheur since 2002 as part of demographic and parentage studies of this population.

Kingbirds arrive at Malheur over a six-week period beginning in mid-May, but the majority arrive between the last week of May and mid-June (Cooper et al., 2009a). Nesting typically begins by mid-June and nearly all reproductive activity is finished by early to mid-August. Beginning in mid-May, we exhaustively surveyed the study site daily to determine the identity of kingbird pairs by resighting color-banded birds. Once located, nests were checked every two to three days to track the progress of females through the laying cycle so that we could determine when they were fertile. Similar to previous work on other species, we assumed that females were fertile from five days 
before the first egg was laid to the day the penultimate egg was laid (Birkhead et al. 1989; Birkhead and Moller 1992; Gil et al. 1999). In addition to documenting date of clutch initiation, we determined clutch size, hatching success (number of eggs to hatch), and nest success (number of young to fledge). Kingbirds raise only a single brood per year, but failed nests (a range of 55-80\% fail annually) are usually replaced up through the first to second week of July, and therefore we located all replacement nests for pairs that failed. Nest locations were recorded using a Garmin GPS 72 ( \pm 3-4 m) and nest distances were measured with ArcMap v. 9 (ESRI, Redlands, CA, USA).

Capture and blood sampling. Kingbirds were captured using mist nets in one of two ways. First, mist nets were positioned to surround nests to capture both parents as they returned to feed nestlings during daylight hours, a passive capture technique. Second, we used mist nets in conjunction with a playback recording of the ritualized dawn song male kingbirds sing prior to sunrise (0230 to 0600 PST, Sexton et al., 2007) to capture males by simulating a conspecific territorial intrusion. Time to capture was recorded as the length of time between the start of the playback and the male's capture. Once captured, kingbirds were removed immediately from the net and a blood sample ( $250 \mathrm{uL}$ ) obtained by brachial venipuncture (usually $<5$ minutes after capture). Time to capture was unknown for passive-capture adults because we had to remove ourselves from the vicinity of the nest so that parents would continue to feed young. Individuals were then banded with a unique combination of one USGS aluminum band and three colored plastic leg bands if not already banded. We measured body mass to the nearest $0.25 \mathrm{~g}$ with a spring scale (Pesola), tarsus and bill length to the nearest $0.05 \mathrm{~mm}$ (dial 
calipers), and wing chord and tail length to the nearest $0.5 \mathrm{~mm}$ (stopped wing ruler). We also measured the height and width of the cloacal protuberance with dial calipers and used these values to calculate cloacal protuberance volume $([0.5 *$ width $] * \pi *$ height; Sax and Hoi, 1998).

Assays. Blood samples were kept on ice for up to 5 hours before they were centrifuged for 10 minutes. After centrifugation, we measured hematocrit (packed cell height divided by total height of cells and plasma) and then removed the plasma from the tube using a Hamilton syringe. Plasma samples were placed in microcentrifuge tubes and frozen at $-20^{\circ} \mathrm{C}$ until assays were performed. We used a commercially available raioimmunoassay kit (ImmuChem ${ }^{\mathrm{TM}}$ Double Antibody I ${ }^{125}$ RIA kit [MP Biomedicals \#07-189102]) to quantify testosterone concentrations (T) in the plasma samples collected from male kingbirds. Assays were conducted following the directions supplied by the manufacturer and counts per minute (CPM) of ${ }^{125}$ I labeled testosterone of each sample were determined using a Wizard 1470 gamma counter (PerkinElmer, Massachusetts, USA). Plasma testosterone concentrations (T) were calculated from the standard curve generated by standards provided in the kit using nonlinear regression and the 'log(inhibitor) vs. response’ option of GraphPad Prism 5.00 for Windows (GraphPad Software, San Diego, CA, USA). We conducted three groups of assays: One for samples collected between 2005 and 2007 ( $n=73$ ), another for samples collected during 2008 (n = 53), and a final group of assays for samples collected in $2009(\mathrm{n}=33)$. Intra-assay and inter-assay variation were $12.8 \%$ and $7.9 \%$, respectively. Mean $\mathrm{T}$ from the assays conducted on samples collected between 2005 and 2007 (mean $=0.18 \pm 0.051 \mathrm{ng} / \mathrm{mL}$ ) 
were significantly lower than samples assays from both 2008 and $2009(0.37 \pm 0.080$ and $0.35 \pm 0.104$, respectively). We found no evidence that this difference was created by any factor (date of collection, day in nest cycle, or time of day) other than a quantitative difference among the three assays that would potentially bias the results. One option to resolve this issue was to always include a variable in analyses that distinguished among cases of the assay groups. However, after preliminary analyses, we felt that this complicated results because of the addition of an extra variable for which there was no biological basis. A second option was to increase T in every sample from 2005-07 in a date-specific manner to incorporate the seasonal decline in $\mathrm{T}$ that was apparent in every year (see below). We attempted this but it amplified the seasonal effect beyond reasonable levels. We therefore opted for a third solution, which was to use the mean differences (0.18) between samples from 2005-07 and 2008 and 2009 as a correction factor that was added to every sample collected prior to 9 July in the 2005-2007 data set. We chose that cutoff because only two samples from the 2005-2007 assays had measureable levels of $\mathrm{T}$ beyond 9 July ( $\geq$ day 70 in Fig. 1A).

Statistical analyses. To assess the efficacy of our measures of $\mathrm{T}$, we regressed $\log _{10}$ transformed cloacal protuberance volume against $\mathrm{T}$ to test the prediction that physiologically meaningful values of $\mathrm{T}$ should be apparent as a positive relationship between the two variables. To test for an effect of playback on $\mathrm{T}$ we first compared $\mathrm{T}$ between males captured passively and those captured using playback with an analysis of variance (ANOVA), and analysis of covariance (ANCOVA) with date included as a covariate. Because variable amounts of time were required to capture males using 
playback (range $=20 \mathrm{sec}$ to $159 \mathrm{~min}$ ) we also tested for an effect of length of playback on $\mathrm{T}$ by regressing $\mathrm{T}$ against log-transformed values of time to capture with the expectation that a positive relationship would emerge if playback influenced T secretion.

We described the breeding season profile of $\mathrm{T}$ by comparing $\mathrm{T}$ among six stages of the reproductive cycle using ANOVA. The six stages were: (1) territory establishment (males on a territory but without a mate, or males caught on the territory of another male), (2) pre-laying (male was paired, a nest had been started, but female had not yet begun to lay), (3) egg laying (clutch begun but not yet completed), (4) incubation (female incubating eggs), (5) nestling care (parents feeding dependent young in nest), and (6) post-fledging care (young out of nest and still under parental care). Some individuals of both sexes never establish territories or pairbonds and appear to remain in a "floater" population (Cooper et al. , 2009b). We assumed males caught on the territory of another male during a dawn song period were unpaired "floaters" (Cooper et al., 2009b) because prior experience had shown that territory holding males are virtually always on their territory during the dawn song period (Sexton et al., 2007).

We used multiple regression analysis to test simultaneously for the contribution of different predictor variables to variation in $\mathrm{T}$ in kingbirds. Our expectation was that $\mathrm{T}$ would vary temporally, declining over the course of the morning and as the breeding season progressed. Time of day was measured as minutes from $0000 \mathrm{hr}$ PST, while date of capture was measured continuously from May 1 (= day 1 ). We also anticipated that T would vary with each male's social environment, and predicted an increase in T with 
increasing nesting density and availability of fertile females. Conspecific nesting density was measured as the inverse of the distance from a captured male's nest to the nearest kingbird neighbor's nest (nearest neighbor distance) and mean of the three nearest kingbird nests (neighbor density). The rationale for our use of the three nearest neighbors was partly to be consistent with our previous work (Sexton et al. 2007), and partly a consequence of the geometry of our study site. Nearly all pairs were arrayed linearly along the river running through MNWR, and the use of the three nearest neighbors would likely include the neighbors up- and downstream from the focal bird, plus one other. Given the linear arrangement of pairs, it seemed to us that including more than these three males would expand the zone of regular interactions of males to an unrealistic level because with three the mean distance of them to the focal bird was already $1 \mathrm{~km}$ (see below). We used two measures of fertility to determine if $\mathrm{T}$ was influenced by females outside of the pair bond. Local fertility was defined as the number of females from the three nearest neighbors that were fertile on the day of the male's capture. However, because distance to a female kingbird's extra-pair mate averaged $1.8 \mathrm{~km}$ and was as great as $15 \mathrm{~km}$ (Dolan et al., 2007), we included the total number of fertile females available in the study population as population fertility.

We used an information theoretic approach to calculate AIC values corrected for small sample size $\left(\mathrm{AIC}_{\mathrm{c}}\right.$ ) to evaluate model fit. All models within $4 \mathrm{AIC}_{\mathrm{c}}$ units of the top model were considered competitive unless they contained uninformative variables (Arnold, 2010). We then calculated $\Delta \mathrm{AIC}_{\mathrm{c}}$, model probabilities, and model weights. Model-averaged parameter estimates of regression coefficients and standard errors were 
calculated (Burnham and Anderson, 2002) to determine if variables were important predictors of T. Variables whose parameter estimate’s 85\% confidence interval (Arnold, 2010) did not include zero were deemed to have contributed to variation in T.

Date and time of sample collection, and population level fertility were known for all captured individuals $(\mathrm{n}=101)$ and we used this sample to describe variation in $\mathrm{T}$ across stages of the nesting cycle. However, we had 17 samples from non-paired males, which, by definition, did not have a nest. Therefore, to comply with requirements of a standard information theoretic approach, we only used samples from paired individuals with complete information on nest density and female fertility in the analysis $(n=81)$. A subset of males were caught more than once, thus we randomly chose one sample per male so each individual was represented by a single sample in the analysis. $\mathrm{T}$ in the subset of males that were captured two or more times in one year were compared using paired t-tests to evaluate whether an individual male’s $\mathrm{T}$ changed between sampling dates. Values for T, population fertility, and local fertility did not conform to a normal distribution and were $\log _{10}$ transformed. Statistical significance was set at $P=0.05$ and statistics are presented as means \pm SE or regression coefficients \pm SE, and sample size (n). Analyses were conducted in Statistix 9.0 (Analytical Software, 2008) and SPSS 11.5 (SPSS Inc., 2002).

\section{RESULTS}

Testosterone concentrations in kingbirds. Plasma $\mathrm{T}$ levels ranged from undetectable to a maximum of $2.89 \mathrm{ng} / \mathrm{mL}$ (mean $=0.28 \pm 0.043 \mathrm{ng} / \mathrm{mL}, \mathrm{n}=101)$. 
Levels of $\mathrm{T}$ in the group of assays that were done for samples collected between 2005 and 2007 (mean $=0.20 \pm 0.047 \mathrm{ng} / \mathrm{mL}, \mathrm{n}=38)$ were lower $(F=11.97, P<0.001)$ than the assays for the samples collected in 2008 (mean $=0.31 \pm 0.064 \mathrm{ng} / \mathrm{mL}, \mathrm{n}=40$ ) and 2009 (mean $=0.39 \pm 0.138 \mathrm{ng} / \mathrm{mL}, \mathrm{n}=23$ ). As confirmation that variation in $\mathrm{T}$ among males represented physiologically relevant differences, cloacal protuberance volume and $\mathrm{T}$ were positively and significantly related $\left(\beta=0.094 \pm 0.0317, R^{2}=0.105, \mathrm{n}=57, P=0.004\right)$.

To test for a possible effect of the capture methods we used, we compared T between passively captured individuals and those captured using playback. Mean T of kingbirds captured using playback $(0.30 \pm 0.049, \mathrm{n}=86)$ was higher than that of those captured passively $(0.13 \pm 0.069, \mathrm{n}=15 ; F=29.47, P<0.001)$. However, capture date (playback: 25 June \pm 1.89 days; passive: 15 July \pm 3.33 days; $t=4.31, P<0.001$ ) and time of day at capture (playback: $0457 \pm 0038 \mathrm{hr}$ PST; passive: $0844 \pm 0203 \mathrm{hr}$ PST; $t=$ 14.23, $P<0.001$ ) differed between playback and passively captured males, and $\mathrm{T}$ varied with both date and time of capture (see below). Inclusion of date and time of capture as covariates in the comparison of $\mathrm{T}$ between playback and passive capture males eliminated the effect of capture method (date: $F=34.85, P<0.001$; time: $F=1.17, P=0.282$; capture method: $F=1.29, P=0.259$ ). T was also not influenced by the length of time required to capture the bird as there was no relationship between $\mathrm{T}$ and time elapsed between the start of playback and capture $(\beta=-0.002 \pm 0.00047, F=0.18, P=0.672$, Fig. 2).

Testosterone profile of kingbirds. Plasma testosterone levels differed among reproductive stages (ANOVA: $F=11.24, P<0.001$, Fig. 3 ). T was highest during 
territory formation and did not decline until dependent young were in the nest. T did not differ between the nestling and fledging stage, and $\mathrm{T}$ from samples collected during the fledging stage did not differ from the laying and incubation stages, probably because of high variability in $\mathrm{T}$ among males during the laying and fledgling stages. We obtained two or more blood samples within a year for 16 males (Fig. 4). Time elapsed between samples for these individuals ranged from 10 to 51 days ( mean $=22.0 \pm 3.04$ days). $\mathrm{T}$ declined between the first and second samples for 11 males (mean difference $=-0.48 \pm$ 0.221 ), increased in four (mean difference $=0.39 \pm 0.397$ ), and was unchanged for one. Counting the male whose $\mathrm{T}$ was unchanged as a decline, a Fisher's Exact Test indicated that the pattern of change (12 decline and 4 increase) did not differ from that expected by chance ( $P=0.140$ for a one-tailed test based on an expected decline). Two males were sampled three times within a year and for both of these individuals $\mathrm{T}$ increased between the first and second sample, and for one of the males the third sample had a higher $\mathrm{T}$ than the first blood sample. A paired $t$-test confirmed that $\mathrm{T}$ did not differ between the first and second samples of the 16 males (mean $=0.23 \pm 0.184 \mathrm{ng} / \mathrm{uL}, t=1.25, P=0.231$ ).

Variation in T: temporal influences and social environment. Sampling dates encompassed essentially the entire kingbird breeding season at MNWR (28 May to 8 August). T was highest from the early to middle breeding season, and from roughly the end of the first week of July onward T dropped to very low levels $(\beta=-0.048 \pm 0.0060$, $R^{2}=0.451, F=64.83, P<0.001$, Fig. $\left.1 \mathrm{~A}\right)$. Nearly all capture attempts were in the morning (0358 to 0900 hrs PST), and T declined with capture time $(\beta=-0.006 \pm 0.0011$, $R^{2}=0.258, F=27.50, P<0.001$, Fig. 1B). Distance to the nearest neighbor $(673 \pm 179.1$ 
$\mathrm{m}$, median $=289$, range $=45$ to $12,163 \mathrm{~m}, \mathrm{n}=81)$ and mean distance to the three nearest neighbors varied widely $(1,005 \pm 191.4 \mathrm{~m}$, median $=543$, range $=141$ to $12,718 \mathrm{~m}, \mathrm{n}=$ 81). In a univariate regression, $\mathrm{T}$ was unrelated to both nearest neighbor distance ( $\beta=$ $0.032 \pm 0.3229, F=0.10, P=0.922)$ and neighbor density $(\beta=-0.254 \pm 0.3891, F=$ $0.43, P=0.516$; Fig. 5 A). Local fertility on the day of sample collection ranged from 0 to 3 (mean $=0.5 \pm 0.09, \mathrm{n}=81$ ) while population fertility ranged from 0 to 16 (mean $=4.1$ $\pm 0.49, \mathrm{n}=81$ ). $\mathrm{T}$ exhibited positive associations with both local fertility and population fertility in separate univariate analyses (local: $\beta=0.427 \pm 0.1641, R^{2}=0.079, F=6.76, P$ $=0.011$; population: $\beta=0.126 \pm 0.0291, R^{2}=0.193, F=18.85, P<0.001$, Fig. 5B).

We used an information theoretic approach to determine how temporal and social variables affected $\mathrm{T}$ in multivariate relationships. The top model from the regression analyses included date and capture time, along with population fertility and neighbor density (Table 1). However, because of considerable model uncertainty we used model averaging to determine which variables best explained variation in $\mathrm{T}$ among males. Confidence intervals of model-averaged parameter estimates for date, population fertility, and neighbor density did not include zero, and indicated that $\mathrm{T}$ declined over the course of the breeding season and as neighbor density increased, and increased as population fertility increased. The parameter estimate for time of capture suggested a probable decline in $\mathrm{T}$ over the course of day, but $\mathrm{T}$ was independent of local fertility and nearest neighbor distance (Table 2). Together, capture date, population fertility, and neighbor density accounted for nearly $60 \%$ of the variation in $\mathrm{T}\left(R^{2}=0.584, F=35.97, \mathrm{df}=3,77\right.$, $P<0.001)$. 
Date and nest stage were strongly correlated (Spearman rank correlation $=0.814$, $\mathrm{n}=81, P<0.001$ ), and the decline of $\mathrm{T}$ with date in the multiple regression was conceivably driven by progressive transitions through nest cycle stages. We therefore simultaneously tested for associations between $\mathrm{T}$ and both date and nest stage by entering date, population fertility, and neighbor density in a general linear model as covariates with nest stage as a categorical variable. All variables contributed significantly to differences in T (Table 3). T declined with date $(\beta=-0.058 \pm 0.0095, F=6.17, P<$ $0.001)$, neighbor density $(\beta=-0.759 \pm 0.2631, F=2.89, P=0.005)$, and increased with population level fertility $(\beta=1.017 \pm 0.2379, F=4.28, P<0.001)$. T did not differ among males at any stage between pre-laying and the nestling period when we accounted for the three other variables (Fig. 3). The significance associated with nest stage was a consequence of unexpectedly high T among males caring for fledglings (Tukey’s test). Reanalysis after restricting the sample to males from the pre-laying through nestling stages indicated T was unrelated to nest stage ( $F=1.20$, $\mathrm{df}=3,69, P=0.317$ ), but that date, population fertility, and neighbor density were all associated significantly with T (all $P^{\prime}$ s $<0.011$ ).

\section{DISCUSSION}

Eastern Kingbirds are socially monogamous, long distance migratory passerines that have a relatively short breeding season at MNWR (Cancellieri and Murphy, 2013). Among many passerines, these properties are associated with a peak in T early in the breeding season, followed by sharp declines as a male’s mate initiates incubation (Hunt et 
al., 1995; Van Roo et al., 2003; Pinxten et al., 2007; Stanley et al., 2011). Contrary to expectations, $\mathrm{T}$ remained relatively constant across stages of the nest cycle. Intraindividual comparisons also suggested that $\mathrm{T}$ showed no consistent pattern of decline between first and later samples for males captured $\geq 2$ times per season. However, independent of stage of the nest cycle, $\mathrm{T}$ declined with date and over the course of the day. Finally, social factors were important contributors of $\mathrm{T}$ variation as the secretion of testosterone increased as the number of fertile females increased in the population but, contrary to our predictions, was lower in areas of high nest density.

Testosterone profile of Eastern Kingbirds. Conventional wisdom (Wingfield et al., 1990) is that $\mathrm{T}$ of monogamous species is high early in the breeding season to support territory establishment and mate attraction, but that $\mathrm{T}$ then declines rapidly during incubation to facilitate the transition of males to parental care (e.g., Hunt et al., 1995; Van Roo et al., 2003; Pinxten et al., 2007; Stanley et al., 2011). However, recent studies suggest that high $\mathrm{T}$ and paternal care are not necessarily incompatible (Townsend et al., 1991; Wynne-Edwards and Timonin, 2007; Neff and Knapp, 2009). In the doublebrooded North American breeding Barn Swallow (Hirundo rustica), for instance, Eikenaar et al. (2011a) showed that male $\mathrm{T}$ did not decline between the female fertile period and incubation, and that male feeding effort was independent of T. T-implanted Great Tits (Parus major) also maintained nestling feeding rates as high as controls (Van Duyse et al., 2000). Our results are similar to the temporal patterns exhibited by Barn Swallows as T was equally high from the pre-breeding phase through the end of nestling feeding (Fig. 3), and when extrinsic factors were accounted for, $\mathrm{T}$ did not decline across 
phases of the nesting cycle. The absence of a decline in $\mathrm{T}$ at incubation is found in polygynous species (e.g., Beletsky et al., 1989), and an increasing number of socially monogamous species such as Superb Fairy-wrens (Malurus cyaneus; Peters et al., 2001), European Stonechats (Saxicola torquata; Schwabl et al., 2005), Dark-eyed Juncos (Junco hyemalis; Jawor et al., 2006), Orange-crowned Warblers (Oreothlypis celata; Horton et al., 2010) and Barn Swallows (Eikenaar et al., 2011a). Experimentally elevated T inhibits paternal behavior (Saino and Møller, 1995b; Schoech et al., 1998; De Ridder et al., 2000; de la Cruz et al., 2003), but individually maintained endogenous male $\mathrm{T}$ does not appear to inevitably inhibit full expression of parental care in males of many species (see above). Maintenance of $\mathrm{T}$ levels could possibly be related to an increased chance that males sire more young, which, for socially monogamous species, would be via attracting females outside of the pair bond thus gaining extra-pair fertilizations (see "Social factors" below).

Courtship display (Wiley and Goldizen, 2003) and song production (Ketterson and Nolan, 1992; de Ridder et al., 2000; Van Duyse et al., 2000) are testosteronedependent in birds. Male kingbirds with dependent young still participate daily in dawn songs well into July (Sexton et al., 2007). We suggest this is a result of the prolonged secretion of $\mathrm{T}$ that we observed. Song appears to be a cue used by female kingbirds to assess male quality (Murphy et al., 2008) as the earliest and most vigorously singing males have the greatest extra-pair success in kingbirds (Dolan et al., 2007). Prolonged secretion of $\mathrm{T}$ by male kingbirds should thus increase reproductive success. 
Relatively little is known about diel variation in $\mathrm{T}$ in birds, but our results agree with the few other published studies in suggesting that it declines over the course of the day (Bachman et al., 1987; Foerster et al., 2002; Hau et al., 2002; but see Schwabl et al., 2005; Peters et al, 2006). Why this is so is not fully understood (Kempenaers et al., 2008), but high T early in the day is possibly favored by anticipation of or actual participation in male-male aggression and mate attraction early in the day when the female’s “fertilization window” occurs (Williams, 2012). Kingbird copulations appear to be limited almost entirely to the pre-dawn darkness as over $40+$ combined years of extensive field experience with kingbirds by Murphy and collaborators has yielded only three observed copulations. If $\mathrm{T}$ acts to inhibit paternal care (which it may not), a circadian pattern of testosterone secretion may be the mechanism that allows males to avoid conflicts between mating and paternal behavior. Higher T in the predawn darkness may stimulate dawn song as a means of pursuing extra-pair copulations. The decline following this time may then ensure that parental behaviors are expressed to promote within-pair nest success.

Social aspects of testosterone variation. Our detection of an inverse relationship between $\mathrm{T}$ and conspecific density is, to our knowledge, unique in that other studies have either reported no relationship (Eikenaar et al., 2011b) or an increase in T under conditions of high density (Wingfield and Hahn, 1994; Sasvári et al., 2009). The latter is the expectation under the assumption that $\mathrm{T}$ mediates aggression and that malemale conflict increases when nesting density is high (Wingfield et al., 1990). The relationship between $\mathrm{T}$ and aggression as mediated through male-male interaction is often 
studied by using simulated territorial intrusions (STI) that mimic aggressive interactions between males. STI typically succeed in generating aggressive behavioral responses from focal males (e.g., Schwabl et al., 2005; McGlothlin et al., 2007; Gill et al., 2008), but the expected rise in T following STI does not always materialize (Wingfield and Hahn, 1994; Silverin et al., 2004; Busch et al., 2008; Gill et al., 2008; this study) and has even been found to lead to a decrease in T (Van Duyse et al., 2004; Peters et al., 2006; Landys et al., 2007).

On the other hand, almost all studies in which testosterone was artificially elevated by T-implants showed that territory size of implanted males increased, which led to decreases in density (e.g., Wingfield, 1984; Chandler et al., 1994; Moss and Lambin, 1994; Alonso-Alvarez and Velando, 2001; but see Chandler et al., 1997). This same mechanism may have generated the inverse relationship we detected between $\mathrm{T}$ and nesting density in kingbirds; males with naturally high T held larger territories. However, given that ours was a non-experimental study, it is equally likely that males with naturally high $\mathrm{T}$ selected territories with few neighbors, whereas low $\mathrm{T}$ males with, presumably greater tolerance, settled in high density areas. The failure of STI to elicit an increase of $\mathrm{T}$ in kingbirds is consistent with the detection of low $\mathrm{T}$ among males nesting at higher density. Short-term aggressive interactions among kingbird males nesting in close proximity to one another probably do not elevate T.

The importance of $\mathrm{T}$ in regulating reproductive behavior of vertebrates is unquestioned (Adkins-Regan, 2007; Hau, 2007). Male T is generally at or near its annual peak when the mates of males of monogamous species are fertile (e.g., Schwabl et al., 
2005; Pinxten et al., 2007). Males of some monogamous (Peters et al., 2001) and polygynous species (Johnsen, 1998) have also been shown to track female fertility at larger spatial scales. Maintenance of relatively constant $\mathrm{T}$ by kingbirds throughout much of the nest cycle and a strong positive association between $\mathrm{T}$ and population level fertility indicates that male kingbirds are responsive to the availability of fertile females at large temporal and spatial scales.

Among socially monogamous species, the potential for multiple broods and/or opportunities for extra-pair fertilizations (Griffith et al., 2002) are likely to favor maintenance of physiologically relevant levels of $\mathrm{T}$. For instance, males of the socially monogamous Superb Fairy-wren maintain T through the nestling period (Peters et al., 2001), pairs raise multiple broods (Cockburn et al., 2003) and exhibit possibly the highest rates of extra-pair paternity known at 76\% (Mulder et al., 1994). Similarly, Barn Swallows regularly raise two broods per year, male $\mathrm{T}$ varies little between the incubation and nestling periods, and nearly a third of Barn Swallow young are of extra-pair origin (Eikenaar et al., 2011a). In both species, fitness payoffs exist for males that maintain sexual activity throughout the nest cycle. Eastern Kingbirds are single brooded, but in virtually all years $>50 \%$ of nests fail, and most females replace failed first nesting attempts if failure occurs before mid-July (Murphy, 1996; Cooper et al., 2011). As a consequence, fertile females are available throughout most of the kingbird breeding season, males advertise their availability through dawn song well into July (Sexton et al., 2007), and every year $60 \%$ ( \pm 5\% SE) of kingbird nests contain extra-pair young (Rowe et al., 2001; Dolan et al., 2007). Tree Swallows (Tachycineta bicolor) also exhibit 
extremely high rates of extra-pair paternity (Whittingham and Dunn, 2014), but unlike the aforementioned species, exhibit a distinct drop in $\mathrm{T}$ between the early nest cycle and incubation (Stanley et al., 2011). Tree Swallows are single brooded, but unlike kingbirds, experience far less nest failure and therefore the decline in $\mathrm{T}$ may reflect a greatly reduced opportunity for males to encounter fertile females after the initial phase of egglaying. The responsiveness of male kingbirds to fertile females on the population but not local level also follows from the spatial scale over which extra-pair fertilizations occur. Dolan et al. (2007) showed that nearly 50\% of extra-pair sires in this population were not nearest neighbors. Instead, extra-pair partners were separated by an average distance of $1.8 \mathrm{~km}$, nearly twice the average distance to the three nearest neighbors upon which local fertility was calculated (1,005 m). Circumstantial evidence suggests that female kingbirds travel to extra-pair male locations, and male kingbirds may respond to population-wide changes in female fertility by maintaining $\mathrm{T}$ to be prepared to enhance reproductive success via extra-pair fertilizations. Much of the interspecific variation in male $\mathrm{T}$ among species (see Garamszegi et al., 2008) may thus relate as much to the availability of fertile females over extended periods of the breeding season as to the potential for aggressive interactions among territory holding males.

\section{CONCLUSION}

Our analysis of breeding season variation in T of Eastern Kingbirds causes us to question the advisability of viewing patterns of $\mathrm{T}$ in socially monogamous male birds solely from the confines of the need to establish a territory to support reproduction by a 
future mate. The view that testosterone is incompatible with full expression of paternal care is eroding, and given the widespread occurrence of extra-pair mating opportunities in many species (Griffith et al., 2002), selection for maintenance of male reproductive capacity beyond his mate's fertile period seems as likely to influence patterns of testosterone production as male-male aggression or selection for parental behavior. Timplant studies demonstrate that increased $\mathrm{T}$ typically elevates aggression and interferes with parental behaviors (see above), but testosterone's role in modulating aggression is increasingly viewed as "permissive"; a little goes a long way and other mechanisms may fine-tune male aggression (Schwabl et al., 2005; Wingfield 2012). Although more manipulative studies on species that have not been previously studied would be useful, we suggest that more studies that evaluate and control for the potential sources of natural variation in $\mathrm{T}$ would be equally useful in furthering our understanding of the role that $\mathrm{T}$ plays in eliciting mating and parental behavior. Given the very high rate of extra-pair paternity of kingbirds (Rowe et al., 2001; Dolan et al., 2007), we suggest that the seasonal $\mathrm{T}$ profile of kingbirds has been mainly influenced by the extra-pair mating system, and we expect this to be true of other species in which mating opportunities exist outside of the pair bond for an extended portion of the breeding season.

\section{ACKNOWLEDGEMENTS}

We would like to thank C. M. Chutter, D. Youngblood and M. Paris for assistance in the field. Richard Roy and all other personnel at Malheur National Wildlife refuge were instrumental in granting access to the refuge's kingbird population so that we could 
conduct our work. This research was supported by a National Science Foundation grant (IOB-0539370) awarded to M. T. M. and K. M. O., a research grant from the Association for the Study of Animal Behaviour to N. W. C., and Forbes-Lea Grants from Portland State University to both L. J. R. and N. W. C. 


\section{CHAPTER 4 TABLES}

Table 4.1. Results of model selection from the regression analysis of variation in testosterone concentration [T] of Eastern Kingbirds breeding at Malheur National Wildlife Refuge, Oregon, in relation to date (Date) and time (Time) of sample collection, availability of fertile females on a local (LocFert) and population level (PopFert), nearest neighbor distance (NND1), and neighbor density (NND3). Statistics include Akaike Information Criterion (corrected for small sample size; $\mathrm{AIC}_{\mathrm{c}}$ ), difference in $\mathrm{AIC}_{\mathrm{c}}$ from the top model $\left(\Delta \mathrm{AIC}_{\mathrm{c}}\right)$, the likelihood and weight of each model, and number of parameters $(\mathrm{K})$.

\begin{tabular}{|c|c|c|c|c|c|}
\hline Model & $\mathrm{AIC}_{\mathrm{c}}$ & $\Delta \mathrm{AIC}_{\mathrm{c}}$ & Likelihood & Weight & $\mathrm{K}$ \\
\hline Date, Time, PopFert, NND3 & -22.176 & 0 & 1 & 0.2014 & 6 \\
\hline Date, PopFert, NND3 & -22.061 & 0.115 & 0.9441 & 0.1902 & 5 \\
\hline Date, Time, PopFert, NND3, LocFert & -20.752 & 1.424 & 0.4907 & 0.0988 & 7 \\
\hline Date, PopFert, NND3, LocFert & -20.372 & 1.804 & 0.4058 & 0.0817 & 6 \\
\hline Date, Time, PopFert, NND1 & -20.195 & 1.981 & 0.3714 & 0.0748 & 6 \\
\hline Date, PopFert, NND3, NND1 & -19.93 & 2.246 & 0.3253 & 0.0655 & 6 \\
\hline Date, Time, PopFert, NND3, NND1 & -19.895 & 2.281 & 0.3197 & 0.0644 & 7 \\
\hline Date, PopFert, NND1 & -19.338 & 2.838 & 0.242 & 0.0487 & 5 \\
\hline Date, Time, PopFert & -19.01 & 3.166 & 0.2054 & 0.0414 & 5 \\
\hline Date, Time, PopFert, NND1, LocFert & -18.901 & 3.275 & 0.1945 & 0.0392 & 7 \\
\hline Date, Time, PopFert, LocFert & -18.638 & 3.538 & 0.1705 & 0.0343 & 6 \\
\hline $\begin{array}{l}\text { Date, Time, PopFert, DenNeigh, DenLoc, } \\
\text { LocFert }\end{array}$ & -18.464 & 3.712 & 0.1563 & 0.0315 & 8 \\
\hline Date, PopFert, NND3, NND1, & -18.244 & 3.932 & 0.14 & 0.0282 & 7 \\
\hline Intercept only & 42.259 & 64.435 & - & - & 2 \\
\hline
\end{tabular}


Table 4.2. Model averaged parameter estimates of variation in testosterone concentration of Eastern Kingbirds in relation to date (Date) and time (Time) of capture, availability of fertile females on a population and local level, and nearest neighbor distance (NND1) and neighbor density (NND3). Data $(\mathrm{n}=81)$ are for birds breeding at Malheur National Wildlife Refuge, Oregon, between 2005 and 2009. Model averaged estimates include the coefficient \pm SE, along with $85 \%$ confidence interval surrounding the regression coefficients.

\begin{tabular}{|c|c|c|c|}
\hline \multirow[b]{2}{*}{ Variable } & \multirow[b]{2}{*}{ Regression coefficient } & \multicolumn{2}{|c|}{ 85\% Confidence Interval } \\
\hline & & Lower & Upper \\
\hline Date & $-0.042 \pm 0.0063$ & -0.0510 & -0.0330 \\
\hline Time & $-0.001 \pm 0.0008$ & -0.0022 & 0.0001 \\
\hline Population fertility & $0.936 \pm 0.2580$ & 0.5649 & 1.3078 \\
\hline NND3 & $-0.533 \pm 0.3159$ & -0.9881 & -0.0783 \\
\hline NND1 & $-0.033 \pm 0.2203$ & -0.3500 & 0.2844 \\
\hline Local fertility & $-0.188 \pm 0.3541$ & -0.6985 & 0.3215 \\
\hline
\end{tabular}


Table 4.3. Analysis of variation in testosterone concentration $(n=81)$ from Eastern Kingbirds breeding at Malheur National Wildlife Refuge, Oregon, between 2005 and 2009 using general linear models with sample date, population level fertility, and neighbor density included as covariates and nest stage as a categorical variable.

\begin{tabular}{|c|c|c|c|}
\hline Source & $\mathrm{df}$ & SS & $F(P)$ \\
\hline Nest stage & 4 & 8.903 & $3.60(0.001)$ \\
\hline Date & 1 & 23.544 & $38.12(<0.001)$ \\
\hline Population fertility & 1 & 11.288 & $18.28(<0.001)$ \\
\hline Neighbor density & 1 & 5.140 & $8.32(0.005)$ \\
\hline Error & 73 & 45.084 & \\
\hline
\end{tabular}




\section{CHAPTER 4 FIGURES}

Figure legends

Fig. 4.1. Testosterone concentration $(\mathrm{T} ; \mathrm{ng} / \mathrm{ml}, \mathrm{n}=81)$ in Eastern Kingbirds sampled at Malheur National Wildlife Refuge, Oregon, between 2005 and 2009 in relation to (A) date of sample collection where 1 May $=1\left(\log _{10}[\mathrm{~T}]\right.$ vs. date, $\left.P<0.001\right)$, and (B) time of day when samples were taken, where time is measured in minutes from midnight ( $\log _{10}[\mathrm{~T}]$ vs. time, $\left.P<0.001\right)$.

Fig. 4.2. Testosterone concentration $(\mathrm{T} ; \mathrm{ng} / \mathrm{ml}, \mathrm{n}=81)$ in Eastern Kingbirds captured by simulated territorial intrusion at Malheur National Wildlife Refuge, Oregon, between 2005 and 2009 in relation to time taken to capture the individual $\left(\log _{10}\right.$ [T] vs. time to capture, $P=0.672)$.

Fig. 4.3. Mean testosterone concentration across stages of the reproductive cycle of Eastern Kingbirds breeding at Malheur National Wildlife Refuge, Oregon, between 2005 and 2009. Error bars represent one SE, while actual mean, SE (in parentheses), and sample sizes at each stage are given above the bars.

Fig. 4.4. Change in testosterone concentration between first and second sample periods for male Eastern Kingbirds captured twice in a year $(n=16)$ at Malheur National Wildlife Refuge, Oregon, between 2005 and 2009. Lines connect first and second sample periods for each male. 
Fig. 4.5. Testosterone concentration of male Eastern Kingbirds $(n=81)$ breeding at Malheur National Wildlife Refuge, Oregon, between 2005 and 2009 in relation to (A) and number of fertile females available in the population $\left(\log _{10}[\mathrm{~T}]\right.$ vs. number of fertile females, $P<0.001)$ and $(\mathrm{A})$ nesting density $\left(\log _{10}[\mathrm{~T}]\right.$ vs. nesting density, $\left.P=0.516\right)$. Nesting density was measured as $\log _{10}$ of the inverse of the mean distance to the three nearest kingbird nests. 
Figure 4.1

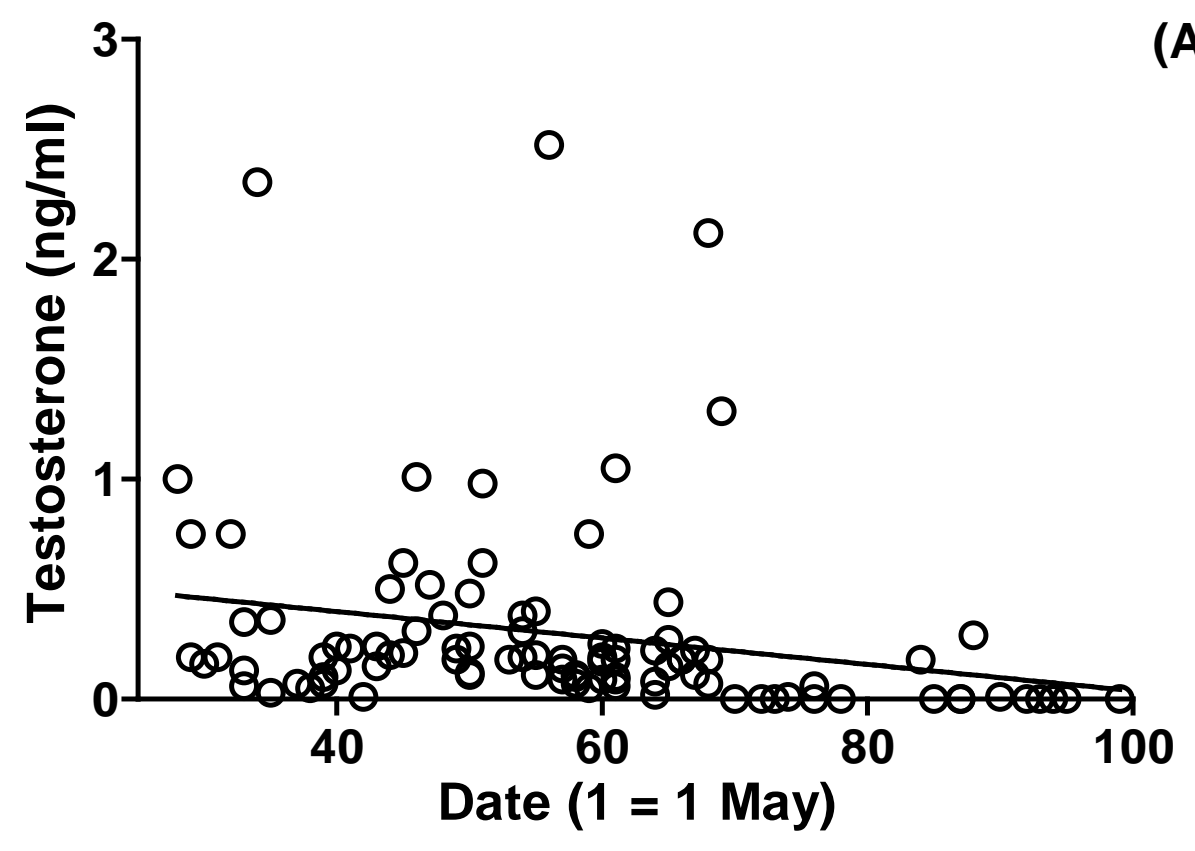

(A)

(B)

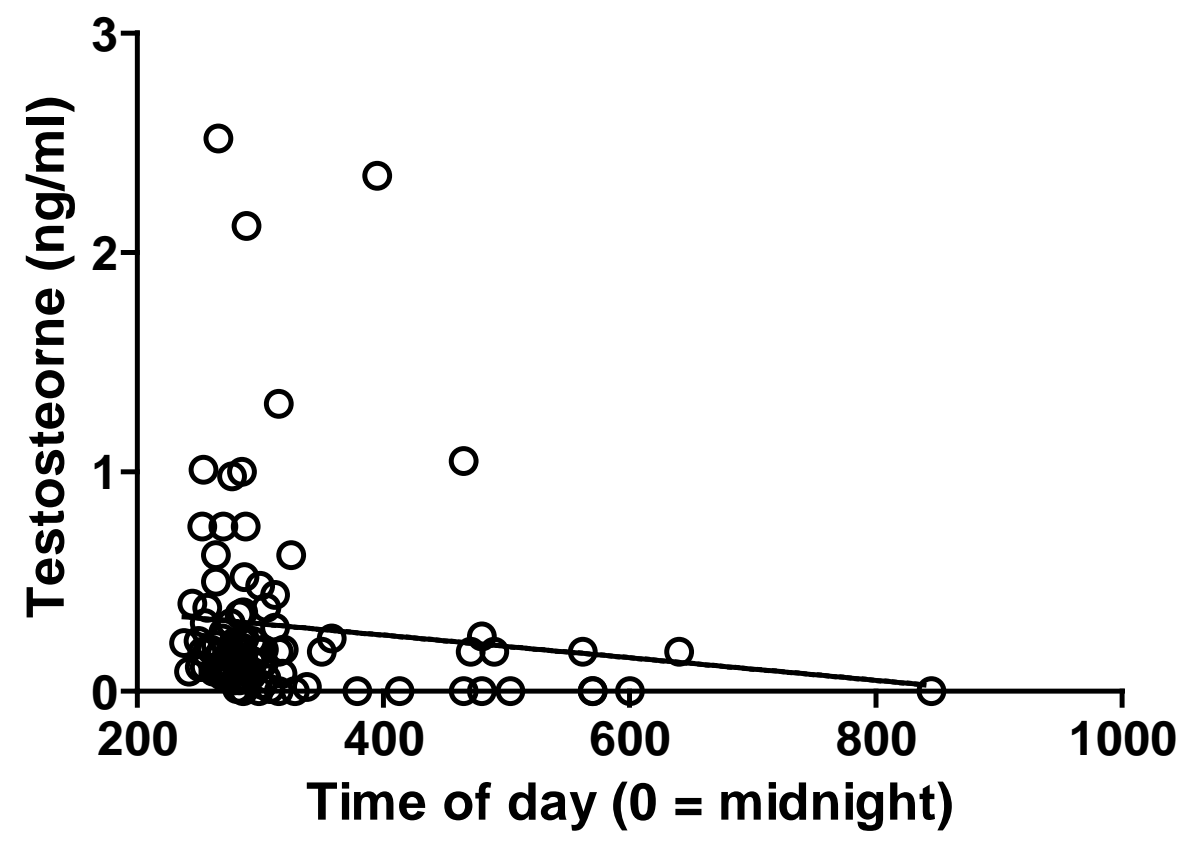


Figure 4.2

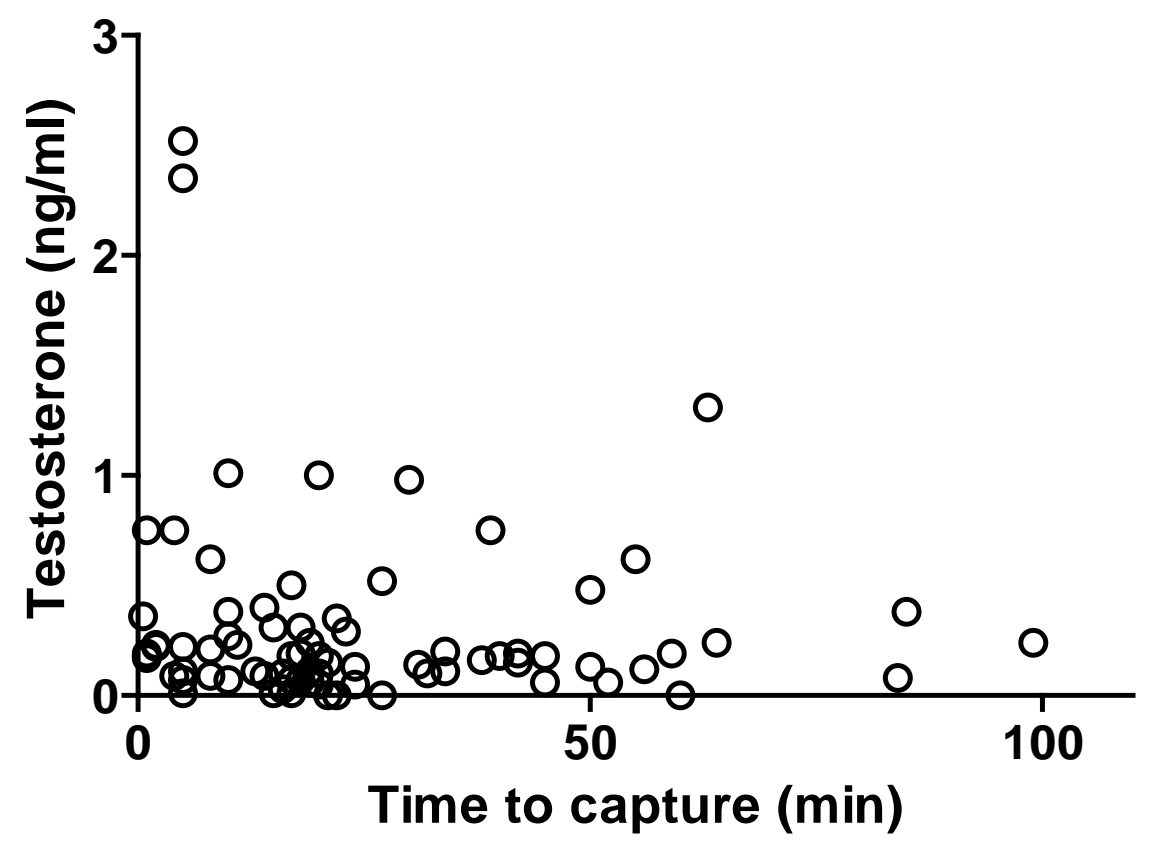


Figure 4.3

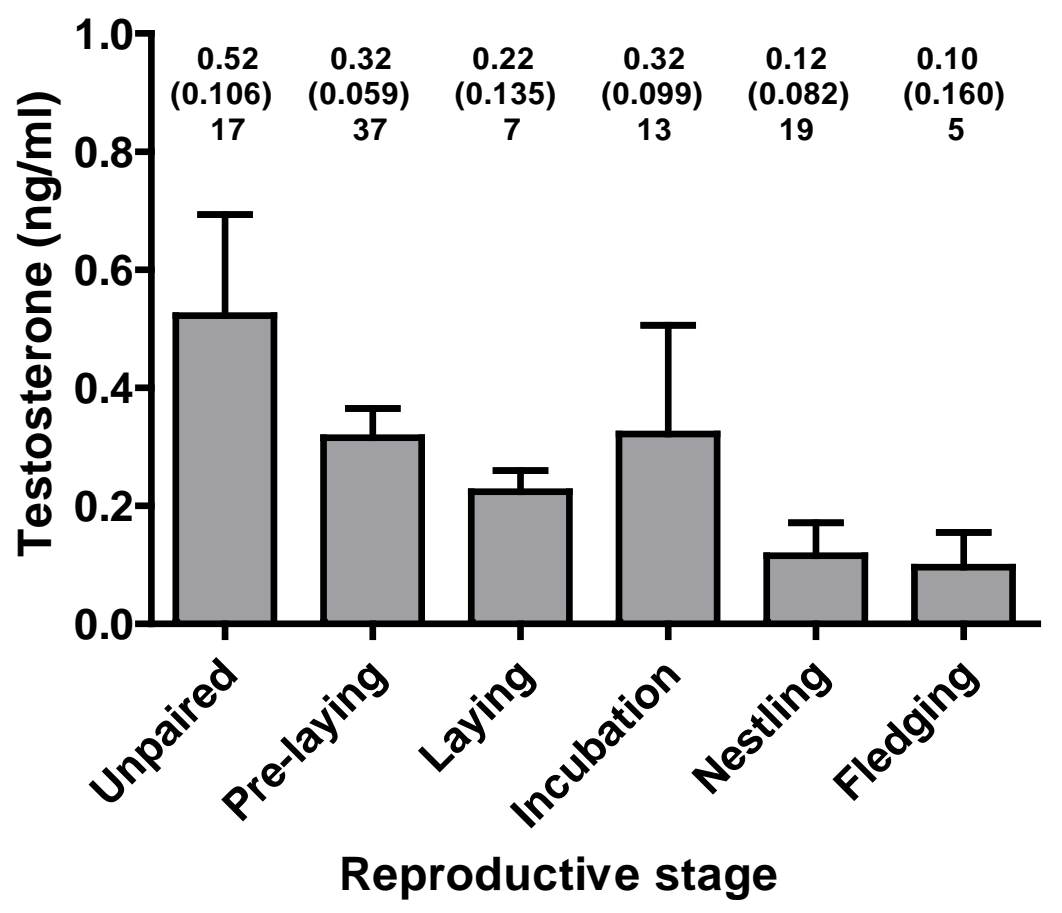


Figure 4.4

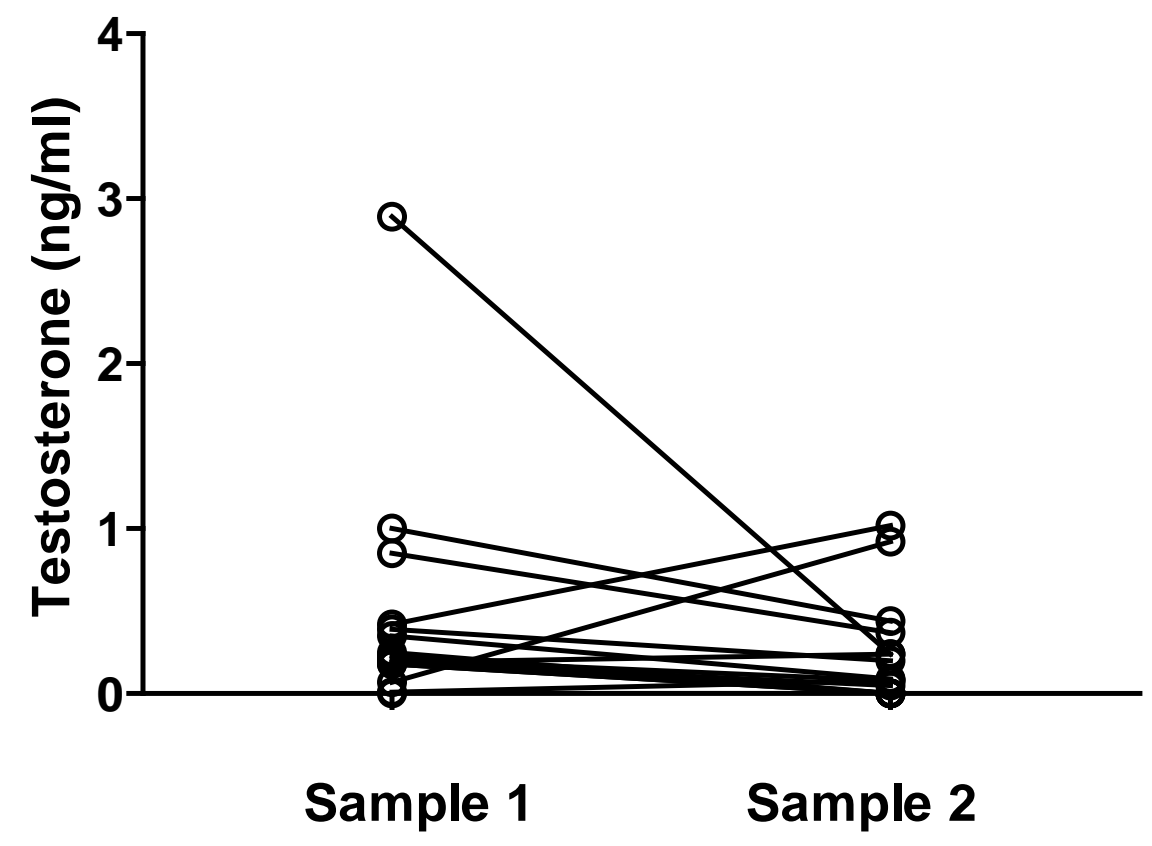


Figure 4.5

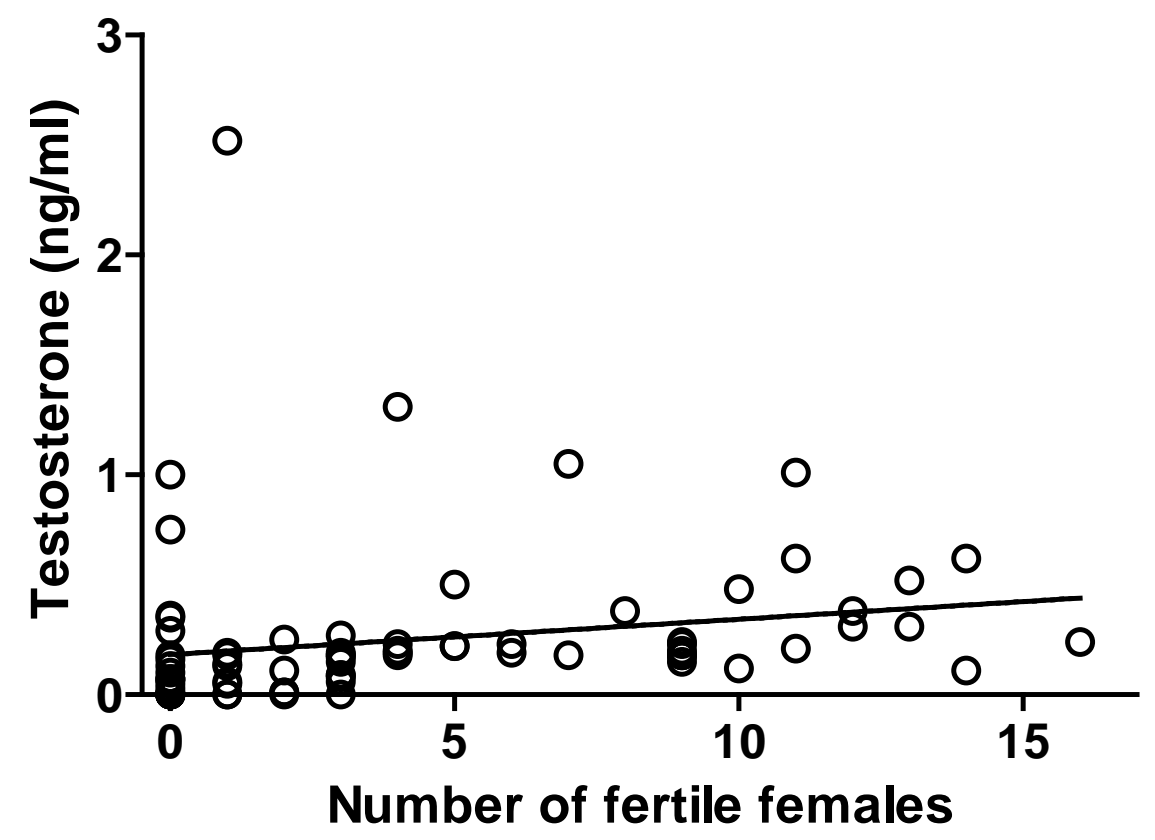

(A)

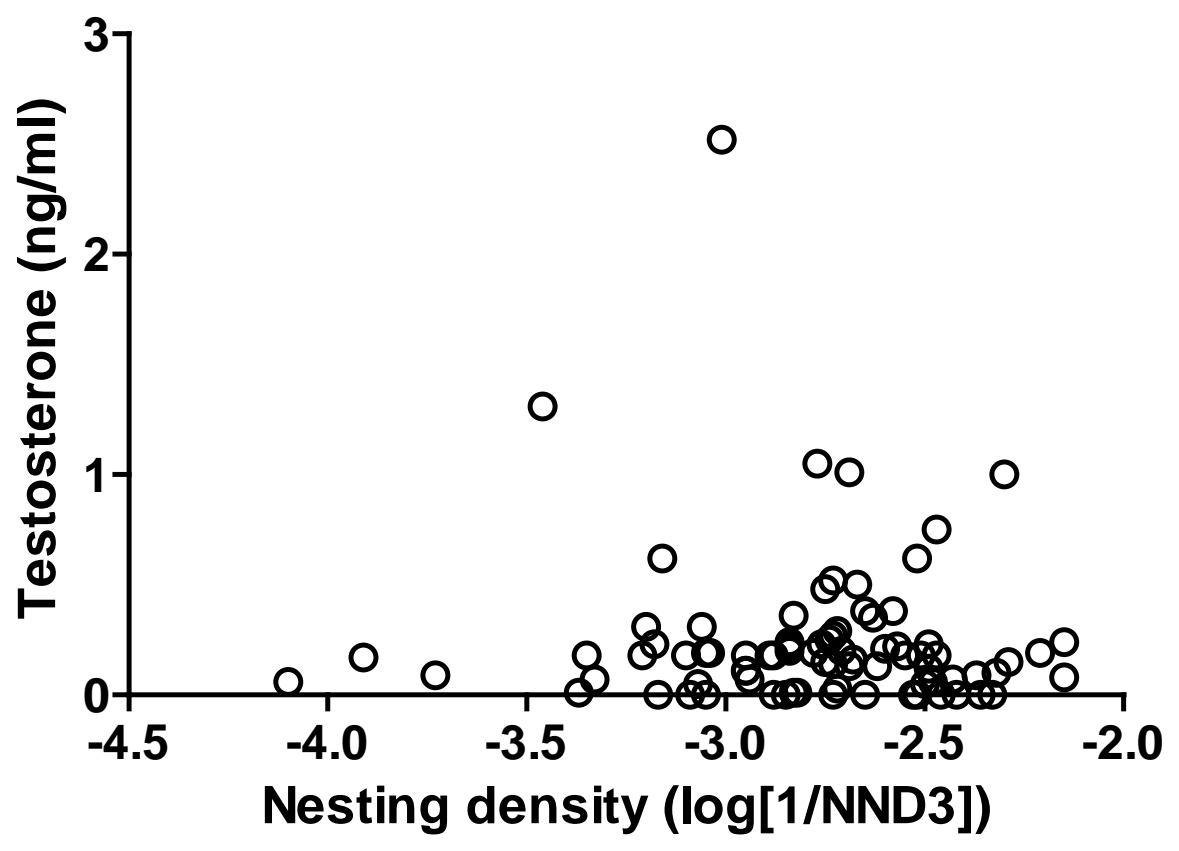

(B) 


\section{CHAPTER 5}

\section{Conclusions}

I studied the breeding biology of a population of Eastern Kingbirds in southeastern Oregon at Malheur National Wildlife refuge from 2003 to 2009. Extensive color banding of the population coupled with resighting banded individuals in following years allowed for a robust estimation of survival of adult kingbirds. In addition, the refuge's nature as an “island in a sea of desert” afforded an almost unprecedented opportunity to produce a very precise estimate of juvenile survival for kingbirds. I also utilized my resighting data to confirm that blood sampling did not cause declines in annual survival. Finally, I documented the breeding season testosterone profile of kingbirds. These results indicated that kingbirds exhibit an atypical testosterone profile compared to most other migratory, synchronously breeding monogamous species due to the fact that testosterone did not exhibit a sharp decline throughout the nest cycle.

There is a mutualistic relationship between science and technology. Advances in science increase technological capability, while at the same time, growth of technology advances science because old questions can be asked in new ways or questions previously unanswerable can now be addressed. The availability and, perhaps more importantly, affordability of equipment and techniques have helped to greatly increase our knowledge of the natural world. This is very much the case in ornithology, and indeed, in my research. Much of ornithology in the late 1800’s and early 1900's was focused on the collection of eggs and study skins. Technological innovation in the early 
$20^{\text {th }}$ century allowed for the production of binoculars that enabled users to view detail as never before and helped usher in the end of the age of "ornithology at the end of gun barrel”. Although present day field ornithology still relies on methods such as mist netting and nest searching, and scientific collecting is still required to help us further our understanding of taxonomic relationships, there is an ever increasing use of highly technical equipment to collect data and analyze results. The study of song, for instance, would not be possible without sound recording equipment and sophisticated analytical technologies. And most recently, the ingenious development of archival geolocators has opened a window into the intricacies of overwintering and migratory behavior that was never imagined (see McKinnon et al. 2013 and associated papers in April 2013 issue of The Auk).

\section{KINGBIRD DEMOGRAPHY AND FACTORS INFLUENCING SURVIVAL}

Deriving estimates of survival in a population of free-living animals usually requires giving individuals some kind of mark so that they are recognizable in the future. In North America, John James Audubon is credited as the first person to mark birds in 1803. From this first experiment with Eastern Phoebes (Sayornis phoebe), bird banding has emerged as the go to method of tracking movement and estimating survival rates. In North America alone, more than 64 million birds have been banded since 1960. Bird banding allows researchers to address a number of interesting questions. Marking individuals and then recapturing them at a later date at a different location has allowed us to better understanding the migratory patterns of a number of species. Bands, and other 
unique marks, allow for easy recognition of individuals in a study which facilitates behavioral observations. Finally, estimating survival is, by far, the most frequent intent of banding birds.

Marking individuals is only the first step in estimating survival. Given the likelihood of movement throughout an individual's life, biologists must account for the possibility that animals may not be encountered despite being alive during census periods and analytical methods that account for this uncertainty are required to produce accurate estimates of survival rates. The early efforts of Cormack, Jolly, and Seber in developing a mathematical model (CJS model) that accounts for the likelihood that marked animals are encountered in future resighting events was an important milestone in the study of population dynamics. Although initially meant as a tool to estimate abundance, the CJS model can also be used to estimate survival. Individuals within a study population can be divided into groups using characteristics such as age and sex, and, when used in combination with other statistical analyses researchers have the ability to test hypotheses related to differences in survival among groups. In this respect, the CJS model and its extensions have become very useful tools for biologists.

Many species of birds exhibit relatively high site fidelity which allows fairly precise estimates of survival. On the other hand, juvenile dispersal, especially for birds, is usually much higher than adult survival. As a consequence, resighting rates of juveniles is much lower (reviewed by Weatherhead and Forbes 1994) and can lead to underestimation of juvenile survival. For example, Murphy (1996) reported age-specific 
estimates of survival for a population of kingbirds in New York. Estimates of adult survival between New York and Malheur were similar (Redmond and Murphy 2012), not surprising considering the high site fidelity of kingbirds (Murphy 1996). However, estimates of juvenile survival were different. Although my estimate of juvenile survival was likely an underestimate considering other demographic parameters of the Malheur population, it was much higher than Murphy's estimate in New York, and much closer to "true" juvenile survival. The best explanation for this is the isolated nature of my study site which limited juvenile dispersal. Estimates of adult survival are available for a number of species, but given the nature of dispersal in juvenile birds, accurate estimates of juvenile survival are not as frequently reported. In this respect, my study adds to the growing body of knowledge describing age-specific variation in vital rates (e.g., Tarwater et al. 2012). Informed management decisions for declining or threatened species and accurate comparisons between different life history strategies require such accurate estimations of survival at all stages of the life cycle.

A number of modifications to the CJS model have been developed that allow researchers to address hypotheses of the effects of individual characteristics on survival. Schwarz et al. (1993) and Brownie et al. (1993) extended the CJS model to allow individuals to transition between groups to produce a more accurate estimate of survival. Unlike the traditional group variable (e.g., age and sex) in the CJS model, these multistate mark-recapture models allowed for the possibility of moving freely among groups in multiple directions throughout the life of marked individuals, such as individuals moving 
between different populations across their lifespan. I utilized multistate mark-recapture models to test for the effects of blood sampling on survival in kingbirds.

Given the amount of data that can be generated, the collection of blood samples from wild birds is an increasingly used practice in field ornithology. Blood samples can be used to locate wintering grounds via stable isotope analysis (Marra et al. 1998), for genetic analyses such as resolving genetic mating systems (Villavicencio et al. 2014), and in hormone assays (Chastel et al. 2005). Researchers strive to ensure that the methods used to collect blood have little to no impact on the welfare of the birds they study by collecting small volumes of blood in as non-invasive a manner as possible. Although Sheldon et al. (2008) reviewed the current literature on the subject and concluded that blood sampling had no effect on the long-term survival in birds, the data that were used to come to this conclusion were potentially flawed in that none of the studies utilized a mark-recapture framework to determine if blood sampling had an effect on annual survival. When the question of how blood sampling effects annual survival was asked correctly in a population of Cliff Swallows (Brown and Brown 2009), a significant, negative effect of blood sampling on survival was observed. This result caused the Ornithological Council to issue a statement in their "Guidelines to the use of wild birds in research" warning ornithologists of the possible serious effects of collecting blood samples on the welfare of birds. My results showed that the negative effects are not universal as blood sampling did not have an effect on annual survival of kingbirds. Although it needs to be noted that Brown and Brown (2009) used a multistate model that could not actually answer the question they were asking, more studies are certainly 
needed in other species to determine the true effects that blood sampling has on annual survival, if any.

\section{Testosterone in Eastern Kingbirds}

Hormone secretion is the proximate mechanism that regulates the interplay between physiology, behavior, and life history events. In male vertebrates, the steroid hormone testosterone stimulates the development of secondary sexual characteristics and promotes mating behaviors such as mate attraction and territoriality. Studies utilizing assays to determine the concentration of circulating testosterone first became prevalent in the mid 1970’s. Over the following three decades, information regarding testosterone levels has become available for many species. Despite the number of species that have received attention, relatively few were studied extensively and these results laid the foundation for what was thought, at the time, to be an almost universal generalization in avian endocrinology. This was the apparent difference in the pattern of testosterone secretion between monogamous and polygynous birds. In recent years, however, as more robust data became available for more species, endocrinologists are beginning to question this long-standing dogma. My results for kingbirds provide more evidence that the difference in testosterone profile between monogamous and polygynous species is not as clear as once thought and other aspects of a species' biology may be more important contributors to interspecific variation in testosterone profile. Male kingbirds, for example, are best described as being genetically polygynous due to extensive extra-pair fertilizations that occur in the populations that have been studied to date (Rowe et al. 2001, Dolan et al. 
2009). My results and those of others (Peters et al. 2001, Eikenaar et al. 2011b) suggest that genetic mating systems may be just as, if not more important, than social mating system in determining interspecific differences in patterns of testosterone secretion. However, only time will tell whether this can be stated as a generalization because too few current studies provide the integrative data on both the endocrine and mating systems needed to address this question (for examples see Raouf et al. 1997, Eikenaar et al. 2011b, Villavicencio et al. 2014, and the present study). Moving forward, this is a question that needs to be addressed if we are to have complete understanding of the importance that testosterone plays in shaping life history characteristics.

\section{Closing remarks}

It is an exciting time to be an ornithologist. New technology is being utilized to address questions that were once unable to be answered. For example, GPS tracking devices are now small enough to be placed on songbirds weighing less than approximately $50 \mathrm{~g}$, while ambient light level geolocators can be deployed on species weighing as little as $9 \mathrm{~g}$ (Streby et al. 2015). Both will give ornithologists a much broader picture of what birds experience across their annual cycle. Genetic analyses have become commonplace. As I transition from a student in ornithology to making a career in this science, I am excited for what the future holds. 


\section{REFERENCES}

Adkins-Regan, E. 2007. Hormones and the development of sex differences in behavior. Journal of Ornithology 148:S17-S26.

Akcakaya, H. R., M. A. Burgman, and L. R. Ginzburg. 1997. Applied population ecology. Applied Biomathematics, Setauket, NY.

Alonso-Alvarez, C., Velando, A. 2001. Effect of testosterone on the behaviour of yellow-legged gulls (Larus cachinnans) in a high density colony during the courtship period. Ethology, Ecology and Evolution 13:341-349.

Anders, A. D., and M. R. Marshall. 2005. Increasing the accuracy of productivity and survival estimates in assessing landbird population status. Conservation Biology 19:66-74.

Arcese, P. 1989. Intrasexual competition, mating system and natal dispersal in song sparrows. Animal Behaviour 38:958-979.

Ardern, S. L., I. G. McLean, S. Anderson, R. Maloney, and D. M. Lambert. 1994. The effects of blood sampling on the behavior and survival of the endangered Chatham Island Black Robin (Petroica traverse). Conservation Biology 8:857862.

Arlt, D., P. Forslund, T. Jeppsson, and T. Part. 2008. Habitat-specific population growth of a farmland bird. PLoS ONE 3: e3006.

Arnason, A. N. 1972. Parameter estimates for mark-recapture experiments on two populations subject to migration and death. Researches on Population Ecology 
13:99-113.

Arnason, A. N. 1973. The estimation of population size, migration rates, and survival in stratified populations. Researches on Population Ecology 15:1-8.

Arnold, T.W. 2010. Uninformative parameters and model selection using Akaike’s information criterion. Journal of Wildlife Management 74:1175-1178.

Ausprey, I. J., and A. D. Rodewald. 2011. Postfledging survivorship and habitat selection across a rural-to-urban landscape gradient. Auk 128:293-302.

Bachman, S.E., Bachman, J.M., Mashaly, M.M. 1987. Effect of photoperiod on the diurnal rhythm of plasma testosterone, dihydrotestosterone, and androstenedione in mature male chickens. Comparative Biochemistry and Physiology Part A: Physiology 87:775-559.

Baker, M., N. Nur, and G. R. Geupel. 1995. Correcting biased estimates of dispersal and survival due to limited study area: theory and an application using Wrentits. Condor 97:663-674.

Balenger, S. L., L. S. Johnson, H. L. Mays, Jr., and B. S. Masters. 2009. Extra-pair paternity in the socially monogamous Mountain Bluebird Sialia currucoides and its effect on the potential for sexual selection. Journal of Avian Biology 40:173180.

Beaulieu, M., Y. Ropert-Coudert, Y. Le Maho, A. Ancel, and F. Criscuolo. 2010. Foraging in an oxidative environment: Relationship between $\delta^{13} \mathrm{C}$ values and oxidative status in Adelie penguins. Proceedings of the Royal Society of London, Series B 277:1087-1092. 
Beletsky, L.D., Orians, G.H., Wingfield, J.C. 1989. Relationships of steroid hormones and polygyny to territorial status, breeding experience, and reproductive sucesss in male Red-winged Blackbirds. Auk 106:107-117.

Berkeley, L. I., J. P. McCarty, and L. L. Wolfenbarger. 2007. Postfledging survival and movement in Dickcissels (Spiza americana): implications for habitat management and conservation. Auk 124:396-409.

Bigler, W. J., G. L. Hoff, and L. A. Scribner. 1977. Survival of Mourning Doves unaffected by withdrawing blood samples. Bird-Banding 48:168.

Braden, G. T., R. L. McKernan, and S. M. Powell. 1997. Association of within-territory vegetation characteristics and fitness components of California Gnatcatchers. Auk 114:601-609.

Breininger, D. R., J. D. Nichols, G. M. Carter, and D. M. Oddy. 2009. Habitat-specific breeder survival of Florida Scrub-jays: Inference from multistate models. Ecology 90:3180-3189.

Brown, C. R, and M. B. Brown. 1995a. Cliff Swallow (Petrochelidon pyrrhonota). In The Birds of North America Online (A. Poole, Ed.). Cornell Lab of Ornithology, Ithaca, New York. Available at bna.birds.cornell.edu/bna/species/149

Brown, C. R., M. B. Brown, and B. Rannala. 1995b. Ectoparasites reduce long-term survival of their avian host. Proceedings of the Royal Society of London, Series B 262:313-319.

Brown, C. R., and M. B. Brown. 1996. Coloniality in the Cliff Swallow: The Effect of Group Size on Social Behavior. University of Chicago Press, Chicago, Illinois. 
Brown, M. B., and C. R. Brown. 2009. Blood sampling reduces annual survival in Cliff Swallows (Petrochelidon pyrrhonota). Auk 126:853-861.

Brown, W. P., and R. R. Roth. 2009. Age-specific reproduction and survival of individually marked Wood Thrushes, Hylocichla mustelina. Ecology 90:218-229.

Brownie, C., J. E. Hines, J. D. Nichols, K. H. Pollock, and J. B. Hestbeck. 1993. Capture-recapture studies for multiple strata including non-Markovian transitions. Biometrics 49:1173-1187.

Bryant, D. M. 1997. Energy expenditure in wild birds. Proceedings of the Nutrition Society 56:1025-1039.

Buehler, D. A., J. J. Giocomo, J. Jones, P. B. Hamel, C. M. Rogers, T. A. Beachy, D. W. Varble, C. P. Nicholson, K. L. Roth, J. Barg, R. J. Robertson, J. R. Robb, and K. Islam. 2008. Cerulean Warbler reproduction, survival, and models of population decline. Journal of Wildlife Management 72:646-653.

Burnham, K. P., and D. R. Anderson. 2002. Model Selection and Multimodel Inference: A Practical Information-Theoretic Approach, 2nd ed. Springer, New York.

Busch, D.S., Robinson, T.R., Hahn, T.P., Wingfield, J.C. 2008. Sex hormones in the song wren: variation with time of year, molt, gonadotropin releasing hormone, and social challenge. Condor 110:125-133.

Cancellieri, S., Murphy, M.T. 2013. Experimental examination of nest reuse by an opencup nesting passerine: savings of time/energy or nest site shortage? Animal Behviour 85:1287-1294. 
Canoine, V., Gwinner, E. 2002. Seasonal differences in the hormonal control of territorial aggression in free-living European Stonechats. Hormones and Behavior 41:1-8.

Cawthorn, J.M., Morris, D.L., Ketterson, E.D., Nolan, Jr., V. 1998. Influence of experimentally elevated testosterone on nest defence in dark-eyed juncos. Animal Behaviour 56:617-621.

Chandler, C.R., Ketterson, E.D., Nolan, Jr., V., Ziegenfus. C. 1994. Effects of testosterone on spatial activity in free-ranging dark-eyed juncos, Junco hyemalis. Animal Behaviour 47:1445-1455.

Chandler C.R., Ketterson E.D., Nolan Jr. V. 1997. Effects of testosterone on use of space by male dark-eyed juncos when their mates are fertile. Animal Behaviour 54:543-549.

Choquet, R., J.-D. Lebreton, O. Gimenez, A.-M. Reboulet, and R. Pradel. 2009. UCARE: Utilities for performing goodness of fit tests and manipulating CAptureREcapture data. Ecography 32:1071-1074.

Choquet, R., A.-M. Reboulet, R. Pradel, O. Gimenez, and J.-D. Lebreton. 2004. MSURGE: New software specifically designed for multistate capture-recapture models. Animal Biodiversity and Conservation 27:207-215.

Clobert, J., and J-D. Lebreton. 1991. Estimation of demographic parameters in bird population dynamics. In: Bird population studies: their relevance to conservation and management (C. M. Perrins, J.-D. Lebreton, and G. J. M. Hirons, eds.), pp. 75-104. Oxford University Press, Oxford, UK. 
Cockburn, A., Osmond, H.L., Mulder, R.A., Green, D.J., Double, M.C. 2003. Divorce, dispersal and incest avoidance in the cooperatively breeding superb fairy-wren Malurus cyaneus. Journal of Animal Ecology 79:189-202.

Cohen, E. B., and C. A. Lindell. 2004. Survival, habitat use, and movements of fledging White-throated Robins (Turdus assimilis) in a Costa Rican agricultural landscape. Auk 121:404-414.

Colwell, M. A., C. L. Gratto, L. W. Oring, and A. J. Fivizzani. 1988. Effects of blood sampling on shorebirds: Injuries, return rates, and clutch desertions. Condor 90:942-945.

Cormack, R. M. 1964. Estimates of survival from the sighting of marked animals. Biometrika 51:429-438.

Cooper, C. B., S. J. Daniels, and J. R. Walters. 2008. Can we improve estimates of juvenile dispersal distance and survival? Ecology 89:3349-3361.

Cooper, N. W., M. T. Murphy, and L. J. Redmond. 2009a. Age- and sex-dependent arrival date in the Eastern Kingbird. Journal of Field Ornithology 80:35-41.

Cooper, N. W., M. T. Murphy, L. J. Redmond, and A. C. Dolan. 2009b. Densitydependent age at first reproduction in the Eastern Kingbird. Oikos 118:413-419.

Davis, D.E. 1941. The belligerency of the kingbird. Wilson Bulletin 53:157-168.

de la Cruz, C., Solís, E., Valencia, J., Chastel, O., Sorci, G. 2003. Testosterone and helping behavior in the azure-winged magpie (Cyanopica cyanus): natural variation and an experimental test. Behavioral Ecology and Sociobiology 55:103111. 
De Ridder, E., Pinxten, R., Eens, M. 2000. Experimental evidence of a testosteroneinduced shift from paternal to mating behaviour in a facultatively polygynous songbird. Behavioral Ecology and Sociobiology 49:24-30.

DiQuinzio, D. A., P. W. C. Paton, and W. R. Eddleman. 2001. Site fidelity, philopatry, and survival of promiscuous Saltmarsh Sharp-tailed Sparrows in Rhode Island. Auk 118:888-899.

Dolan, A. C., M. T. Murphy, L. J. Redmond, K. Sexton, and D. Duffield. 2007. Extrapair paternity and the opportunity for sexual selection in a socially monogamous passerine. Behavioral Ecology 18:985-993.

Dolan, A. C., M. T. Murphy, L. J. Redmond, and D. Duffield. 2009. Maternal characters and the production and recruitment of sons in the eastern kingbird (Tyrannus tyrannus). Behavioral Ecology and Sociobiology 63:1527-1537.

Donovan, T. M., R. H. Lamberson, A. Kimber, F. R. Thompson III, and J. Faaborg. 1995. Modeling the effects of habitat fragmentation on source and sink demography of Neotropical migrant birds. Conservation Biology 9:1396-1407.

Dufty, A. M., Jr. 1988. The effects of repeated blood sampling on survival in Brownheaded Cowbirds. Condor 90:939-941.

Eikenaar, C.M. Whitham, M., Komdeur, J., van der Velde, M., Moore, I.T. 2011 a. Endogenous testosterone is not associated with the trade-off between paternal and mating effort. Behavioral Ecology 22:601-608. 
Eikenaar, C.M. Whitham, M., Komdeur, J., van der Velde, M., Moore, I.T. 2011b. Testosterone, plumage colouration and extra-pair paternity in Male North American Barn Swallows. PLoS ONE 6.

Fair, J., E. Paul, and J. Jones, Eds. 2010. Guidelines to the Use of Wild Birds in Research. Ornithological Council, Washington, D.C.

Fair, J., S. Whitaker, and B. Pearson. 2007. Sources of variation in haematocrit in birds. Ibis 149:535-552.

Fitzpatrick, J. W. 1980. Foraging behavior of Neotropical tyrant flycatchers. Condor 82:43-57.

Foerster, K., Poesel, A., Kunc, H., Kempernaers, B. 2002. The natural plasma testosterone profile of male blue tits during the breeding season and its relation to song output. Journal of Avian Biology 33:269-275.

Franklin, A. B., R. J. Gutierrez, J. D. Nichols, M. E. Seamans, G. C. White, G. S. Zimmerman, J. E. Hines, T. E. Munton, W. S. LaHaye, J. A. Blakesley, G. N. Steger, B. R. Noon, D. W. H. Shaw, J. J. Keane, T. L. McDonald, and S. Britting. 2004. Population dynamics of the California Spotted Owl (Strix occidentalis occidentalis): A meta-analysis. Ornithological Monographs 54:1-54.

Franks, E. C. 1967. Mortality of bled birds as indicated by recapture rate. Bird-Banding 38:125-130.

Frederick, P. C. 1986. Parental desertion of nestlings by White Ibis (Eudocimus albus) in response to muscle biopsy. Journal of Field Ornithology 57:168-173. 
Fridolfsson, A. K., and H. Ellegren. 1999. A simple and universal method for molecular sexing of non-ratite birds. Journal of Avian Biology 30:116-121.

Garamszegi, L.Z., Eens, M., Hurtrez-Boussès, S., Møller, A.P. 2005. Testosterone, testes size, and mating success in birds: a comparative study. Hormones and Behavior 47:389-409.

Garamszegi, L.Z., Hirschenhauser, K., Bókony, V., Eens, M., Hurtrez-Boussès, S., Møller, A.P., Oliveira, R.F., Wingfield, J.C. 2008. Latitudinal distribution, migration, and testosterone levels in birds. American Naturalist 172:533-546.

Gardali, T., D. C. Barton, J. D. White, and G. R. Geupel. 2003. Juvenile and adult survival of Swainson's Thrush (Catharus ustulatus) in coastal California: Annual estimates using capture-recapture analyses. Auk 120:1188-1194.

Gill, S.A., Costa, L.M., Hau, M. 2008. Males of a single-brooded tropical bird species do not show increases in testosterone during social challenges. Hormones and Behavior 54:115-124.

Goyman, W., Moore, I.T., Scheuerlein, A., Hirschenhauser, K., Grafen, A., Wingfield, J.C. 2004. Testosterone in tropical birds: effects of environmental and social factors. American Naturalist 164:327-334.

Goyman, W., Landys, M.M. 2011. Testosterone and year-round territoriality in tropical and non-tropical songbirds. Journal of Avian Biology 42:485-489.

Greenwood, P. J. and P. H. Harvey. 1982. The natal and breeding dispersal of birds. Annual Review of Ecology, Evolution, and Systematics 13:1-21. 
Griffith, S.C., Owens, I.P.F., Thuman, K.A. 2002. Extra pair paternity in birds: a review of interspecific variation and adaptive function. Molecular Ecology 11:21952212.

Hatch, M. I., R. J. Smith, and J. C. Owen. 2010. Arrival timing and hematological parameters in Gray Catbirds (Dumetella carolinensis). Journal of Ornithology $151: 545-552$

Hau, M. 2007. Regulation of male traits by testosterone: Implications for the evolution of vertebrate life histories. BioEssays 29:133-144.

Hau, M., Gill, S.A., Goymann, W. 2008. Tropical field endocrinology: Ecology and evolution of testosterone concentrations in birds. General and Comparative Endocrinology 157:241-248.

Hau, M., Romero, L.M., Brawn, J.D., Van’t Hof, T.J. 2002. Effect of polar day on plasma melatonin, testosterone, and estradiol in high-Arctic Lapland Longspurs. General and Comparative Endocrinology 126:101-112.

Hayes, P.A., Robertson, R.J. 1989. The impact of male parental care on female eastern kingbird reproductive success. Wilson Bulletin 101:462-467.

Hestbeck, J. B., J. D. Nichols, and R. A. Malecki. 1991. Estimates of movement and site fidelity using mark-resight data of wintering Canada Geese. Ecology 72: 523533.

Hirschenhauser, K., Winkler, H., Oliveira, R.F. 2003. Comparative analysis of male androgen responsiveness to social environment in birds: the effects of mating system and paternal incubation. Hormones and Behavior 43:508-519. 
Horton, B.M., Yoon, J., Ghalambor, C.K., Moore, L.T., Sillett, T.S. 2010. Seasonal and population variation in male testosterone levels in breeding orange-crowned warblers (Vermivora celata). General and Comparative Endocrinology 168:333339.

Hoysak, D. J., and P. J. Weatherhead. 1991. Sampling blood from birds: A technique and an assessment of its effect. Condor 93:746-752.

Hunt, K., Wingfield, J.C., Astheimer, L.B., Buttemer, W.A., Hahn, T.P. 1995. Temporal patterns of territorial behavior and circulating testosterone in the Lapland Longspur and other Arctic passerines. American Zoologist 35:274-284.

Jawork, J.M., McGlothlin, J.W., Casto, J.M., Greives, T.J., Snajdr, E.A., Bentley, G.E., Ketterson, E.D. 2006. Seasonal and individual variation in response to GnRH challenge in male dark-eyed juncos (Junco hyemalis). General and Comparative Endocrinology 149:182-189.

Johnsen, T.S. 1998. Behavioural correlates of testosterone and seasonal changes of steroids in red-winged blackbirds. Animal Behaviour 55:957-965.

Johnson, M. D., and G. R. Geupel. 1996. The importance of productivity to the dynamics of a Swainson’s Thrush population. Condor 98:133-141.

Jolly, G. M. 1965. Explicit estimates from capture-recapture data with both death and immigration-stochastic model. Biometrika 52:225-247.

Kempenaers, B., Peters, A., Foerster, K. 2008. Sources of individual variation in plasma testosterone levels. Philosophical transactions of the Royal Society B 363:17111723. 
Keyser, A. J., M. T. Keyser, and D. E. L. Promislow. 2004. Life-history variation and demography in Western Bluebirds (Sialia mexicana) in Oregon. Auk 121:118133.

Knowles, S. C. L., M. J. Wood, and B. C. Sheldon. 2010. Context-dependent effects of parental effort on malaria infection in a wild bird population, and their role in reproductive trade-offs. Oecologia 164:87-97.

Krebs, C. J. 1999. Ecological methodology, second edition. Addison-Wesley Educational Publishers, Menlo Park, CA.

Lande, R. 1988. Demographic models of the Northern Spotted Owl (Strix occidentalis caurina). Oecologia 75:601-607.

Landys, M.M., Goymann, W., Raess, M., Slagsvold, T. 2007. Hormonal responses to male-male social challenge in the blue tit Cyanistes caeruleus: single-broodedness as an explanatory variable. Physiological and Biochemical Zoology 80:228-240.

Landys, M.M., Goymann, W., Schwabl, I., Trapschuh, M., Slagsvold, T. 2010. Impact of season and social challenge on testosterone and corticosterone levels in a yearround territorial bird. Hormones and Behavior 58:317-325.

Lebreton, J. D., K. P. Burnham, J. Clobert, and D. R. Anderson. 1992. Modeling survival and testing biological hypotheses using marked animals: a unified approach with case studies. Ecological Monographs 62:67-118.

Lebreton, J. D., J. E. Hines, R. Pradel, J. D. Nichols, and J. A. Spendelow. 2003. Estimation by capture-recapture of recruitment and dispersal over several sites. Oikos 101:253-264. 
Lescroel, A., K. M. Dugger, G. Ballard, and D. G. Ainley. 2009. Effects of individual quality, reproductive success and environmental variablility on survival of a longlived seabird. Journal of Animal Ecology 78:798-806.

Lobato, E., J. Moreno, S. Merino, J. Morales, G. Tomás, J. Martínez, R. A. Vásquez, A. Kuchar, E. Möstl, and J. L. Osorno. 2010. Arrival date and territorial behavior are associated with corticosterone metabolite levels in a migratory bird. Journal of Ornithology 151:587-597.

Logan, C.A, Wingfield, J. C. 1995. Hormonal correlates of breeding status, nest construction, and parental care in multiple-brooded northern mockingbirds, Mimus polyglottos. Hormones and Behavior 29:12-30.

Lyons, J. E., J. A. Collazo, and C. G. Guglielmo. 2008. Plasma metabolites and migration physiology of Semipalmated Sandpipers: Refueling performance at five latitudes. Oecologia 155:417-427.

Martin, T. E., J. Clobert, and D. R. Anderson. 1995. Return rates in studies of life history evolution: Are biases large? Journal of Applied Statistics 22:863-875.

McCoy, T. D., M. R. Ryan, E. W. Kurzejeski, and L. W. Burger Jr. 1999. Conservation Reserve Program: source or sink habitat for grassland birds in Missouri? Journal of Wildlife Management 63:530-538.

McGlothlin, J.W., Jawor, J.M., Ketterson, E.D. 2007. Natural variation in a testosterone-mediated trade-off between mating effort and parental effort. American Naturalist 170:864-875. 
Moore, M.C. 1984. Changes in territorial defense produced by changes in circulating levels of testosterone: a possible hormonal basis for mate-guarding behavior in white-crowned sparrows. Behaviour 88:215-226.

Moss, R., Parr, R., Lambin, X. 1994. Effect of testosterone on breeding density, breeding success, and survival of red grouse. Proceedings of the Royal Society of London B 258:175-180.

Mulder, R.A., Dunn, P.O., Cockburn, A., Lazenby-Cohen, K.A., Howell, M.J. 1994. Helpers liberate female fairy-wrens from constraints on extra-pair mate choice. Proceedings of the Royal Society of London B 255:223-229.

Murphy, M. T. 1987. The impact of weather on kingbird foraging behavior. Condor 89:721-730.

Murphy, M. T. 1996a. Eastern Kingbird (Tyrannus tyrannus). In The Birds of North America Online (A. Poole, Ed.). Cornell Lab of Ornithology, Ithaca, New York. Available at bna.birds.cornell.edu/bna/species/253.

Murphy, M. T. 1996b. Survivorship, breeding dispersal and mate fidelity in Eastern Kingbirds. Condor 98:82-92.

Murphy, M. T. 2000. Evolution of clutch size in the Eastern Kingbird: tests of alternative hypotheses. Ecological Monographs 70:1-20.

Murphy, M. T. 2001. Habitat-specific demography of a long-distance, Neotropical migrant bird, the Eastern Kingbird. Ecology 82:1304-1318.

Murphy, M.T., Sexton, K., Dolan, A.C., Redmond, L.J. 2008. Dawn song of the eastern kingbird: an honest signal of male quality? Animal Behaviour 75:1075-1084. 
Naef-Daenzer, B., F. Widmer, and M. Nuber. 2001. Differential post-fledging survival of Great and Coal tits in relation to their condition and fledging date. Journal of Animal Ecology 70:730-738.

Neff, B.D., Knapp, R. 2009. Paternity, parental behavior and endogenous steroid hormone concentrations in nest-tending male bluegill. Hormones and Behavior 56:239-245.

Oring, L.W., Fivizzani, A.J., El Halawani, M.E. 1989. Testosterone-induced inhibition of incubation in the Spotted Sandpiper (Actitis mecularia). Hormones and Behavior 23:412-423.

Owens, P.F., Short, R.V. 1995. Hormonal basis of sexual dimorphism in birds: implications for new theories of sexual selection. TREE 10:44-47.

Perkins, K. A., R. R. Roth, J. L. Bowman, and J. Green. 2004. Flushing, capture, and bleeding do not affect return rate of female Wood Thrushes (Hylocichla mustelina) in Delaware. Auk 121:354-360.

Peters, A, Ashtheimer, L.B., Cockburn, A. 2001. The annual testosterone profile in cooperatively breeding superb fairy-wrens, Malurus cyaneus, reflects their extreme infidelity. Behavioral Ecology and Sociobiology 50:519-527.

Peters, A., Cockburn, A., Cunningham, R. 2002. Testosterone treatment suppresses paternal care in suberb fairy-wrens, Malurus cyaneus, despite their concurrent investment in courtship. Behavioral Ecology and Sociobiology 51:538-547. 
Peters, A., Delhey, K., Goymann, W., and Kempenaers, B. 2006. Age-dependent association between testosterone and crown UV coloration in male blue tits (Parus caeruleus). Behavioral Ecology and Sociobiology 59:666-673.

Pinxten, R., De Ridder, E., Arckens, L., Darras, V.M., Eens, M. 2007. Plasma testosterone levels of male European starlings (Sturnus vulgaris) during the breeding cycle and in relation to song and paternal care. Behaviour 144:393-410.

Ploucha, J. M., J. B. Scott, and R. K. Ringer. 1981. Vascular and hematologic effects of hemorrhage in the chicken. American Journal of Physiology 240:H9-H17.

Raouf, S.A, Parker, P.G., Ketterson, E.D., Nolan, Jr., V., Ziegenfus, C. 1997. Testosterone affects reproductive success by influencing extra-pair fertilizations in male dark-eyed juncos (Aves: Junco hyemalis). Proceedings of the Royal Society of London B 264:1599-1603.

Raveling, D. G. 1970. Survival of Canada Geese unaffected by withdrawing blood samples. Journal of Wildlife Management 34:941-943.

Redmond, L.J., Murphy, M.T., Dolan, A.C., Sexton, K. 2009a. Parental investment theory and nest defense by Eastern Kingbirds. Wilson Journal of Ornithology 121:1-11.

Redmond, L. J., M. T. Murphy, A. C. Dolan, and K. Sexton. 2009b. Public information facilitates habitat selection of a territorial species: The Eastern Kingbird. Animal Behaviour 77:457-463. 
Redmond, L. J., and M. T. Murphy. 2011. Multistate mark-recapture analysis reveals no effect of blood sampling on survival and recapture of Eastern Kingbirds (Tyrannus tyrannus). Auk 128:514-521.

Redmond, L.J., Murphy, M.T. 2012. Using complementary approaches to estimate survival of juvenile and adult Eastern Kingbirds. Journal of Field Ornithology 83:247-259.

Redpath, S.M., Mougeot, F., Leckie, F.M., Evans, S.A. 2006. The effects of autumnal testosterone on survival and productivity in red grouse, Lagopus lagopusscoticus. Animal Behaviour 71:1297-1305.

Reid, J. M., E. M. Bignal, S. Bignal, D. I. McCracken, and P. Monaghan. 2004. Identifying the demographic determinants of population growth rate: a case study of red-billed choughs Pyrrhocorax pyrrhocorax. Journal of Animal Ecology 73:777-788.

Ricklefs, R. E. 1973. Fecundity, mortality, and avian demography. In: Breeding biology of birds (D. S. Farner, ed.), pp. 366-435. National Academy of Sciences, Washington, D.C.

Ringsby, T. H., B. E. Saether, H. Jensen, and S. Engen. 2006. Demographic characteristics of extinction in a small insular population of House Sparrows in northern Norway. Conservation Biology 20:1761-1767.

Robinson, W.D., Hau, M., Klasing, K.C., Wikelski, M., Brawn, J.D., Austin, S.H., Tarwater, C.E., Ricklefs, R.E. 2010. Diversification of life histories in New World birds. Auk 127:253-262. 
Rodenhouse, N. L., T. W. Sherry, and R. T. Holmes. 1997. Site-dependent regulation of population size: a new synthesis. Ecology 78:2025-2042.

Rodnan, G. P., F. G. Ebaugh, Jr., M. R. Spivey Fox, and D. M. Chambers. 1957. The life span of the red blood cell and the red blood cell volume in the chicken, pigeon and duck as estimated by the use of $\mathrm{Na}_{2} \mathrm{Cr}^{51} \mathrm{O}_{4}$ : With observations on red cell turnover rate in the mammal, bird and reptile. Blood 12:355-366.

Rowe, D.L., Murphy, M.T., Fleishcer, R.C., Wolf, P.G. 2001. High frequency of extrapair paternity in Eastern Kingbirds. Condor 103:845-851.

Ryan, M. R., B. G. Root, and P. M. Mayer. 1993. Status of Piping Plovers in the Great Plains of North America: a demographic simulation model. Conservation Biology 7:581-585.

Saino, N., and Møller, A.P. 1995a. Testosterone correlates of mate guarding, singing and aggressive behaviour in male barn swallows, Hirundo rustica. Animal Behaviour 49:465-472.

Saino, N., Møller, A.P. 1995b. Testosterone-induced depression of male parental behavior in the barn swallow: female compensation and effects on seasonal fitness. Behavioral Ecology and Sociobiology 36:151-157.

Sax, A., Hoi, H. 1998. Individual and temporal variation in cloacal protuberance size of male Bearded Tits (Panurus biarmicus). Auk 115:964-969.

Schaub, M., and J. von Hirschheydt. 2009. Effect of current reproduction on apparent survival, breeding dispersal, and future reproduction in Barn Swallows assessed by multistate capture-recapture models. Journal of Animal Ecology 78:625-635. 
Schlinger, B.A., Day, L.B., Fusani, L. 2008. Behavior, natural history, and neuroendocrinology of a tropical bird. Hormones and Behavior 157:254-258.

Schoech, S.J., Ketterson, E.D., Nolan, Jr., V., Sharp, P.J., Buntin, J.D. 1998. The effect of exogenous testosterone on parental behavior, plasma prolactin, and prolactin binding sites in Dark-eyed Juncos. Hormones and Behavior 34:1-10.

Schwabl, H., Flinks, H., Gwinner, E. 2005. Testosterone, reproductive stage, and territorial behavior of male and female European stonechats Saxicola torquata. Hormones and Behavior 47:503-512.

Schwarz, C. J., J. F. Schweigert, and A. N. Arnason. 1993. Estimating migration rates using tag-recovery data. Biometrics 49:177-193.

Seber, G. A. F. 1965. A note on the multiple-recapture census. Biometrika 52:249-259.

Sexton, K., M. T. Murphy, L. J. Redmond, and A. C. Dolan. 2007. Dawn song behavior of Eastern Kingbirds: intrapopulation variability and sociobiological correlates. Behaviour 144:1273-1295.

Sheldon, L. D., E. H. Chin, S. A. Gill, G. Schmaltz, A. E. M. Newman, and K. K. Soma. 2008. Effects of blood collection on wild birds: An update. Journal of Avian Biology 39:369-378.

Shutler, D., R. G. Clark, C. Fehr, and A. W. Diamond. 2006. Time and recruitment costs as currencies in manipulation studies on the cost of reproduction. Ecology 87:2938-2946.

Sillett, T. S., and R. T. Holmes. 2002. Variation in survivorship of a migratory songbird throughout its annual cycle. Journal of Animal Ecology 71:296-308. 
Silverin, B., Baillien, M., Balthazart, J. 2004. Territorial aggression, circulating levels of testosterone, and brain aromatase activity in free-living pied flycatchers. Hormones and Behavior 45:225-234.

Small, S. L., F. R. Thompson, G. R. Geupel, and J. Faaborg. 2007. Spotted Towhee population dynamics in a riparian restoration context. Condor 109:721-733.

Spinney, L. H., G. E. Bentley, and M. Hau. 2006. Endocrine correlates of alternative phenotypes in the White-throated Sparrow (Zonotrichia albicollis). Hormones and Behavior 50:762-771.

SPSS. 2002. Statistics for Windows, V. 11.5. Chicago, IL, USA.

Stangel, P. W. 1986. Lack of effects from sampling blood from small birds. Condor 88:244-245

Stearns, S. C. 1992. The evolution of life histories. Oxford University Press, Oxford, UK.

STATISTIX. 2008. Version 9.0. Analytical Software, Tallahassee, FL.

Stenzel, L. E., G. W. Page, J. C. Warriner, J. S. Warriner, D. E. George, C. R. Eyster, B. A. Ramer, and K. K. Neuman. 2007. Survival and natal dispersal of juvenile Snowy Plovers (Charadrius alexdrinus) in central coastal California. Auk 124:1023-1036.

Stouffer, P.C., Johnson, E.I., Bierregaard, Jr., R.O. 2013. Breeding seasonality in central Amazonian rainforest birds. Auk 130:529-540.

Studds, C. E., and P. P. Marra. 2005. Nonbreeding habitat occupancy and population processes: An upgrade experiment with a migratory bird. Ecology 86:2380-2385. 
Tarof, S. A., P. M. Kramer, J. R. Hill III, J. Tautin, and B. J. M. Stutchbury. 2011. Brood size and late breeding are negatively related to juvenile survival in a Neotropical migratory songbird. Auk 128: 716-725.

Tarwater, C. E., R. E. Ricklefs, J. D. Maddox, and J. D. Brawn. 2011. Pre-reproductive survival in a tropical bird and its implications for avian life histories. Ecology 92:1271-1281.

Temple, S. A., and J. R. Cary. 1988. Modeling dynamics of habitat-interior bird populations in fragmented landscapes. Conservation Biology 2:340-347.

Townsend, D.S., Palmer, B., Guillette, L.J., Jr. 1991. The lack of influence of exogenous testosterone on male parental behavior in a neotropical frog (Eleutherodactylus). Hormones and Behavior 25:313-322.

Utter, J. M., E. A. LeFebvre, and J. S. Greenlaw. 1971. A technique for sampling blood from small passerines. Auk 88:169-171.

Van Duyse, E., Pinxten, R., Eens, M. 2000. Does testosterone affect the trade-off between investment in sexual/territorial behavior and parental care in male great tits? Behaviour 137:1503-1515.

Van Duyse, E., Pinxten, R., Darras, V.M., Arckens, L., Eens, M. 2004. Opposite changes in plasma testosterone and corticosterone levels following a simulated territorial challenge in male great tits. Behaviour 141:451-467.

Van Hout, A. J.-M., M. Eens, V. M. Darras, and R. Pinxten. 2010. Acute stress induces a rapid increase of testosterone in a songbird: Implications for plasma testosterone sampling. General and Comparative Endocrinology 168:505-510. 
Van Roo, B.L., Ketterson, E.D., Sharp, P.J. 2003. Testosterone and prolactin in two songbirds that differ in paternal care: the blue-headed vireo and the red-eyed vireo. Hormones and Behavior 44:435-441.

Van Roo B.L. 2004. Exogenous testosterone inhibits several forms of male parental behavior and stimulates song in a monogamous songbird: the blue-headed vireo (Vireo solitarius). Hormones and Behavior 46:678-683.

Voss, M., D. Shutler, and J. Werner. 2010. A hard look at blood sampling of birds. Auk 127:704-708.

Weatherhead, P. J., and M. R. L. Forbes. 1994. Natal philopatry in passerine birds: genetic or ecological influences? Behavioral Ecology 5:426-433.

Wheelwright, N. T. and R. A. Mauck. 1998. Philopatry, natal, dispersal, and inbreeding avoidance in an island population of Savannah Sparrows. Ecology 79:753-767.

White, G. C., and K. P. Burnham. 1999. Program MARK: Survival estimation from populations of marked animals. Bird Study 46 (Supplement):120-138.

Whittingham, L.A., Dunn, P.O. 2014. Extra-pair mating and sexual selection on male traits across populations. Wilson Journal of Ornithology 126:9-18.

Wikelski, M., Hau, M., Wingfield, J.C. 1999. Social instability increases plasma testosterone in a year-round territorial Neotropical bird. Proceedings of the Royal Society, Series B 266:551-556.

Wiley, C.J., Goldizen, A.W. 2003. Testosterone is correlated with courtship but not aggression in the tropical buff-banded rail, Gallirallus philippensis. Hormones and Behavior 43:554-560. 
Williams, T.D. 2012. Physiological Adaptations for Breeding in Birds. Princeton University Press, Princeton, NJ, USA.

Wingfield, J.C. 1984. Environmental and endocrine control of reproduction in the song sparrow, Melospiza melodia. II. Agonistic interactions as environmental information stimulating secretion of testosterone. General and Comparative Endocrinology 56:417-424.

Wingfield, J.C. 2012. Regulatory mechanisms that underlie phenology, behavior, and coping with environmental perturbations: an alternative look at biodiversity. Auk 129:1-7.

Wingfield, J. C., and D. S. Farner. 1976. Avian endocrinology—Field investigations and methods. Condor 78:570-573.

Wingfield, J.C., and Hahn, T.P. 1984. Testosterone and territorial behaviour in sedentary and migratory sparrows. Animal Behaviour 47:77-89.

Wingfield, J.C., Hegner, R.E., Dufty, Jr., A.M., Ball, G.F. 1990. The “challenge hypothesis”: theoretical implications for patterns of testosterone secretion, mating systems, and breeding strategies. American Naturalist 136:829-846.

Winkler, D. W., P. H. Wrege, P. E. Allen, T. L. Kast, P. Senesac, M. F. Wasson, and P. J. Sullivan. 2005. The natal dispersal of Tree Swallows in a continuous mainland environment. Journal of Animal Ecology 74:1080-1090.

Woodard, J.D., Murphy, M.T. 1999. Sex roles, parental experience and breeding success of Eastern Kingbirds. Animal Behaviour 57:105-115. 
Woodworth, B. L. 1999. Modeling population dynamics of a songbird exposed to parasitism and predation and evaluating management options. Conservation Biology 13:67-76.

Wynne-Edwards, K.E., Timonin, M.E. 2007. Paternal care in rodents: weakening support for hormonal regulation of the transition to behavioral fatherhood in rodent animal models of biparental care. Hormones and Behavior 52:114-12.

Yackel Adams, A. A., S. K. Skagen, and J. A. Savidge. 2006. Modeling post-fledging survival of Lark Buntings in response to ecological and biological factors. Ecology 87:178-188. 


\section{APPENDIX}

\section{Copyright information for CHAPTERS 2, 3 and 4}

CHAPTER 2 of this dissertation has been published as a journal article in The Journal of Field Ornithology. See PREFACE for complete citation. The content and title of this article is the same as what appears in the previously mentioned journal which is published by Wiley-Blackwell. Under the copyright transfer agreement, authors are allowed to grant third parties the right to reproduce published material as long as the content is the same, proper citations are given, and the authors give permission.

Therefore, Lucas J. Redmond and Michael T. Murphy grant permission to Portland State University to re-publish this article as CHAPTER 2 of this dissertation.

CHAPTER 3 of this dissertation has been published as a journal article in The Auk. See PREFACE for complete citation. The content and title of this article is the same as what appears in the previously mentioned journal which is published by BioOne. According to the copyright agreement of the publisher, authors are allowed to grant third parties the right to reproduce published material as long as the content is the same, proper citations are given, and the authors give permission. Therefore, Lucas J. Redmond and Michael T. Murphy grant permission to Portland State University to re-publish this article as CHAPTER 3 of this dissertation. 
CHAPTER 4 of this dissertation will hopefully soon be published as an article in the journal General and Comparative Endocrinology. See PREFACE for complete citation. The content and title of this article is the same as what appears in the previously mentioned journal which is published by Elsevier. According to the copyright agreement of the publisher, authors are allowed to grant third parties the right to reproduce published material as long as the content is the same, proper citations are given, and the authors give permission. Therefore, Lucas J. Redmond, Michael T. Murphy, Nathan W. Cooper, and Kathleen M. O’Reilly grant permission to Portland State University to republish this article as CHAPTER 4 of this dissertation. 